University of South Florida

DIGITAL COMMONS

@ UNIVERSITY OF SOUTH FLORIDA
Digital Commons @ University of

South Florida

$9-1-2010$

\title{
Moving the Bus Safely Back into Traffic Phase II
}

CUTR

Follow this and additional works at: https://digitalcommons.usf.edu/cutr_nctr

\section{Recommended Citation}

"Moving the Bus Safely Back into Traffic Phase II," National Center for Transit Research (NCTR) Report No. CUTR-NCTR-RR-2009-02, Center for Urban Transportation Research, University of South Florida, 2010. DOI: https://doi.org/10.5038/CUTR-NCTR-RR-2009-02

Available at: https://scholarcommons.usf.edu/cutr_nctr/140

This Technical Report is brought to you for free and open access by the National Center for Transit Research (NCTR) Archive (2000-2020) at Digital Commons @ University of South Florida. It has been accepted for inclusion in Research Reports by an authorized administrator of Digital Commons @ University of South Florida. For more information, please contact digitalcommons@usf.edu. 
BDK85 TWO 977-03

\section{MOVING THE BUS SAFELY BACK INTO TRAFFIC}

Final Report

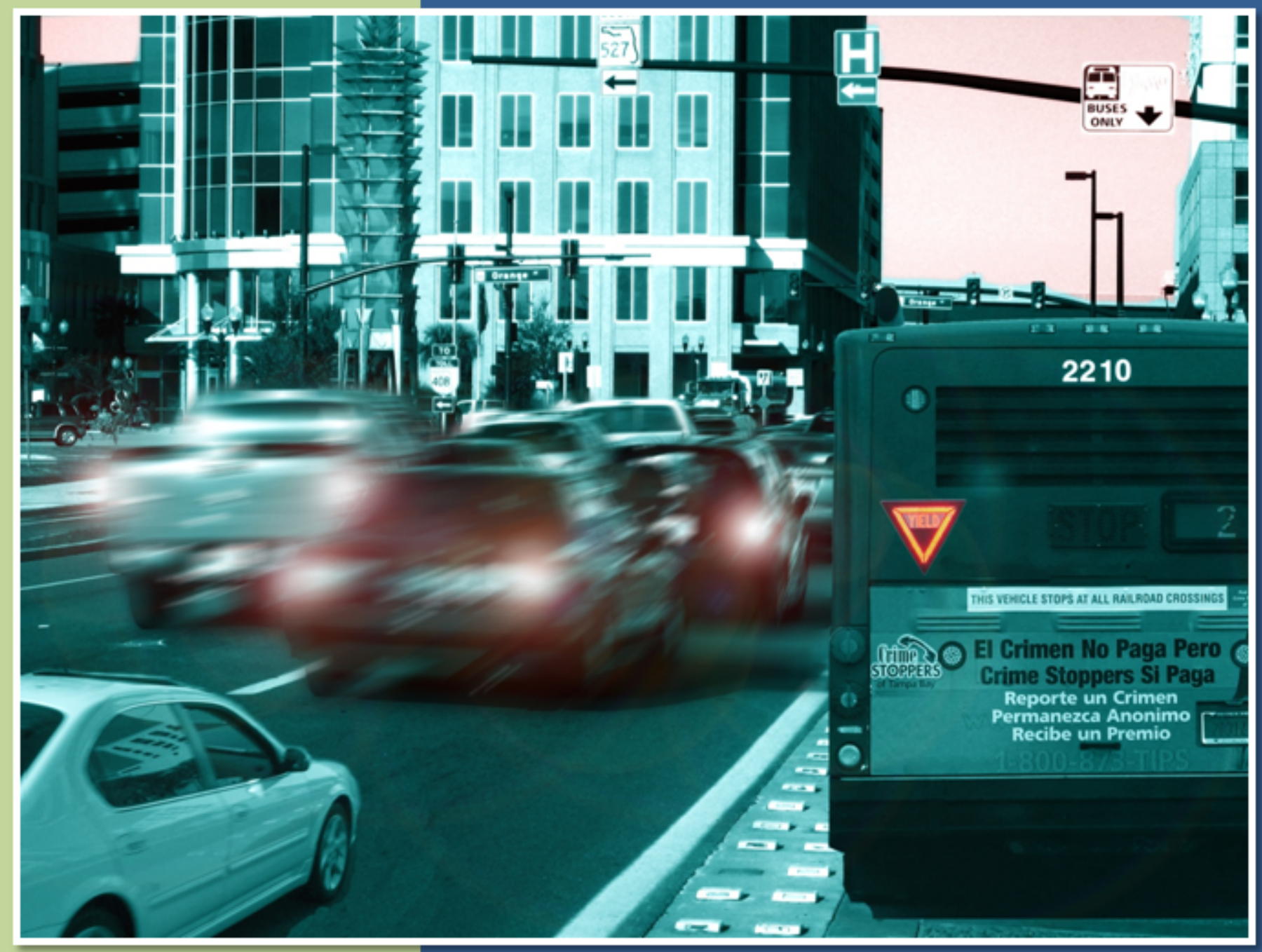

Prepared for:

Prepared by:
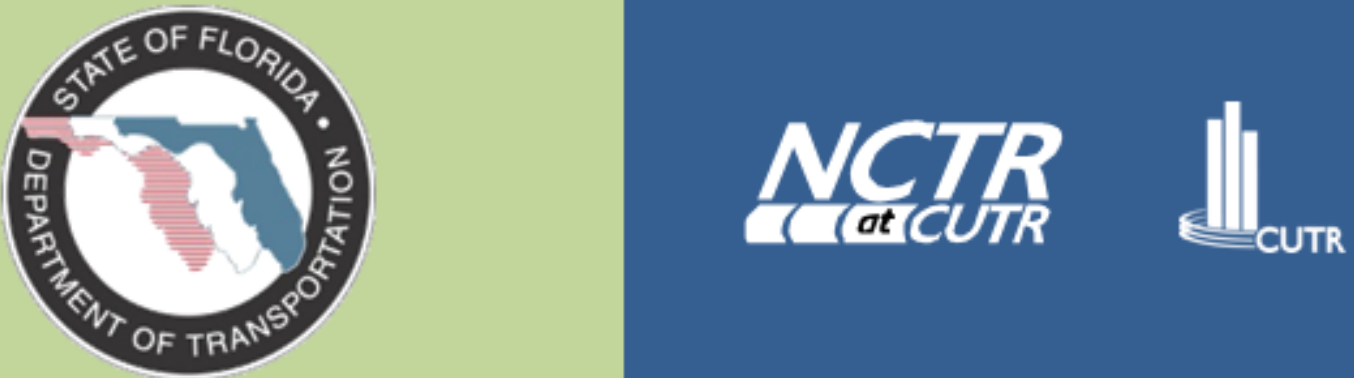


\section{MOVING THE BUS SAFELY BACK INTO TRAFFIC PHASE II}

\section{BDK85 TWO 977-03 \\ Final Report}

Prepared for:

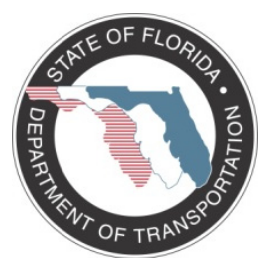

Florida Department of Transportation

Research Center

605 Suwannee Street, MS 30

Tallahassee, FL 32399-0450

Prepared by:

Pei-Sung Lin, Ph.D., P.E., PTOE

Aldo Fabregas

Enrique Gonzalez-Velez

Huaguo Zhou, Ph.D., P.E.
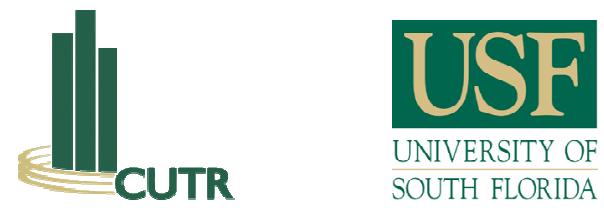

Center for Urban Transportation Research (CUTR)

University of South Florida

4202 E. Fowler Ave. CUT100

Tampa, FL 33620-5375

September 2010 
The opinions, findings, and conclusions expressed in this publication are those of the authors and not necessarily those of the State of Florida Department of Transportation. 
Approximate Conversions to SI Units

\begin{tabular}{ccccc}
\hline SYMBOL & WHEN YOU KNOW & MULTIPLY BY LENGTH & \multicolumn{1}{c}{ TO FIND } & SYMBOL \\
\hline in & inches & 25.4 & millimeters & $\mathrm{mm}$ \\
$\mathrm{ft}$ & feet & 0.305 & meters & $\mathrm{m}$ \\
$\mathrm{yd}$ & yards & 0.914 & meters & $\mathrm{m}$ \\
$\mathrm{mi}$ & miles & 1.61 & kilometers & $\mathrm{km}$ \\
\hline
\end{tabular}

Approximate Conversions to SI Units

\begin{tabular}{ccccc}
\hline SYMBOL & WHEN YOU KNOW & MULTIPLY BY LENGTH & TO FIND & SYMBOL \\
\hline $\mathrm{mm}$ & millimeters & 0.039 & inches & in \\
$\mathrm{m}$ & meters & 3.28 & feet & $\mathrm{ft}$ \\
$\mathrm{m}$ & meters & 1.09 & yards & $\mathrm{yd}$ \\
$\mathrm{km}$ & kilometers & 0.621 & miles & $\mathrm{mi}$ \\
\hline
\end{tabular}


TECHNICAL REPORT DOCUMENTATION PAGE

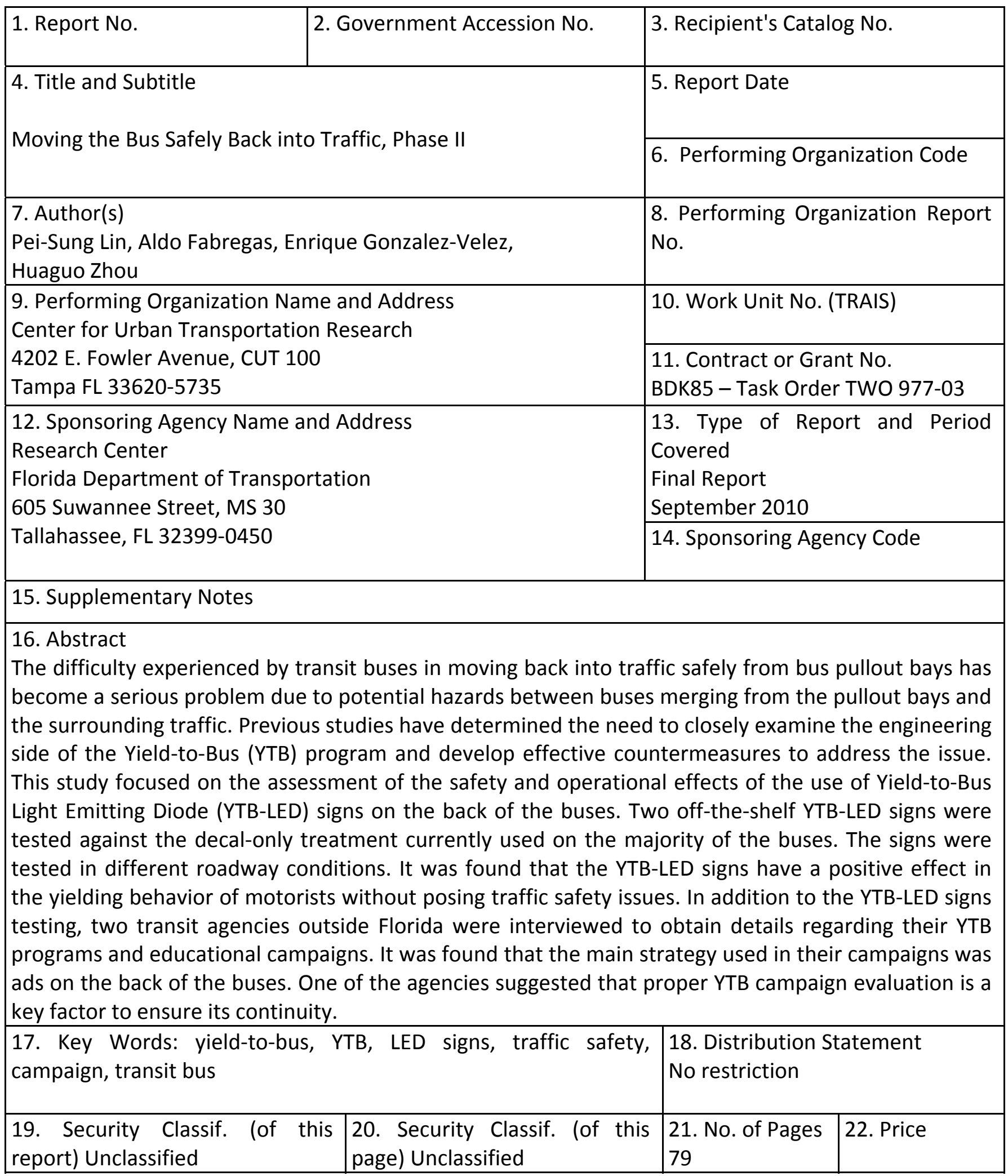

Form DOT F 1700.7 (8-72) Reproduction of completed page authorized 
Many people contributed to this research project; this final report could not have been completed without their assistance and support. The authors would like to express our gratitude to FDOT project manager Ms. Amy Datz and FDOT project panel members Ms. Diane Quigley, Mr. Jerry Hicks, and Mr. Victor Wiley for their full support and coordination of this project. Also, thanks to Mr. Joel Volinski, NCTR Director at CUTR, for his input and continuous support.

The research team also would like to thank the participating transit agencies' yield-to-bus teams:

- Hillsborough Area Regional Transit Authority (HART)

Thanks to Mr. David Kelsey, Assistant Manager of System Security and Operations Training, and Mr. Robert Andis, Manager of Technical Services, for coordinating efforts to make this project possible at HART.

Special thanks to the HART technical team - Mr. Everett Shaffer, Maintenance Coordinator; Mr. John Russell, Master Communications Technician; and Mr. Howard Dumas, Master Communications Technician - for their exceptional work installing the data collection equipment and YTB-LED signs on HART's test buses.

The research team also would like to thank Mr. Oscar McDaniel, Safety, Security, and Training Specialist, for his dedication on the controlled data collection tests, and the following HART bus operators for their cooperation with this project: Ms. Christine Laegel, Mr. Ronald Hancock, Mr. Thomas Mouling, Ms. Tamika Jackson, Mr. Carlos Martinez, Ms. Faye Hargrove, Mr. Ozzie Jackson, and Mr. Pedro Rodriguez.

- Lee County Transit (LeeTran)

The research team would like to thank the YTB team at LeeTran - Mr. Mike Horsting, Principal Planner; Mr. Paul Goyette, Operations Manager, Fixed Route Service; and Mr. Robert Southall, Senior Operations Supervisor - for their outstanding support throughout all the steps of this project.

Thanks to Mr. Larry Ralston, Maintenance Manager, and his technical team - Mr. Rich Gould, Shop Foreman, and Mr. Brian Burns, Fleet Mechanic - for their incredible work installing the data collection equipment and the YTB-LED signs.

Also, special thanks to bus operators Mr. Randall Henderson and Mr. Gerard Tierney for their efforts during the data collection period. 


\section{- Volusia County Transit (Votran)}

The research team would like to thank Votran's yield-to-bus team - Ms. Elizabeth Suchsland, Assistant General Manager of Operations and Maintenance; Mr. Bill Mayer, Operations Manager; and Mr. Paul Doyle, Director of Safety and Training - for their exceptional support facilitating this study at Votran.

The research team would also like to thank Mr. Rick Kazawitch, Director of Maintenance, and Mr. John Foderaro, Lead Mechanic, for their outstanding efforts on the installation of the YTB-LED signs and subsequent integration into the event logger of the digital video recorder of the bus. Their efforts greatly facilitated the data collection for the study.

Also, thanks to bus operators Ms. Diane Therrian, Mr. Jeff Sampson, Mr. Johnny Johnson, Ms. Sonia Shaw, and Mr. Walter Sankey for their dedication to this project.

- Broward County Transit (BCT)

Thanks to the BCT yield-to-bus team - Mr. Harold Tutt, Maintenance Manager; Mr. Alejandro Bengochea, Maintenance Coordinator; Mr. Craig Collins, System Safety Manager; and Mr. Richard Day, Training Instructor, Maintenance - for their valuable efforts on the YTB-LED sign testing and participation in this study.

The CUTR project team thanks Mr. Allen Morgan, Manager of Operations Training, Tri-County Metropolitan Transportation District of Oregon, Portland, Oregon, and Mr. William Capps, Deputy Director of Operations, Santa Clara Valley Transportation Authority, San Jose, California, who provided their expertise and experiences on the implementation and maintenance of YTB programs.

The research team would like to give special thanks to Ms. Georgia Johnston, President, and Mr. Raymond Roche, V.P. of Operations, Dataled, for their continuous and valuable support through the procurement and installation of some of the YTB-LED signs used in this project. Thanks to Mr. Jim Haigh, Special Accounts Manager, SMI Group, for the legal documentation provided on some of the LED signs used in this project.

Thanks to Mr. Mike Schwerman of Safety Vision for his cooperation in the installation and troubleshooting of the data collection cameras at LeeTran. The research team would also like to thank Mr. Aaron Alvarado, Technical Support Manager of Safety Vision, for his expert advice and support on video handling and retrieval.

Thanks to the following CUTR faculty who helped with the research for this project: Dr. Steve Polzin, Mobility Research Program Director; Mr. Ed Bart, Senior Research Associate; and Mr. Henry Cusack, Senior Research Associate. 


\section{Background}

The difficulty experienced by transit buses in moving back into traffic safely from bus pullout bays has become a serious problem due to potential hazards between buses merging from the pullout bays and the surrounding traffic. Previous studies have determined the need to closely examine the engineering side of the Yield-to-Bus program and develop effective countermeasures to address the issue.

This study focused on the assessment of the safety and operational benefits of the use of Yieldto-Bus Light Emitting Diode (YTB-LED) signs on the back of the buses. The main objectives of this study are as follows:

- Determine if the use of YTB-LED signs has an effect on the yield-to-bus behavior of the motorists behind the bus.

- Assess the potential effects on traffic safety of the use of YTB-LED signs.

- Establish the operational benefits of the YTB-LED signs.

- Provide recommendations for the implementation of YTB-LED signs and a public awareness campaign for YTB programs.

\section{Data Collection}

To accomplish the study's objectives, two types of off-the-shelf YTB-LED signs were procured and deployed in the participating transit agencies. The transit agencies participating in the study were Hillsborough Area Regional Transit (HART) in Tampa, Lee County Transit (LeeTran) in Fort Myers, and Volusia County Transit (Votran) in Daytona Beach. Data were collected by installing a camera on the back of a bus, aimed at the traffic behind the bus. Video-based data on YTB behavior, traffic conflicts, and re-entry time were collected at the participating agencies.

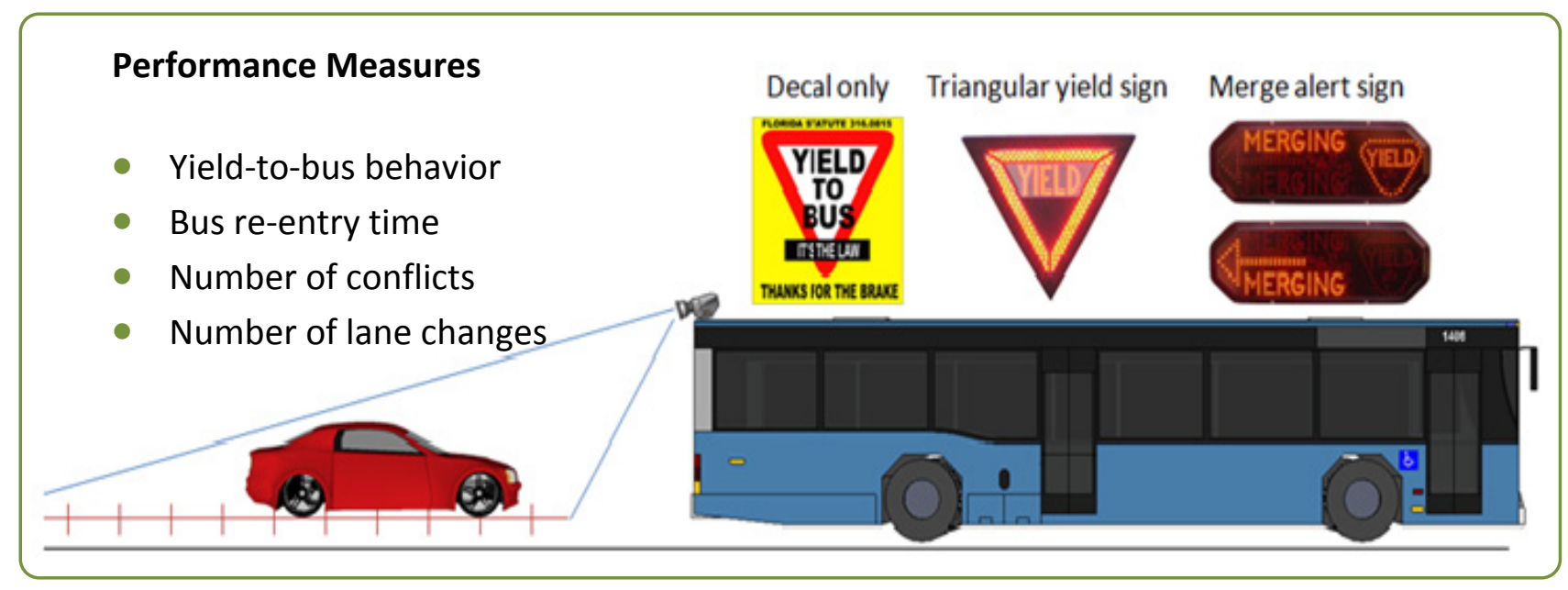

Figure A: Data collection setting for the evaluation of YTB LED signs. 


\section{Results}

\section{Yield-to-Bus Behavior}

At each bus stop, merging maneuvers were analyzed and classified as yield, no-yield, or lanechange. The results for the test corridors are presented in Figure B. For the test corridor in Tampa, the proportion of merging maneuvers ending in a yield while using the decal was 41 percent and while using YTB-LED signs was 78 percent. The use of YTB-LED signs had a statistically significant effect on the number of merging maneuvers that ended in a yield. On the test corridor in Fort Myers, the proportion of merging maneuvers that ended in a yield was 77 percent while using the decal and 88 percent while using YTB-LED signs. The difference also was statistically significant in the case of the Fort Myers test corridor. On the test corridor in Daytona Beach, the proportion of merging maneuvers that ended in a yield was 57 percent while using the decal and 85 percent while using YTB-LED signs. The impact of YTB-LED sign on yield-to-bus behavior also was significant for the Daytona Beach corridor.

\section{Traffic Conflicts}

Traffic conflicts were analyzed from the video-based data. The results of the traffic conflict counts on the test corridors are presented in Figure C. On the test corridor in Tampa, the proportion of merging maneuvers involving conflicts was 41 percent with the decal-only treatment and only 8 percent with the use of YTB-LED signs. The reduction of traffic conflicts was statistically significant on the test corridor in Tampa. On the test corridor in Fort Myers, the proportion of maneuvers involving conflicts was 8.4 percent with the decal-only treatment and 6.25 percent with the YTB-LED signs. There were no statistically significant changes in the number of conflicts associated with the YTB-LED signs. On the test corridor in Daytona Beach, the proportion of maneuvers involving conflicts was 20 percent with the decal-only treatment and 7 percent with the YTB-LED signs, leading to a statistically significant reduction in the observed traffic conflicts.

\section{Re-Entry Time}

Re-entry time was measured as an operational performance measure to assess the effectiveness of the use of YTB-LED signs. The results for the re-entry time observations are presented in Figure D. For the test corridor in Tampa, the re-entry time was reduced by 1.87 seconds. For the test corridor in Fort Myers, the re-entry time was not significantly improved. However, the Fort Myers data show a trend in which the minimum values of re-entry time were observed using YTB-LED signs. This means that the use of YTB-LED signs can potentially reduce the re-entry time for buses in Fort Myers. In the Daytona Beach test corridor, the use of YTBLED signs led to a reduction in the re-entry time. The reduction in re-entry time ranged from 0.8 to 1.62 seconds. 

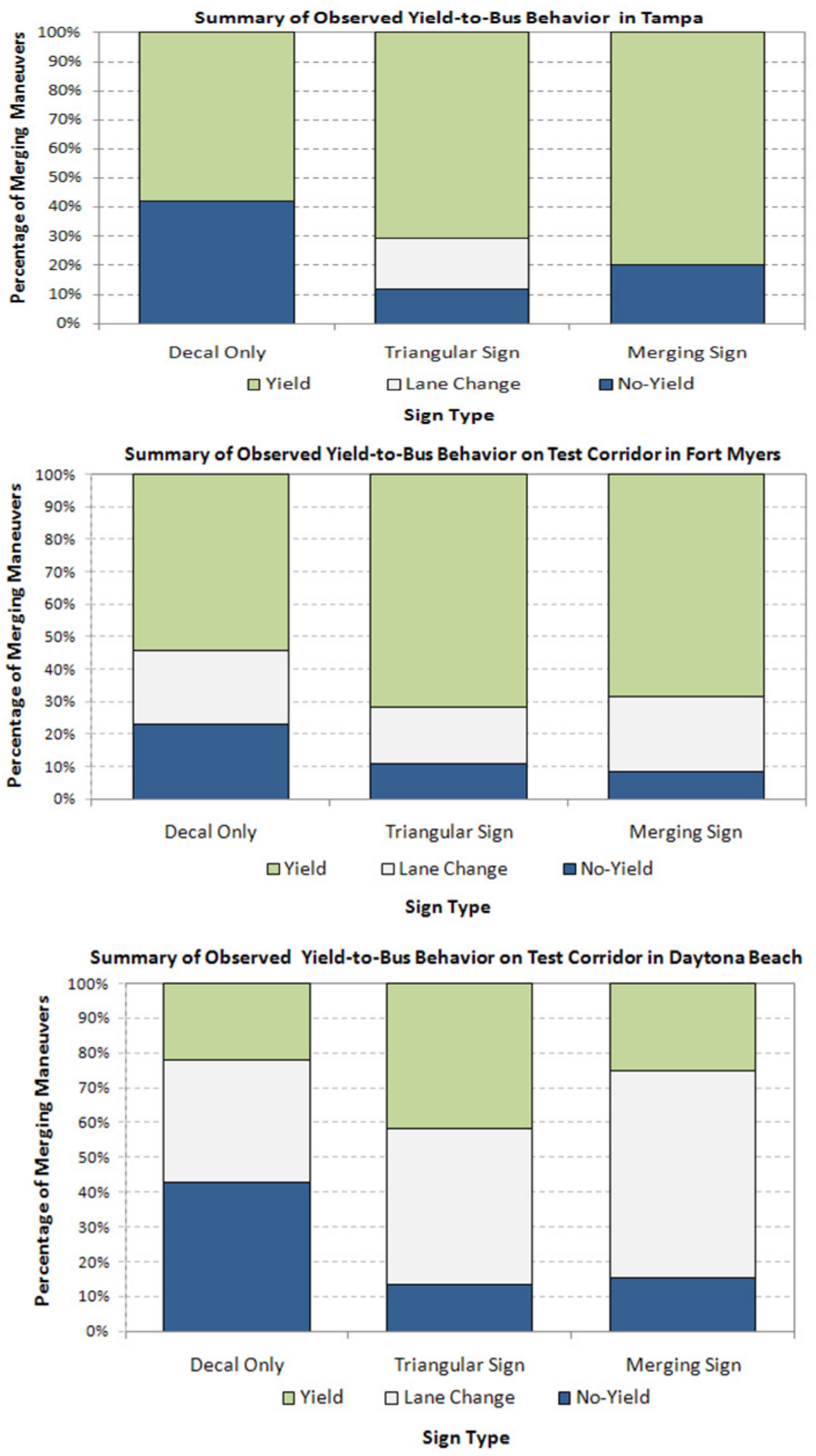

Figure B: Summary of observed yield-to-bus behavior. 


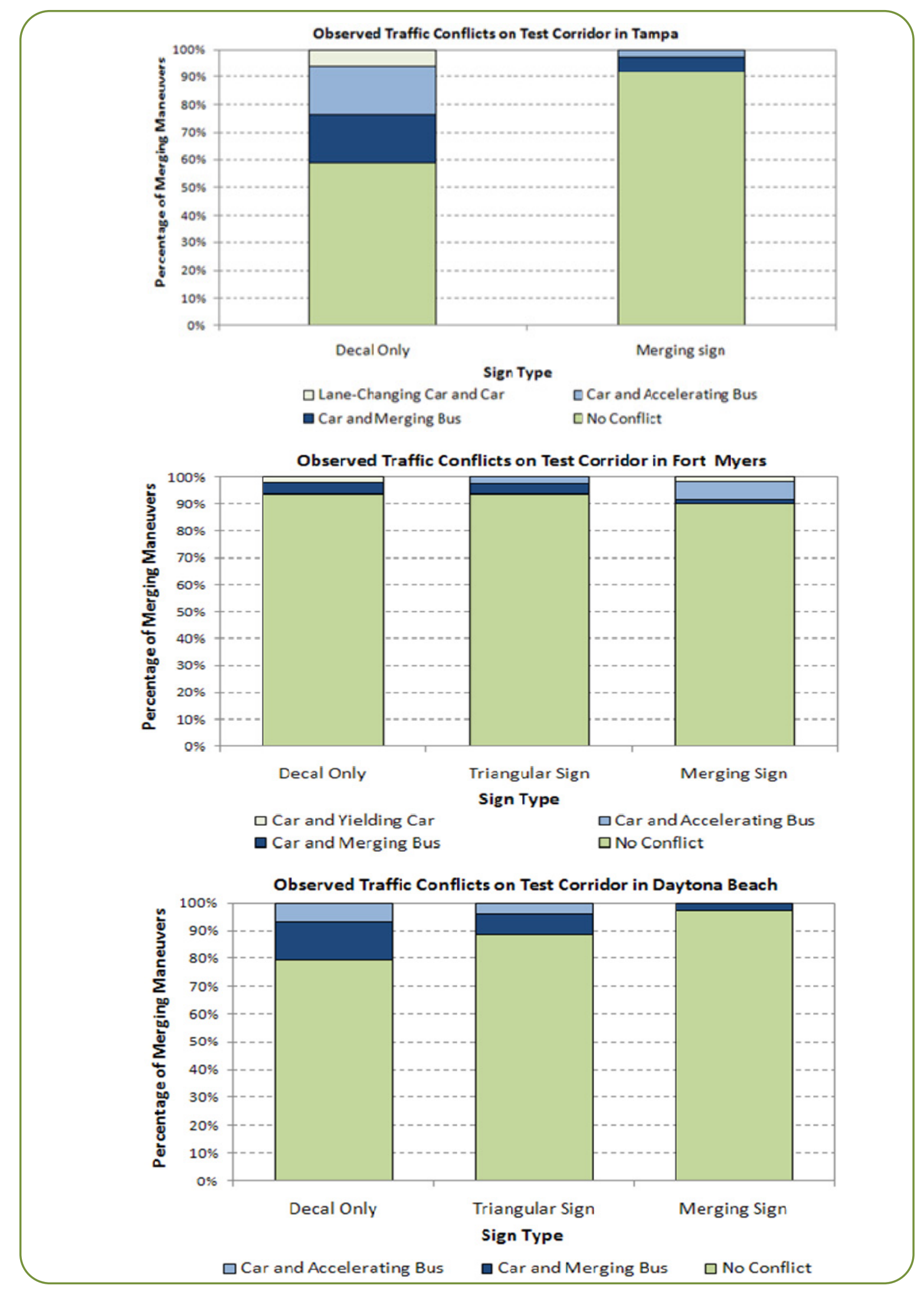

Figure C: Observed traffic conflicts. 


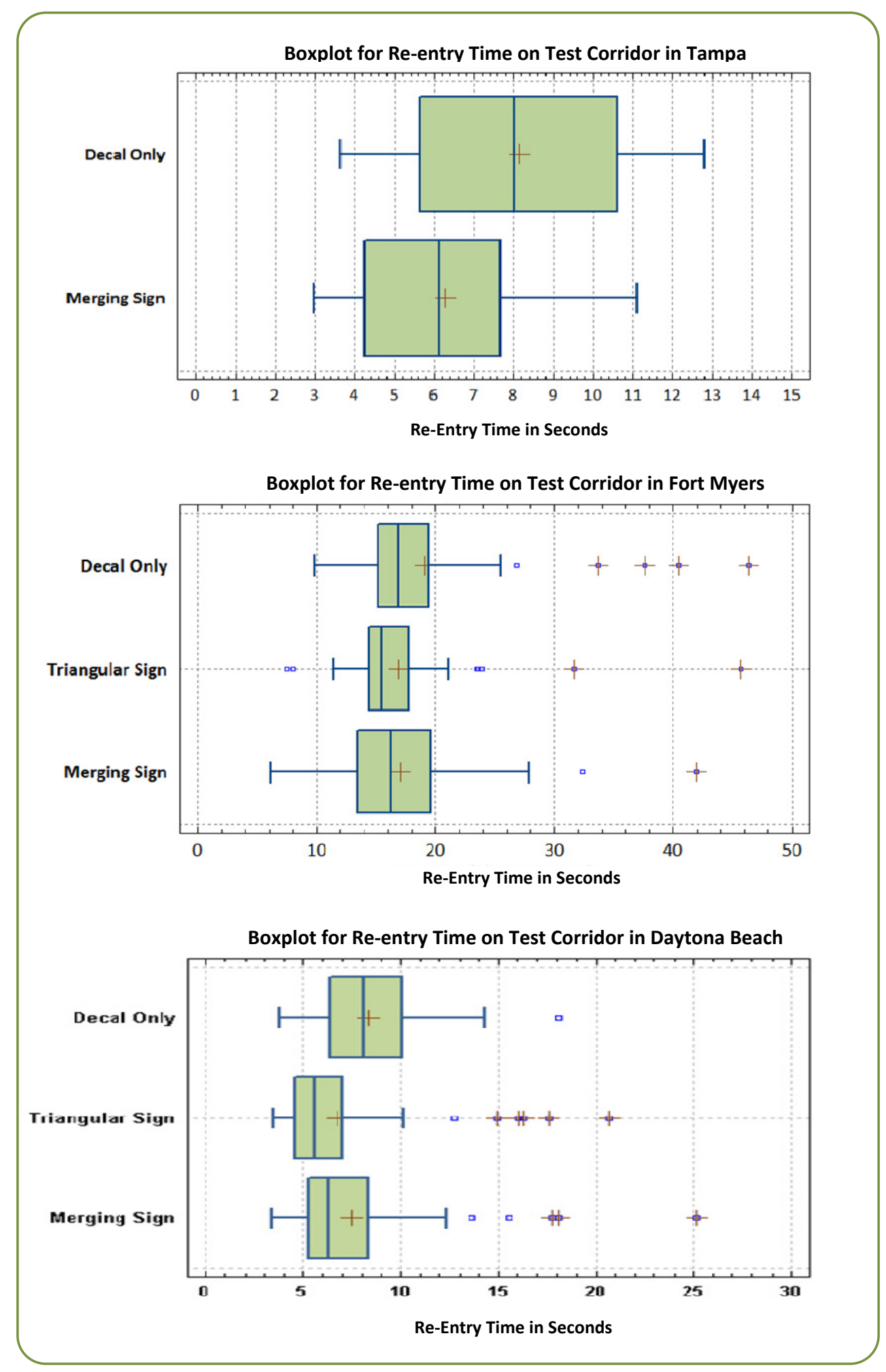

Figure D: Summary of re-entry time on test corridors. 


\section{Conclusions}

Based on the video-based data collection on the test buses at the participating agencies, the following conclusions were obtained.

\section{Safety}

1. Yield-to-bus issues are present not only in bus bays but also at several locations that require transit buses to pull out of the traffic mainline. All these locations can benefit from the implementation of YTB-LED signs.

2. There is statistical evidence that the use of YTB-LED signs will have a positive effect on the yield-to-bus behavior of motorists behind the bus. In all three test corridors in this study, the proportion of maneuvers involving yielding to the bus increased with the implementation of YTB-LED signs. The signs will help the bus to better signal when merging back into traffic.

3. On the test corridor in Tampa, where buses were observed merging from bus bays, it was found that with the implementation of YTB-LED signs, the proportion of merging maneuvers involving a yield increased in 34 percent compared to the use of the decalonly treatment. On the test corridor in Fort Myers, where buses were observed merging from right turn lanes, the implementation of the YTB-LED sign improved yielding behavior by 20 percent. On the test corridor in Daytona Beach, where buses were observed merging from parallel parking spaces, the use of YTB-LED signs improved the yielding behavior by 50 percent.

4. Bus bays are more likely to experience direct conflicts than bus stops at right turn lanes. This is mainly because in a bus bay the bus cannot gain enough speed to facilitate the merging maneuver. Longer bus bays potentially could alleviate this issue.

5. On the test corridor in Tampa, the total number of maneuvers involving conflicts was reduced by 80 percent through the implementation of YTB-LED signs. On the Daytona Beach corridor, the number of conflicts was reduced by 66 percent. On the Fort Myers corridor the number of conflicts across the different YTB treatments (YTB-LED signs and Decal) was similar.

6. The use of YTB-LED signs has great potential for reducing the number of conflicts for buses merging back into traffic from pullout bays on urban minor arterials. For major roads, the use of YTB-LED signs may improve yield-to-bus behavior without compromising safety.

7. The YTB-LED sign can potentially help to improve the yield-to-bus behavior of motorists without introducing new traffic conflicts. 


\section{Operations}

1. The use of YTB-LED signs on the back of the buses helps to reduce the re-entry time of buses in bus bays on minor urban arterials. Based on field observations, this reduction ranged from 10 to 23 percent.

2. YTB-LED signs can help the bus to merge back into traffic in long traffic lines during peak hours.

3. In general, the minimum observed values for re-entry time were observed in buses using YTB-LED signs. In contrast, the maximum observed values for re-entry time were observed in buses with decals only in the case of major arterial roads.

4. YTB-LED signs have a considerable impact on reducing re-entry time for cases of 2-lane and 4-lane corridors. This is mainly due to the reduced space in which to maneuver on such corridors for both transit buses and motorists. On 6-lane corridors, the re-entry time was not significantly affected.

The Santa Clara Valley Transportation Authority (VTA, San Jose, California) and Tri-County Metropolitan Transportation District of Oregon (TriMet, Portland) were interviewed to obtain details regarding their YTB programs and educational campaigns. The following insights and lessons learned were obtained.

\section{Public Education}

1. Periodic reminders to the public and bus operators are needed to carry out a successful yield-to-bus program.

2. Placing educational ads on the back of buses is one of the most effective ways to keep the general public informed about traffic safety practices related to transit buses.

3. Traffic safety and engineering studies are important to justify the benefits of the YTB program. This will also help to ensure the continuity of the program.

Promotion of effective communications between YTB program leaders and enforcement officials is necessary. In this way, police can help the YTB efforts and improve road safety for transit buses. 


\section{Recommendations}

1. Implement YTB-LED signs on transit buses to help the buses merge back into traffic safely. The final sign design of the bus should be unified such that motorists become familiar with a single sign type. Both the triangular sign and the merging sign have the potential to improve yield-to-bus behavior. The triangular sign design has been adopted by several agencies throughout the United States and displays an actual traffic control device. The merging sign offers more visibility and displays an arrow and a small yield sign. Other designs for YTB-LED signs also may work similarly as long as they are properly introduced to the public.

2. Off-traffic bus stops (e.g., right turn lanes, curbside parking) with yield-to-bus problems can be designated as pullout bays to promote compliance and enhance safety. For instance, a right turn lane can be restriped such that a part of it is designated as a bus pullout bay and, therefore, motorists should yield the right-of-way to a bus leaving the designated area.

3. If implemented, YTB-LED signs should be installed as aftermarket equipment. The signs should be wired to operate only when the left turn signal is active. However, the left turn signal can be activated independently.

4. If the YTB-LED signs are activated manually, it is recommended to provide a handle that is different from other controls, not only in color but also in texture and size. In this way, the bus operator can find the yield activation switch easily among the existing controls in the operator's control board.

5. The yield sign activation could be automated by linking its operation to left turn signal activation and positional information of the bus via Global Positioning Systems (GPS) or Radio Frequency Identification (RFID) beacons at certain bus stops. A bus stop can be coded as a merge/no merge type such that every time the bus departs from locations tagged as merge, the yield sign can be activated automatically with the left turn. The sign can be deactivated when the left turn signal is deactivated.

6. The use of YTB-LED signs is only one of many treatments that can be used to improve the yield-to-bus behavior; additional treatments include roadside signs and pavement markings, as pointed out in Phase I of this project.

7. Yield-to-bus programs should encompass several initiatives involving motorists, buses/operators, law enforcement officers, and local governments.

- For motorists, YTB initiatives may include public education through billboards, ads on the back of buses, and YTB-LED information signs on the back of buses. 
- For buses/operators, YTB initiatives may include training on the proper use of bus bays and YTB-LED signs. Also, technological improvements such as sensors or rearview cameras can help bus operators avoid car-accelerating bus conflicts. Research into sensor-assisted merging maneuvers for transit buses is an area where potential safety improvements can be achieved.

- Law enforcement agent training and awareness of the YTB law are important to ensure the success of YTB programs.

- Local governments can request specific features for construction of new bus bays, such as more space for acceleration.

8. YTB-LED signs should be properly introduced to the public though a public awareness campaign. This campaign may include the following initiatives:

- Ads on the back of buses

- Print advertising

- News coverage

- Yield-to-bus flyers

- Yield-to-bus posters

- Incentive items

More aggressive campaign initiatives may include radio ads and billboards on critical transit corridors.

9. Critical transit corridors with increased YTB-related accidents should be identified. Enforcement of YTB law should be intensified on these corridors during the YTB campaign.

10. Evaluations of YTB programs are necessary to ensure their continuity. Detailed evaluations can be performed by conducting engineering studies. Regular evaluations can be performed by transit agencies by carrying out the following procedures:

- Identify segments of transit corridors with merging problems for off-traffic stops.

- Collect data on accidents related to buses in the selected transit corridor segments.

- Classify the data, tagging left-rear accidents as possible YTB accidents.

- The number of possible YTB accidents could be a measure of effectiveness for a YTB program (see Figure E). 


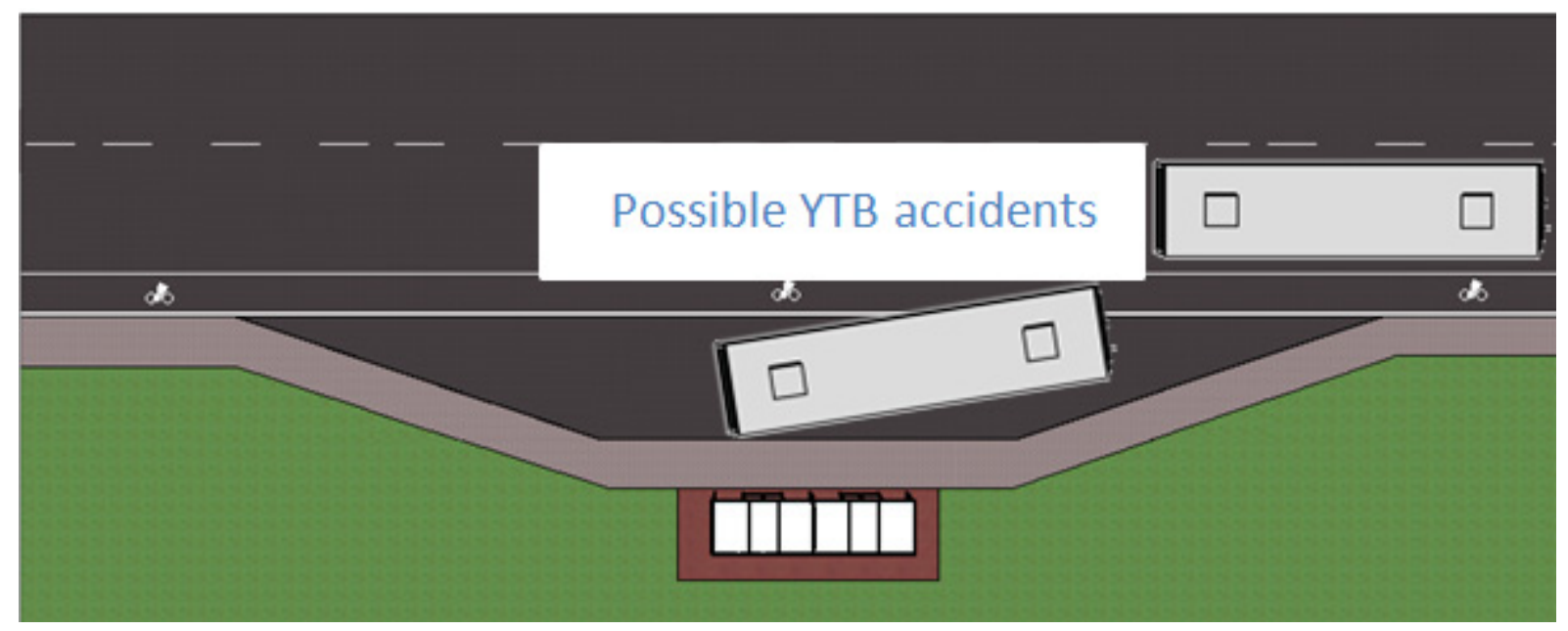

Figure E: Possible YTB accident classification zone.

- If the technology is available, transit agencies can record event times at bus stops in the corridor, such as the amount of time the left turn signal was on for each bus stop. Since the left turn signal is turned off when the bus returns to traffic, this can be used to estimate the re-entry time per bus stop.

- If the technology is not available, travel time can be calculated between two critical time points in the corridor as a measure of operational benefits of the YTB program. Operational measures should be collected for peak time periods. Large sample sizes are recommended if the segment between time points contains a traffic light.

11. Additional recommendations for potential funding sources for local agencies to implement YTB-LED signs are provided in Appendix B. Potential funding programs may include bus equipment and facilities programs, rural and small urban areas programs, and large urban cities programs. 


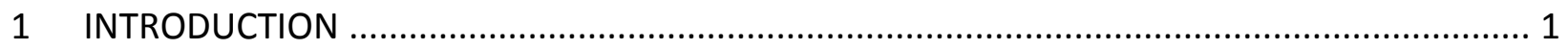

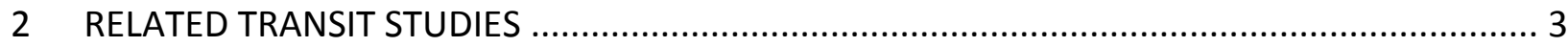

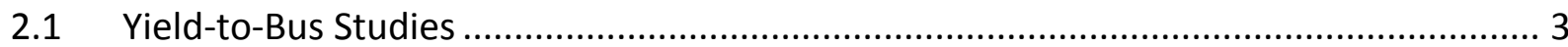

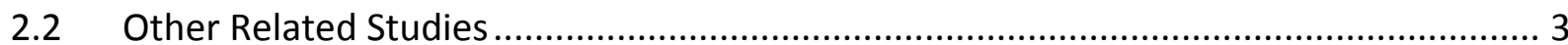

3 YIELD-TO-BUS CONCEPTS AND PERFORMANCE MEASURES ….............................................. 7

3.1 Operational Concepts and Performance Measures ……………………………............ 7

3.1.1 Yield-to-bus indicator variables .......................................................................... 7

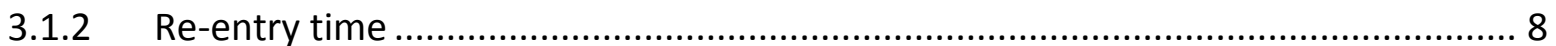

4 SAFETY CONCEPTS AND PERFORMANCE MEASURES......................................................... 9

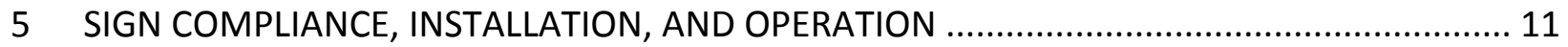

5.1 Sign Compliance and Installation ......................................................................... 11

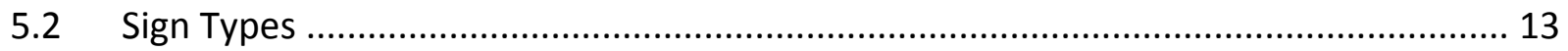

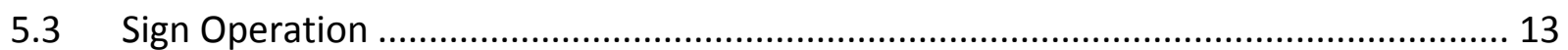

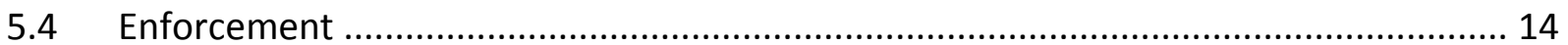

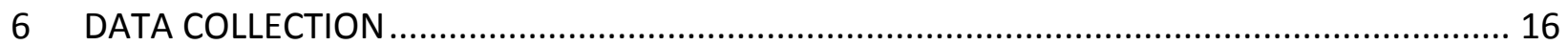

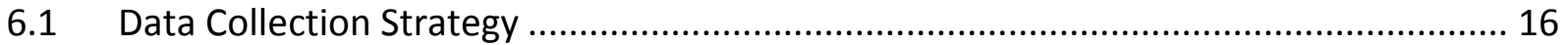

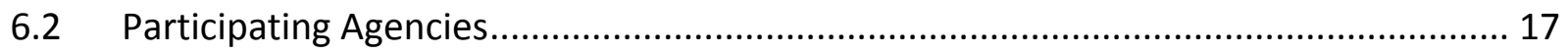

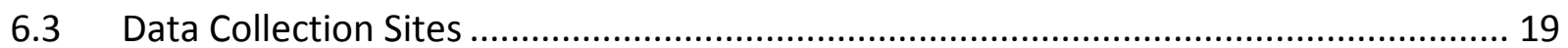

6.4 Yield-to-Bus Behavior Examples ............................................................................... 21

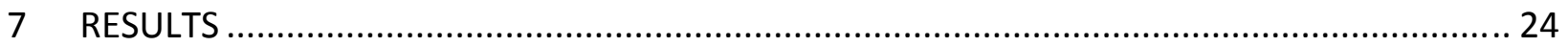

7.1 Observed Behavior at Bus Stops in Tampa ............................................................. 24

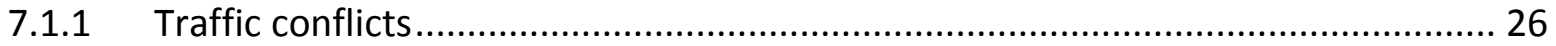

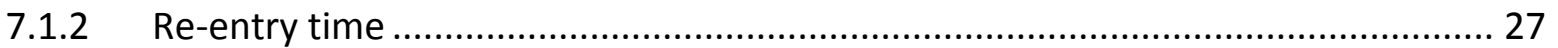

7.2 Observed Behavior at Bus Stops in Fort Myers ………………............................. 28

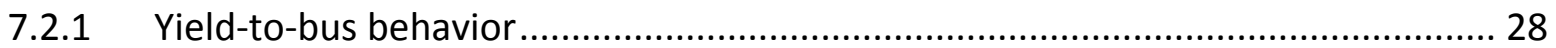

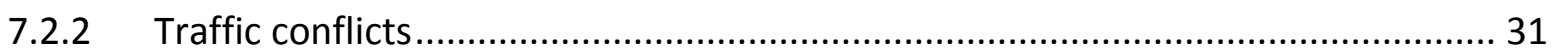

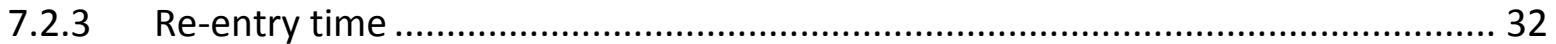

7.3 Observed Behavior at Bus Stops in Daytona Beach................................................... 34

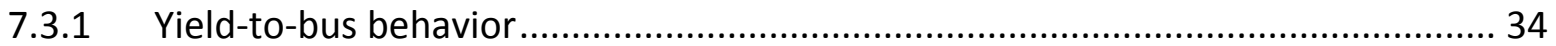

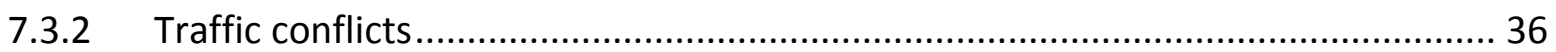

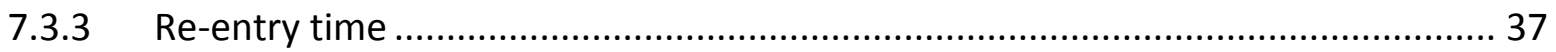




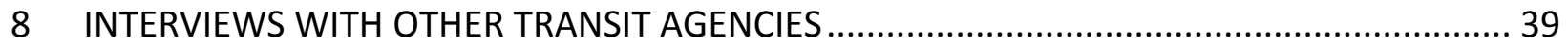

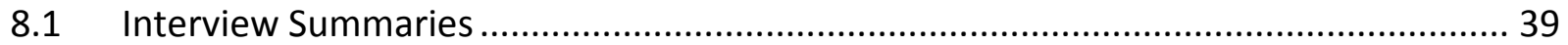

8.2 Santa Clara Valley Transportation Authority (VTA) ..................................................... 39

8.2.1 YTB public education campaign ....................................................................... 39

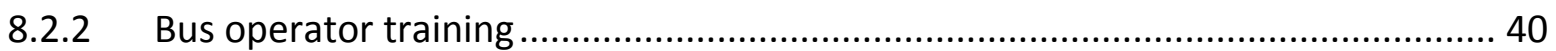

8.2.3 Yield LED sign operation and maintenance ....................................................... 40

8.2.4 Lessons learned and recommendations ........................................................... 41

8.3 Tri-County Metropolitan Transportation District of Oregon (TriMet).......................... 42

8.3.1 YTB public education campaign .............................................................................. 42

8.3.2 Bus operator training ................................................................................... 42

8.3.3 Yield LED sign operation and maintenance ....................................................... 42

8.3.4 Lessons learned and recommendations ............................................................. 44

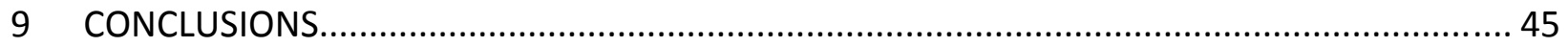

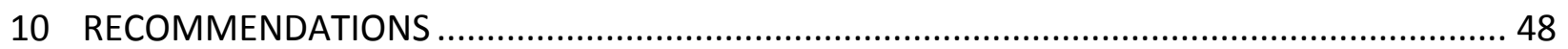

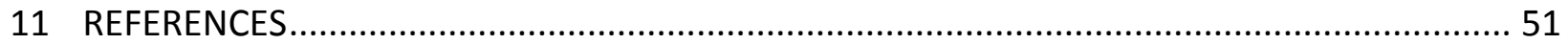

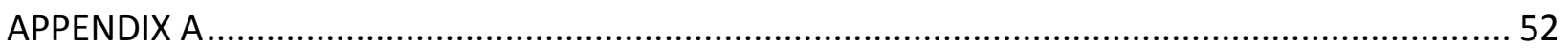

Sample of Observed Conflicts in the Field ...................................................................... 52

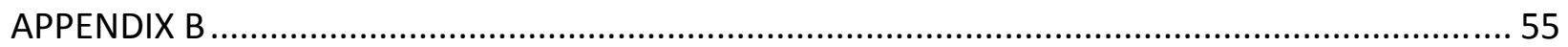

Potential Funding Sources for Local Agencies to Implement YTB-LED Signs ............................ 55 


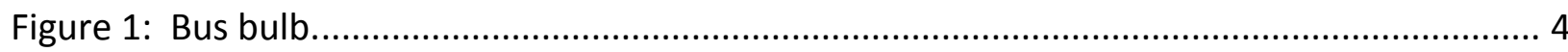

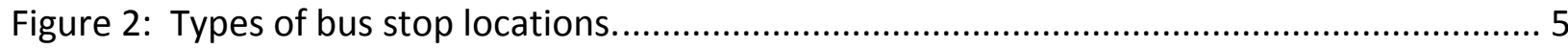

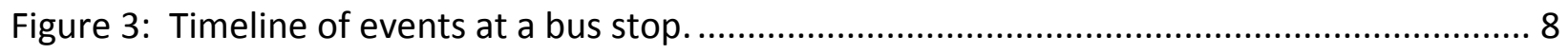

Figure 4: Traffic conflicts for yield-to-bus treatments safety evaluation............................... 9

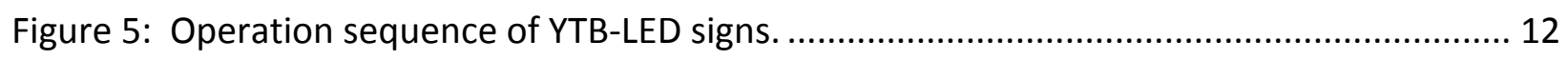

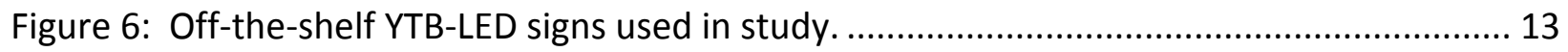

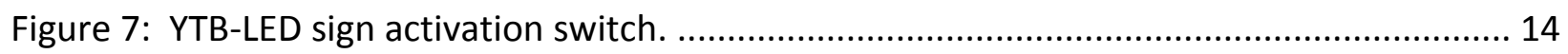

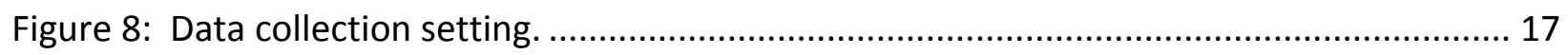

Figure 9: Sign installation and data collection setting for HART. .......................................... 18

Figure 10: Sign installation and data collection setting for LeeTran. ...................................... 18

Figure 11: Characteristics of test corridor in Tampa. .......................................................... 19

Figure 12: Characteristics of test corridor in Fort Myers................................................. 20

Figure 13: Characteristics of test corridor in Daytona Beach.............................................. 21

Figure 14: Screenshot of vehicle yielding to bus on test corridor in Tampa............................ 22

Figure 15: Screenshot of vehicle yielding to bus on test corridor in Fort Myers. ..................... 22

Figure 16: Screenshot of vehicle yielding to bus on test corridor in Daytona Beach................. 23

Figure 17: Summary of observed yield-to-bus behavior at test bus stops in Tampa................ 24

Figure 18: Observed yield-to-bus behavior on test corridor in Tampa. .................................. 25

Figure 19: Observed conflicts on test corridor in Tampa................................................. 26

Figure 20: Boxplot for re-entry time on test corridor in Tampa.......................................... 27

Figure 21: Summary of observed yield-to-bus behavior on test corridor in Fort Myers. ........... 29

Figure 22: Comparison of YTB treatments in yield-to-bus behavior in Fort Myers................... 30

Figure 23: Observed traffic conflicts on test corridor in Fort Myers...................................... 31

Figure 24: Boxplot for re-entry time on test corridor in Fort Myers. ..................................... 33

Figure 25: Summary of observed yield-to-bus behavior on test corridor in Daytona Beach....... 34

Figure 26: Comparison of YTB treatments in yield-to-bus behavior in Daytona Beach.............. 36 
Figure 27: Observed conflicts on test corridor in Daytona Beach........................................ 37

Figure 28: Boxplot for re-entry time on test corridor in Daytona Beach. .............................. 38

Figure 29: Public education ad on back panel of VTA buses. ................................................ 40

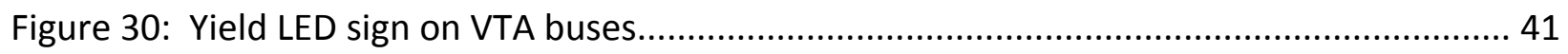

Figure 31: Samples of public education campaign in TriMet. ................................................ 43

Figure 32: Possible YTB accident classification zone. ..................................................... 50 


\section{LIST OF TABLES}

Table 1: Quantitative indicator for yield-to-bus behavior................................................. 8

Table 2: Annual Average Daily Traffic (AADT) by milepost on test corridor in Tampa............... 19

Table 3: AADT by milepost on test corridor in Fort Myers. ................................................... 20

Table 4: AADT by milepost on test corridor in Daytona Beach. ........................................... 21

Table 5: Analysis of yield-to-bus behavior on test corridor in Tampa.................................... 25

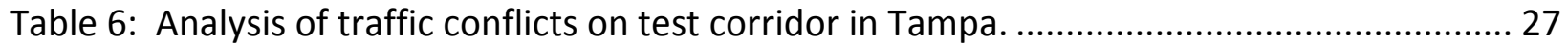

Table 7: Analysis of re-entry time on test corridor in Tampa................................................. 28

Table 8: Analysis of yield-to-bus behavior on test corridor in Fort Myers. ............................. 29

Table 9: Multiple-proportion comparison test for yield-to-bus behavior in Fort Myers. ........... 30

Table 10: Analysis of traffic conflicts on test corridor in Fort Myers....................................... 32

Table 11: ANOVA table for re-entry on test corridor in Fort Myers....................................... 33

Table 12: Analysis of re-entry time on test corridor in Fort Myers. ........................................ 33

Table 13: Analysis of yield-to-bus behavior on the test corridor in Daytona Beach.................. 35

Table 14: Multiple-proportion comparison test for yield-to-bus behavior in Daytona Beach.... 35

Table 15: Analysis of traffic conflicts on test corridor in Daytona Beach................................ 37

Table 16: ANOVA table for re-entry on test corridor in Daytona Beach. ................................ 38

Table 17: Analysis of re-entry time on test corridor in Daytona Beach. ................................. 38

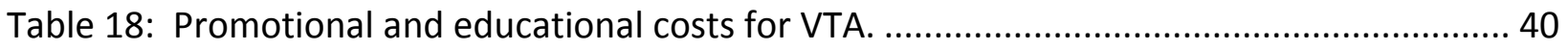




\section{INTRODUCTION}

The difficulty experienced by transit buses in moving back into traffic safely from bus pullout bays has become a serious problem due to potential hazards between buses merging from the pullout bays and the surrounding traffic. Previous studies have determined the need to closely examine the engineering side of the Yield-to-Bus (YTB) program and to develop effective countermeasures to address the issue.

In 2004, a crash study was conducted to examine all reported bus crashes during the period of 1998 to 2002 on the State Highway System in Florida (1). The study aimed to find significant factors contributing to transit bus crashes. It was found that most of the serious crashes occurred near bus stops and were characterized by vehicles striking the back of the bus. In the survey section of the study, most transit agencies expressed their preferences for the implementation of more pullout bays, while those with reservations about this measure were concerned regarding the ability of the buses to merge back into traffic safely. In light of these survey results, the Florida Department of Transportation (FDOT), through the National Center for Transit Research (NCTR) at the Center for Urban Transportation Research (CUTR) at the University of South Florida, has actively focused on determining the best set of treatments to promote YTB compliance. As part of these efforts, Phase I of this research was completed in November 2007 (2). It presented a comprehensive overview of the existing signage, lighting configurations, and existing YTB laws to help buses merge back into traffic from bus pull-out bays. The recommendations from Phase I include: (1) develop potential traffic control devices, i.e., signs, pavement markings, and flashing beacons to help buses merge safely back into traffic, (2) evaluate the latest YTB Light Emitting Diode (LED) flashing signs on the back of buses, (3) assess safety and operational benefits, and (4) develop recommendations and implementation of an effective public awareness program to increase public awareness of YTB laws.

This study focuses on the assessment of the safety and operational benefits of the use of YTBLED signs on the back of buses. The main objectives of this study are as follows:

- Determine if the use of YTB-LED signs has an effect on the yield-to-bus behavior of motorists behind the bus.

- Assess the potential effects on traffic safety with the use of YTB-LED signs.

- Establish the operational benefits of YTB-LED signs.

- Provide recommendations for implementation of YTB-LED signs and a public awareness campaign for YTB programs.

To accomplish these goals, two types of off-the-shelf YTB-LED signs were procured and deployed at the participating transit agencies. The transit agencies participating in the study were Hillsborough Area Regional Transit (HART) in Tampa, Lee County Transit (LeeTran) in Fort Myers, and Volusia County Transit (VOTRAN) in Daytona Beach. Data were collected by installing a camera on the back of a bus, aimed at the traffic behind the bus. Video-based data 
on yield-to-bus behavior, traffic conflicts, and re-entry time were collected at the participating agencies. The field observations and quantitative data analyses confirmed that the use of the YTB-LED signs on the back of buses has a statistically positive influence on the yield-to-bus behavior of motorists and the potential to reduce the number of traffic conflicts. The use of YTB-LED signs also provided operational benefits by reducing the re-entry time of the buses.

Two transit agencies outside Florida were interviewed to obtain recommendations and lessons learned from their implementation of yield-to-bus campaigns. Santa Clara Valley Transportation Authority (VTA, San Jose, California) and Tri-County Metropolitan Transportation District of Oregon (TriMet, Portland) also were interviewed via conference calls to obtain valuable experience and details regarding their YTB programs and educational campaigns. Educational ads on the back of buses were found to be one of the most effective ways to keep the general public informed about traffic safety practices related to transit buses.

This study provides quantitative evidence of the potential benefits of the implementation of YTB-LED signs on the back of buses and recommendations for sign compliance, installation, and operation. Recommendations for a public awareness campaign based on transit agency interviews also are provided. 


\section{RELATED TRANSIT STUDIES}

In this section, a review of transit studies dealing with before-and-after data collection for implementation of yield-to-bus treatments is presented. Since evaluation data for yield-to-bus treatments were found to be limited, the review was extended to other studies that may contain information relevant to this subject.

\subsection{Yield-to-Bus Studies}

Transit Cooperative Research Program (TCRP) Synthesis 49, "Yield-to-Bus - State of the Practice" (3), presents a comprehensive study of the most representative YTB initiatives at the national level. The study performed a comprehensive survey of transit agencies to assess the operational and safety benefits of the implementation of the YTB programs. The study reported that no quantitative information regarding the time savings or safety benefits had been collected to evaluate the before-and-after performance measures of the implementation of YTB programs.

An extensive review of YTB laws and practices, including TRCP Synthesis 49, can be found in NCTR's study "Moving the Bus Back into Traffic Safely - Signage and Lighting Configuration Phase I" (2). The study conducted a bus operator survey in Florida and suggested a series of YTB treatments such as LED flashing signs, roadside signs, and pavement markings.

\subsection{Other Related Studies}

TCRP Report 65, "Evaluation of Bus Bulbs" (4), includes before-and-after studies for curbsides and roadways. These studies were concentrated on the assessment of the operational benefits for pedestrian operations as a result of bus bulb implementation. A bus bulb is a section of sidewalk that extends from the curb of a parking lane to the edge of a through lane (see Figure 1). Bus bulbs operate the opposite of a bus bay - buses stop in the traffic lane instead of weaving into a parking-lane curbside stop. Bus bulbs are useful in reducing sidewalk pedestrian congestion. They are best applied in conditions of high patronage volumes, crowded city sidewalks, and permitted curbside parking.

The data collection in TRCP Report 65 included photographs, videos of pedestrian flows, and boarding/alighting information. Data were collected using travel-time software (license plate matching), palmtop computers, cameras, and general field observations. The data focused on obtaining the following information:

- Bus and vehicle speeds near a bus stop (peak and non-peak time periods)

- Bus and vehicle speeds for the corridor (peak time period)

- Length of queue behind a bus and driver behavior near the bus stop

- Bus operations 


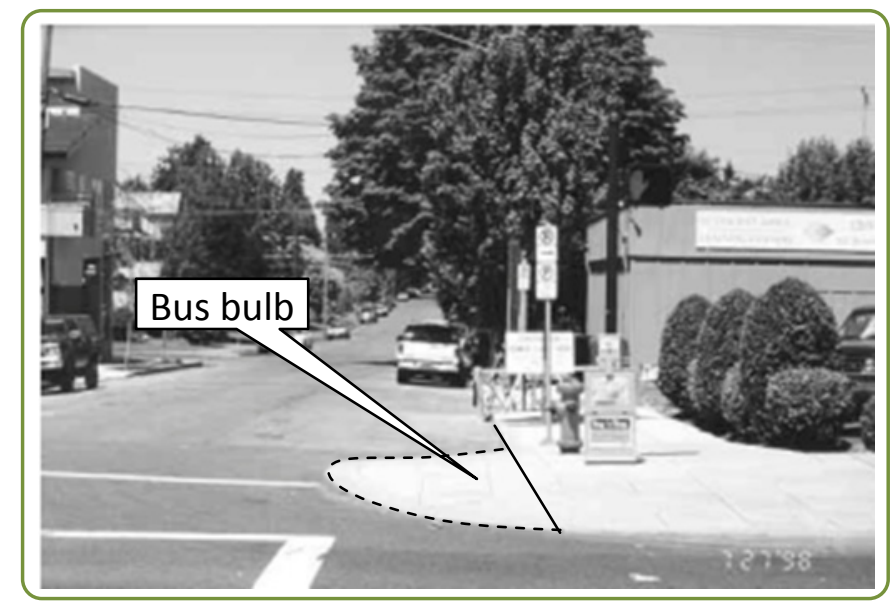

Source: Fitzpatrick et al. (4)

Figure 1: Bus bulb.

In TCRP Report 19, "An Evaluation of Bus Bulbs on Transit, Traffic, and Pedestrian Operations" (5), before-and-after data resulting from the implementation of bus bulbs were collected. Data regarding the vehicle operations around a bus stop included the number of vehicles queued and the number of lane changes that occurred behind a stopped bus. The study reports several observed near "sideswipes" between vehicles and buses when a bus tried to re-enter the traffic stream from a bus bay. Also, the study reported observations of instances when a bus was caught in the queue created by traffic signals before reaching the bus stop. Dwell times were collected using palmtop computers. The times when the bus stopped at the bus stop and the doors closed were recorded. Dwell time was computed as the difference between those events. Re-entry delay was collected using palmtop computers.

The study "Guidelines for the Location and Design of Bus Stops" (6) provides recommendations for the implementation of bus bays. According to the report, bus bay locations can be of three types: far-side, mid-block, or near-side, as presented in Figure 2. The report also provides the following recommendations for when to implement bus bays:

- Traffic in the curb lane exceeds 250 vehicles during the peak hour.

- Traffic speed is greater than $40 \mathrm{mph}$.

- Bus volumes are 10 or more per peak hour on the roadway.

- Passenger volumes exceed 20 to 40 boardings per hour.

- Average peak-period dwell time exceeds 30 seconds per bus.

- Buses are expected to lay over at the end of a trip.

- Potential exists for auto/bus conflicts warrants separation of transit and passenger vehicles.

- History exists of repeated traffic and/or pedestrian accidents at stop location.

- Right-of-way width is adequate to construct the bay without adversely affecting sidewalk pedestrian movement. 
- Sight distances (i.e., hills, curves) prevent traffic from stopping safely behind a stopped bus.

- A right turn lane is used by buses as a queue jumper lane.

- Appropriate bus signal priority treatment exists at an intersection.

- Bus parking in the curb lane is prohibited.

- Improvements such as widening are planned for a major roadway. (This provides the opportunity to include the bus bay as part of the reconstruction, resulting in a betterdesigned and less-costly bus bay.)

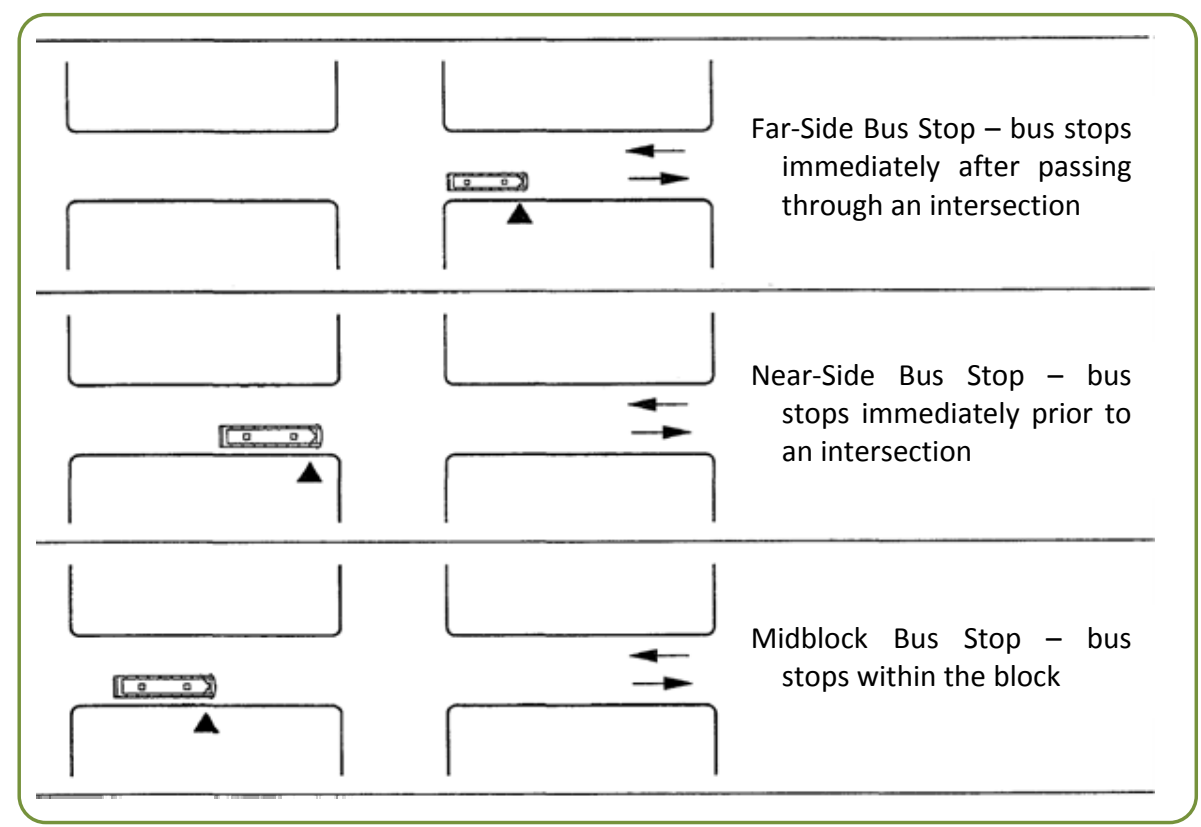

Source: Fitzpatrick et al. (6)

Figure 2: Types of bus stop locations.

TCRP Report 19 also mentions that bus drivers will not use bus bays when traffic volumes exceed 1,000 vehicles per hour per lane. Under these traffic conditions, it is difficult to maneuver a bus out of a midblock or near-side bay, forcing the bus to wait an unacceptable period of time to re-enter the travel lane. In the same report, it is recommended that far-side bus stops and acceleration lanes are useful for bus bays on high-volume roads.

TCRP Report 19 also documents a number of field observations on the following conflicts for different bus stop configurations:

- Traffic queue occurring due to bus blocking lane while stopped (curb-side stop).

- Traffic queue occurring due to vehicle stopping in through lane to allow bus to re-enter traffic stream (bus bay).

- Driver of vehicle changes lanes due to bus (curb-side stop). 
- Bus operator pulls out in front of car, causing driver to slow down, change lanes, or stop (bus bay).

- Conflict occurs between bus and car while bus is re-entering traffic stream causing delay to bus.

- At a bus bay, bus driver stops in main lanes to board passengers.

- Conflict occurs between bus and car due to driveway location.

The Federal Transit Administration (7) suggested that bus merging delay can be calculated as a function of the adjacent lane traffic flow and the critical gap length needed by the bus operator to merge. Also, in the same report, it is stated that the point of significant delay is above 450 vehicles per hour per lane and that for a 4-mile trip the cumulative delay could be 10 minutes or more.

Based on the findings of the literature review, the following measures of effectiveness are required to properly evaluate the impact of yield-to-bus treatments:

- A quantitative indicator of YTB behavior

- Safety conflicts

- Re-entry time 


\section{YIELD-TO-BUS CONCEPTS AND PERFORMANCE MEASURES}

In this section, the required performance measures for the evaluation of YTB treatments are established based on the findings in the literature review.

\subsection{Operational Concepts and Performance Measures}

In traffic operations, a yield action consists of slowing down and giving the right-of-way to the main traffic stream. In a yield action, the driver must be prepared to stop if necessary, but, in general, it is not required. In contrast, at a stop sign, drivers are required to perform a complete stop before continuing on their travel path. According to the Florida Drivers' Handbook, a yield action consists of the following: "Slow down and give vehicles crossing your path the right-ofway. If the way is clear, you may move forward slowly without stopping."

The yield concept can be applied to transit buses at bus stops requiring a merging maneuver. Right turn lanes and bus bays are the most common locations for bus stops where merging maneuvers are required to return to the traffic stream. The number of bus bays on transit routes varies significantly among geographic locations. On the other hand, bus stops at right turn lanes are more uniform across the state. In this study, merging maneuvers at both bus bays and right turn lanes were analyzed.

\subsubsection{Yield-to-bus indicator variables}

A merging maneuver is finalized when the bus completely returns to the travel lane after a stop. This can occur in three major ways with respect to the traffic in the adjacent lane:

- Yield: a vehicle in the adjacent lane gives the right-of-way to the bus.

- Lane change: a vehicle in the traffic lane safely changes lanes, giving the bus the rightof-way.

- Gap in traffic: no yield or lane change occurs and the bus waits for an acceptable gap in traffic.

The yield and gap termination criteria are clearly defined. On the other hand, the lane change termination criteria could be considered a type of yield behavior if performed safely. By changing lanes, motorists allow the bus to merge back into traffic more easily. The quantitative indicator variables of YTB behavior can be defined as described in Table 1. It is important to note that not all of the stops at bus bays or right turn lanes require a merging maneuver. When there is no traffic in the adjacent lane, the bus can merge back into traffic freely. A merging maneuver with no traffic is not considered a data point for measuring yield-to-bus behavior. 
Table 1: Quantitative indicator for yield-to-bus behavior.

\begin{tabular}{c|cl|}
\hline Indicator variable & Value & Description \\
\hline Y & 1 & Merging maneuver finalized in yield \\
& 0 & Otherwise \\
\hline \multirow{2}{*}{ L } & 1 & Merging maneuver finalized in lane change \\
\hline \multirow{2}{*}{ G } & 0 & Otherwise \\
\hline & 1 & Merging maneuver finalized in gap \\
\hline
\end{tabular}

The indicator variables should reflect that these are the only three possible ways to finalize a merging maneuver. This can be expressed as $\mathrm{Y}+\mathrm{L}+\mathrm{G}=1$ for a particular bus stop. The performance measure for yield-to-bus behavior evaluation will be the percentage of maneuvers that are finalized in the yield. This can be found by summing the $Y$ indicator variables for all bus stops and dividing by the sample size.

\subsubsection{Re-entry time}

The Highway Capacity Manual (HCM) (8) defines bus start-up time as the point at which a bus starts moving and travels its own length while exiting an off-traffic bus stop. The re-entry time is defined as the time experienced while waiting for a sufficient gap in traffic to allow the bus to merge back into the travel lane, as presented in Figure 3. The HCM reports that typical values for start-up times range from 2 to 5 seconds.

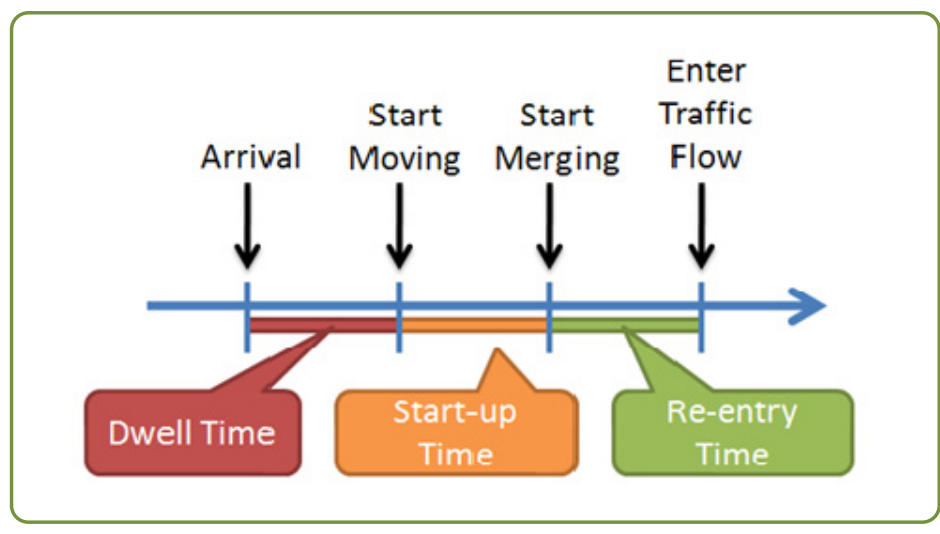

Figure 3: Timeline of events at a bus stop.

As depicted in Figure 3, start-up time is measured from the moment the bus starts to move back into traffic until it is completely back in the adjacent traffic lane. Re-entry time depends on different factors such as traffic conditions, bus type, and bus operator behavior. The re-entry time was measured using video data from the front camera of the bus. For bus stops with no traffic on the adjacent lane, no re-entry time was calculated. 


\section{SAFETY CONCEPTS AND PERFORMANCE MEASURES}

A before-and-after evaluation of YTB treatments using traffic accident data requires a long time span to perform a reliable analysis. Traffic conflicts often are used in lieu of accident data when data for a complete before-and-after analysis are not available. According to Federal Highway Administration (FHWA) report FHWA-IP-88-027 (9), a traffic conflict can be defined as "a traffic event involving the interaction of two or more road users, usually motor vehicles, where one or both drivers take evasive action such as braking or swerving to avoid a collision." Based on the definition of conflicts and the conflict types presented in the FHWA report, four main conflicts are defined to evaluate the safety of yield-to-bus treatments, as illustrated in Figure 4.

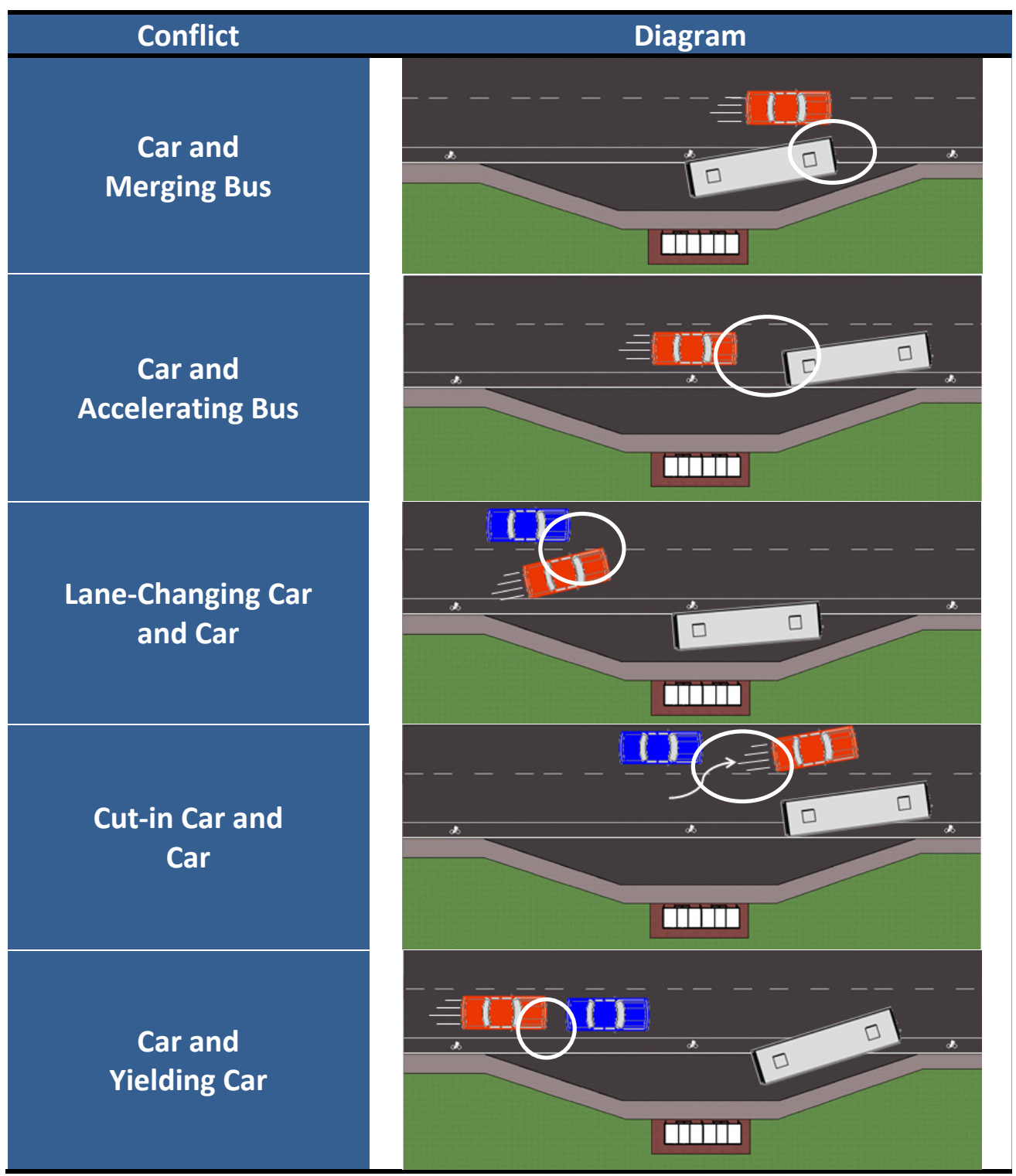

Figure 4: Traffic conflicts for yield-to-bus treatments safety evaluation. 
- Car and Merging Bus: This is a direct conflict involving a bus leaving a bus bay or right turn lane in which the bus gets too close to a car in the travel lane.

- Car and Accelerating Bus: This is a direct conflict in which a bus enters the traffic lane at low speed and the car behind has to brake to avoid a collision.

- Lane-Changing Car and Car: This is a secondary conflict caused by a car in the travel lane performing an unsafe lane change in an attempt to avoid yielding to a bus entering the traffic.

- Cut-in Car and Car: This is a secondary conflict in which a car changes lanes after the bus has entered the traffic and conflicts with the car in front that is traveling at a lower speed.

- Car and Yielding Car: This is a secondary conflict in which a car that yielded the right-ofway to the bus experiences a conflict with a close-following car.

Conflict counts based on these conflict types were performed at the different data collection sites to assess the effects on traffic safety derived from the use of YTB LED signs on the back of the buses. Samples of conflicts observed in the field can be found in Appendix A. 


\section{SIGN COMPLIANCE, INSTALLATION, AND OPERATION}

In this section, the federal standards applicable to yield signs are reviewed. Suggested practices are recommended for YTB LED sign implementation. Also, the sign types used in the study are introduced. At the end of this section, a description of the operation of the yield LED sign is presented.

\subsection{Sign Compliance and Installation}

According to National Highway Traffic Safety Administration (NHTSA) (10), the applicable regulations for YTB-LED flashing signs are found in Federal Motor Vehicle Safety Standards (FMVSS) No. 108, U.S.C. 49 Chapter 301. Also, state regulations such as the Florida Administrative Code, FAC Rule 14-90 can be applicable to YTB-LED signs.

According to the applicable standards, prior to the initial sale, YTB-LED signs cannot be installed on transit buses as an item of original equipment or installed by any manufacturer or dealer. In addition, the flashing operation of lamps on buses is restricted to lamps for signaling purposes (FMVSS No. 108, Section 5.5.10).

However, these regulations do not apply to YTB-LED signs if they are installed as aftermarket equipment. The applicable standard for aftermarket equipment is 49 U.S.C. $\S 30122$, indicating that any equipment installed on a vehicle must not make inoperative any of the required safety equipment, which, in this case, refers to the lamps required by the FMVSS No. 108.

In addition to federal laws, state laws also apply. In the case of Florida, the applicable standard states that only amber lights are allowed to flash for non-official vehicles.

Based on the existing regulations, the following practices are suggested for the implementation of YTB-LED signs on transit buses:

- YTB-LED signs can be installed on buses as aftermarket equipment by bus owners without the assistance of a manufacturer, distributor, or dealer.

- YTB-LED signs can be wired to flash if done in conjunction with the regulatory turning lamps for the purpose of signaling. This implies that the YTB-LED sign cannot flash independently of the left turn lamp, but the left turn lamp can be activated independently of the YTB-LED sign (e.g., left turns at intersections).

- YTB-LED signs cannot impair the effectiveness of any of the regulatory lamps.

- YTB-LED signs should comply with local regulations regarding color and configuration.

Note that it is always good practice to request an interpretation from NHTSA before engaging in major initiatives involving new lamps on buses.

Figure 5 shows the operation sequence of a YTB-LED sign for a bus entering and leaving a bus bay. In stage 1 , the bus is traveling in the traffic lane and no lamp is active. As the bus 
approaches the bay, the right turn lamp is activated, signaling the motorists behind the bus (stage 2). At stage 3, tail lights and right turn lamps are active, indicating that the bus is stopping. A stop light also may be present at this stage. The bus comes to a full stop in stage 4, and stop lights and tail lights are active during this stage. In stage 5 , the bus is ready to merge back into traffic. The left turn lamp is active, as is the YTB-LED sign. In this case, the YTB-LED sign assists the left turn lamp to effectively deliver the signaling message to the motorists behind the bus. Once the bus is back in traffic, all the lights are off (stage 6). Note that if used as suggested by Figure 5, the YTB-LED signs do not impair any of the regulatory lamps.

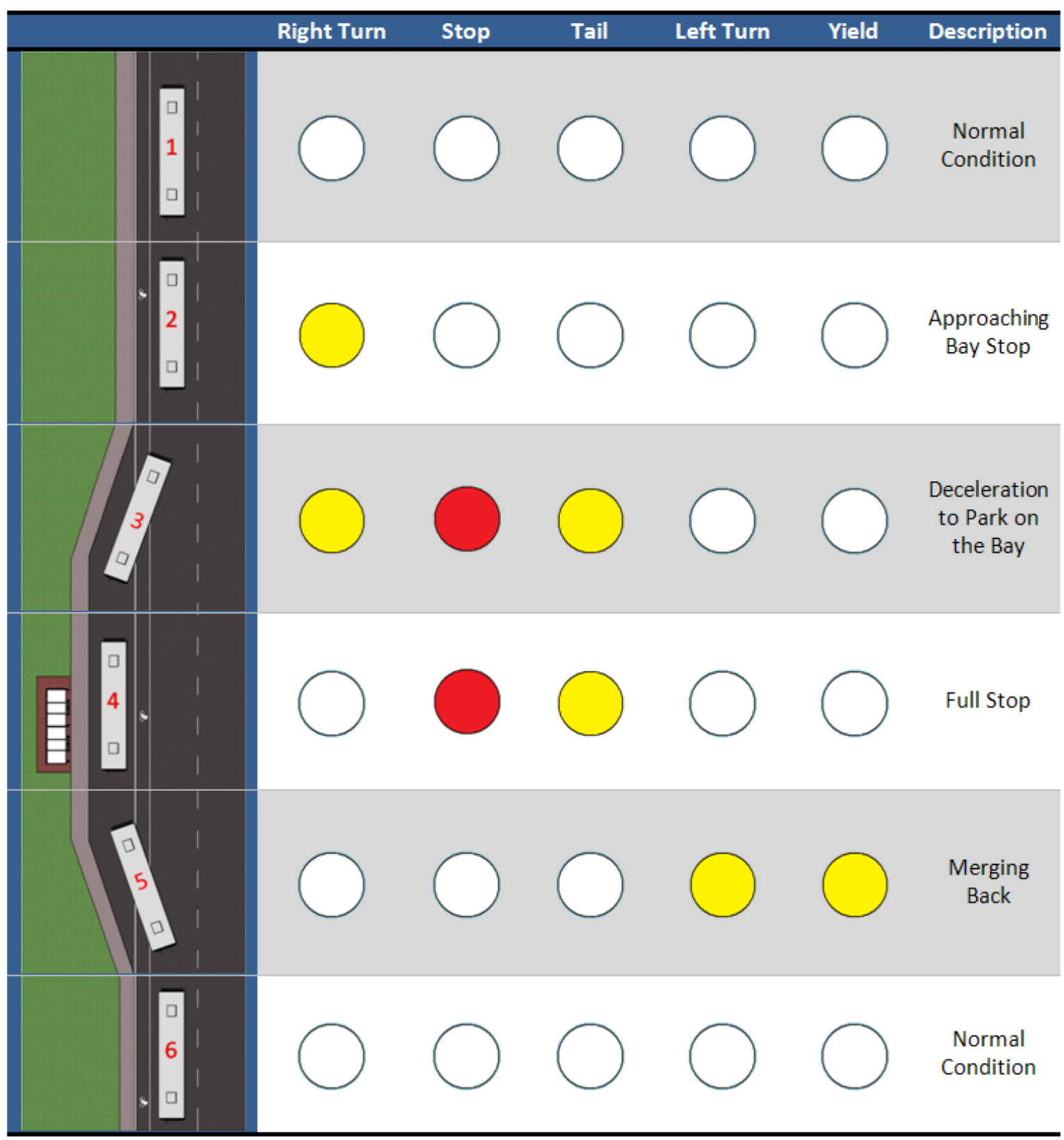

Figure 5: Operation sequence of YTB-LED signs. 


\subsection{Sign Types}

Based on the literature review, input from transit agencies in Florida, and previous reports (2), two off-the-shelf YTB-LED flashing signs were selected for testing.

The triangular yield LED sign (see Figure 6a) currently is used by several transit agencies in the United States, including Tri-Met (Oregon), Pierce Transit (Washington State), Santa Cruz Metro (California), Santa Clara Valley Transportation Authority (California), and St. Cloud (Minnesota). In Florida, the Lee County and Volusia County transit agencies have some buses with this type of YTB-LED sign.

The merge alert LED sign (see Figure 6b) also was used in the study. This sign alternatively displays in one phase the word "merging" along with a yield sign and an arrow in the second phase. As of the date of this report, the research team is not aware of any transit agencies currently using this sign.

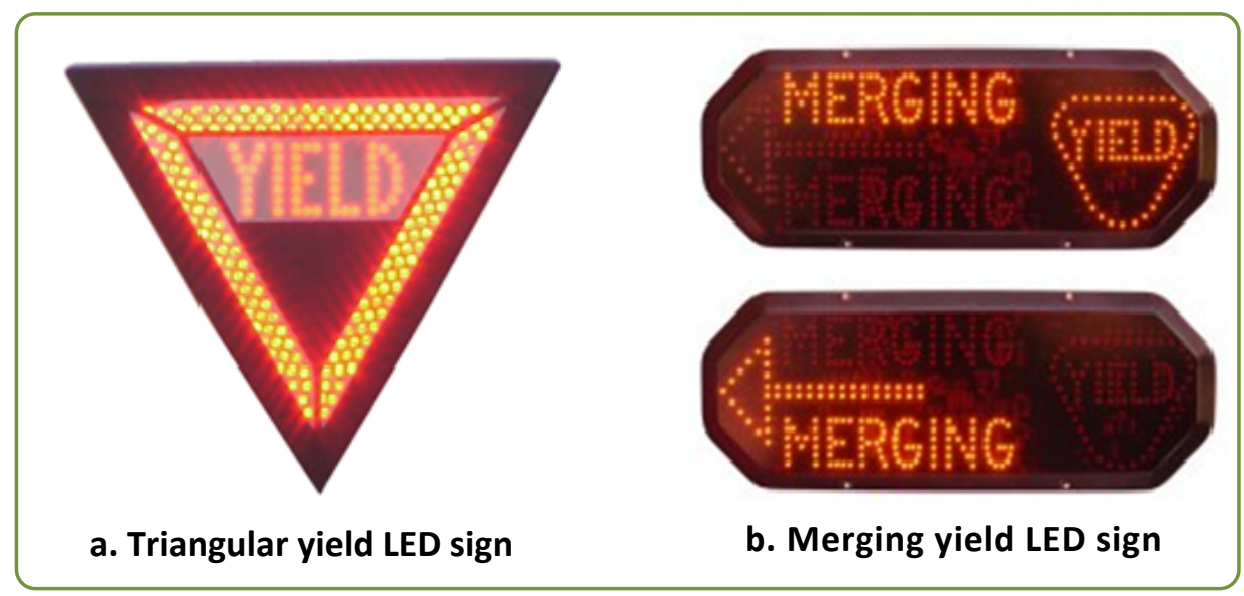

Figure 6: Off-the-shelf YTB-LED signs used in study.

\subsection{Sign Operation}

Sign operation is related to the left turn operation since the yield sign will assist the left turn signal at selected locations. An activation switch is provided on the operator's control panel, as presented in Figure 7. Since bus makes and models have different panel configurations, two types of operation models for the YTB-LED sign were implemented: timer-mode and touchswitch mode.

\section{Yield sign in timer mode:}

- Activate the left turn signal.

- Push the yield signal activation button.

- The indicator lamp will illuminate, showing that the yield signal is flashing.

- The yield signal will go off after 10 seconds. 
- If the operator cannot move within a 10 -second period, the left turn signal must be released and the yield signal button pushed again to re-activate it for 10 seconds more.

Yield sign with touch switch mode:

- Activate the left turn signal.

- Push the yield signal activation button while merging back into traffic.

- When the switch is released, the yield sign will be turned off.

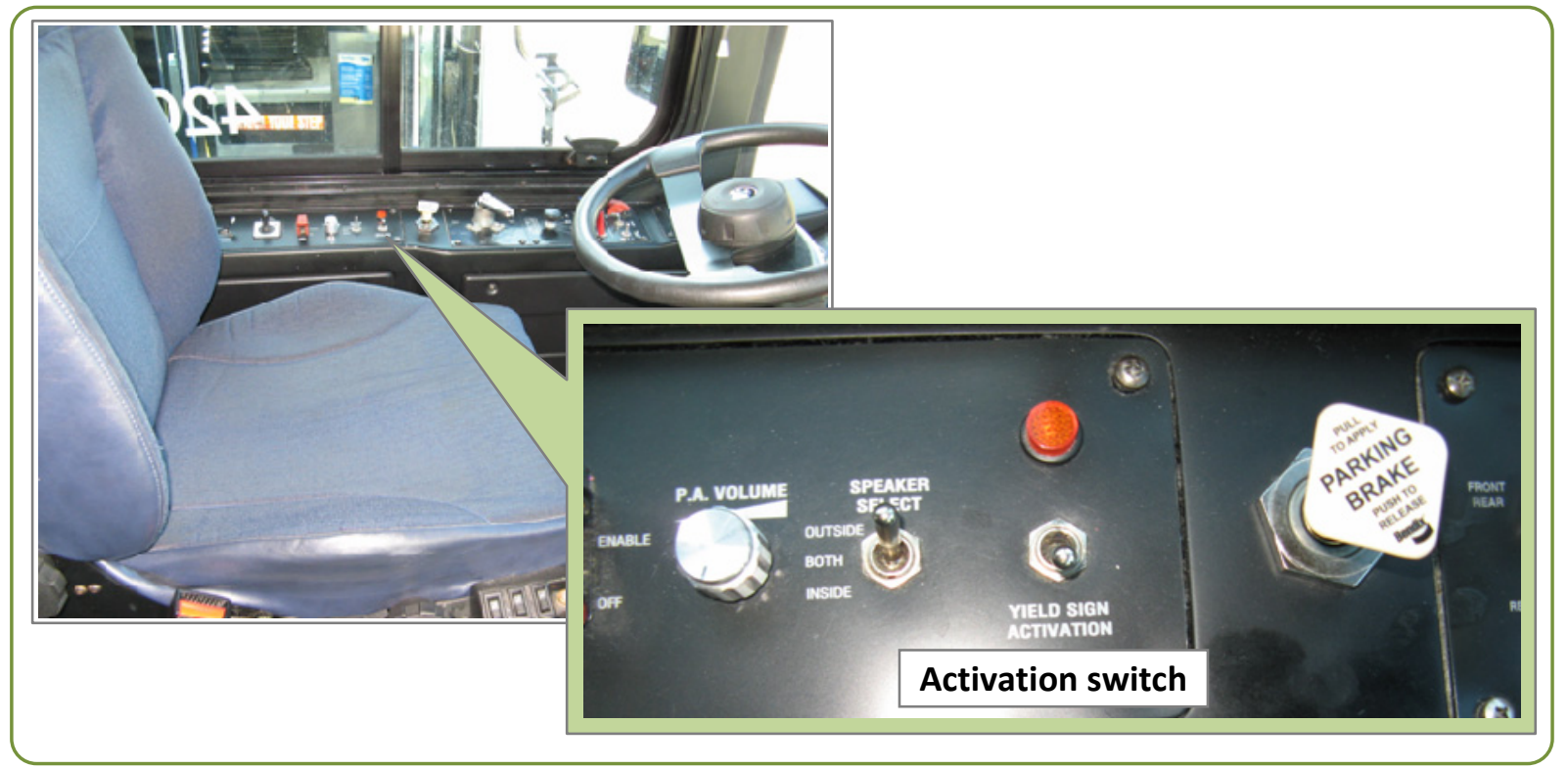

Figure 7: YTB-LED sign activation switch.

As can be observed in Figure 7, the bus operator control panel has a significant number of controls. Depending on the operation mode and the frequency of use, the yield sign control preferably should be located in the front-left section of the panel with a different switch handle. This will help the bus operator become familiar with the control.

\subsection{Enforcement}

In Florida, motorists are required to yield the right-of-way to a public transit bus merging back into traffic from designated pullout bays. The applicable Florida statute requires the bus to signal prior to re-entering the traffic flow. YTB-LED signs, when used in conjunction with left turn signals, help to signal the merging maneuvers on designated pull out bays, therefore promoting law compliance. For designated pullout bays, motorists should more frequently allow the bus to re-enter traffic safely.

For other locations requiring merging maneuvers, such as right turn lanes, motorists are not required to yield to a bus entering traffic. The use of YTB-LED signs does not grant any special treatment to the bus. A forceful merging maneuver from a location other than a designated pullout bay could be chargeable to the bus operator even if the YTB-LED sign is used. 
As a note of caution, Florida statutes also emphasize that in spite of the YTB law, or signaling method (YTB-LED or left turn lamp only), bus operators must exercise caution when re-entering the traffic, even in the case of pullout bays. 


\section{DATA COLLECTION}

This section presents the data collection strategy used to evaluate the effectiveness of YTB-LED signs. It also provides a description of the process followed by transit agencies to deploy and test the YTB-LED signs. A description of the geometric features of the test routes also is provided at the end of the section.

\subsection{Data Collection Strategy}

Several events must occur at the same time to observe a potential YTB scenario. First, a bus stop must occur with either a boarding or alighting at a location requiring a merging maneuver (bus bay or right turn lane). Second, traffic must be present. At certain locations, the proximity of an upstream traffic signal may benefit the bus stop operation since it filters the traffic such that the bus often can get the right-of-way. If one or two fixed locations with the desired geometric characteristics are selected for observation, the chances of observing YTB scenarios are significantly low. For instance, if two buses have YTB-LED signs on a route with a two-hour cycle, there are approximately six chances to observe a potential YTB scenario per day.

To maximize the number of potential YTB scenarios, a rear-view camera aimed at the traffic behind the bus was installed on the buses of the participating agencies. In this way, a wide range of bus stops with different geometries was covered. Since the YTB scenarios rely on several uncontrollable factors such as motorist behavior, a significant number of observations was required to achieve valid conclusions. The process followed by the research team to conduct the data collection is as follows:

1. Transit agency recruitment/installation agreement

2. Sign evaluation and troubleshooting

3. Selection of bus, route, and schedule with merging problems

4. Selection and training of test drivers

5. Sign installation and testing

6. Camera installation and testing

7. Running of data collection

a. Triangular yield sign/ Decal only

b. Merge alert sign/ Decal only

8. Retrieval of video-based data from bus DVR system

9. Removal of cameras and signs

First, several transit agencies were recruited to participate in the study. Within a participating agency, this project required the involvement of personnel from the maintenance/engineering, safety/training, and planning/operations departments. Also, the directors of the participating transit agencies were informed about the objectives and the data collection methodology of the study.

The first step was to work with the technical team of the participating agencies on the details of sign installation, operation, and interface with bus operators. Also, technical details about 
camera installation and wiring were discussed. Once the technical details of the study were clarified, the next step was to work closely with safety and planning personnel to select the routes with appropriate ridership that were located in corridors that have the desired geometric characteristics at bus stops. Several bus operators were selected to participate in the study. A special training session was provided by the safety/training specialist from the participating transit agency on the operation of the YTB-LED sign.

Once the sign and the camera were installed, the data collection period started. For data collection, bus operators were asked to drive using the YTB-LED when merging back in to traffic along bus stops on selected test corridors. One-way trips were assigned randomly to YTB-LED signs or decal-only treatments. In the latter case, the YTB-LED sign remained off during the all merging maneuvers in the segment. At the end of the data collection period, the video information was extracted and analyzed to evaluate the performance measures, as presented in Figure 8.

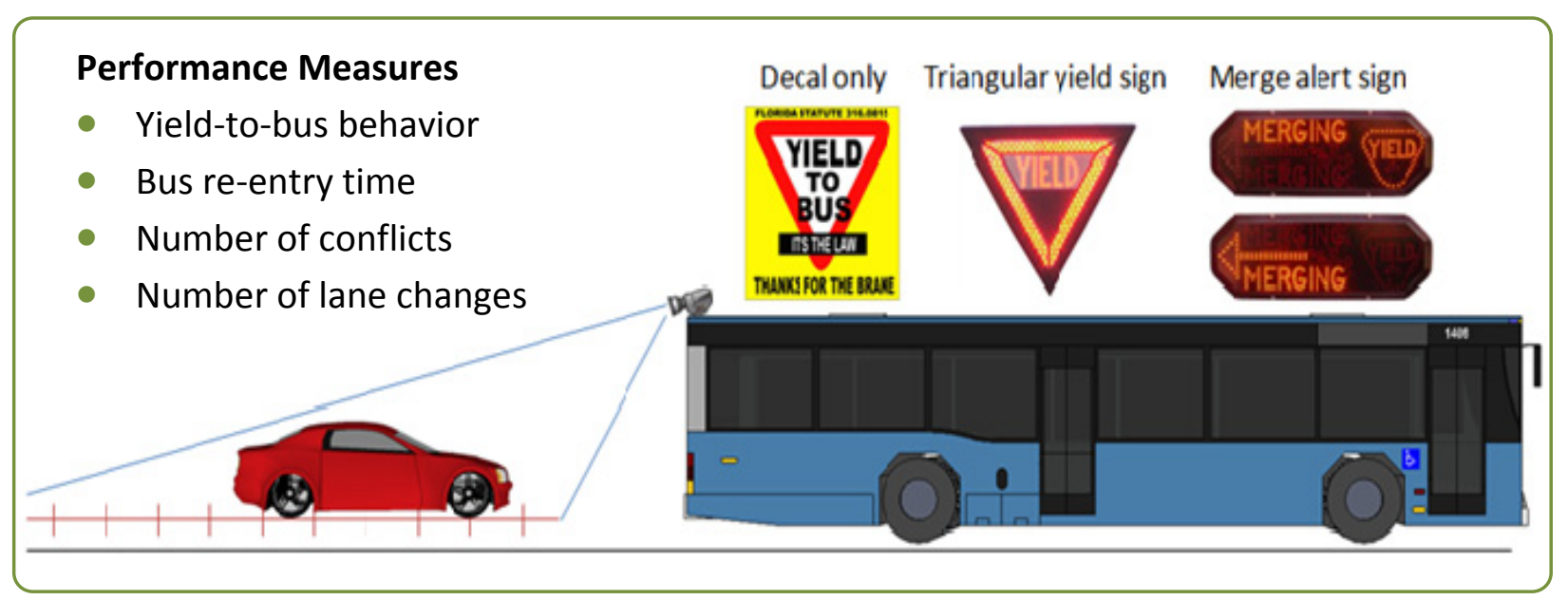

Figure 8: Data collection setting.

\subsection{Participating Agencies}

Three transit agencies in Florida participated in the study: Hillsborough Area Regional Transit (HART) in Tampa, Lee Transit (LeeTran) in Fort Myers, and Volusia County Transit (Votran) in Daytona Beach. LeeTran and Votran had triangular yield LED signs installed on some of its buses. This feature facilitated data collection for these agencies since the wiring and bus operator interface were already in place.

Two buses were used at HART. One bus was equipped with a triangular sign and the other with a merging sign. Both buses were equipped with rear-view cameras for data collection. Photographs of the data collection setting used at HART are presented in Figure 9. For LeeTran and Votran, one bus was equipped with a rear-view camera, and the signs (triangular and merging) were exchanged according to the test schedule. 
All installation and technical work was performed by technical staff at the participating agencies. The technical staff was very knowledgeable about the installation of the cameras and YTB-LED signs. The sign installation and data collection equipment for LeeTran is presented in Figure 10.

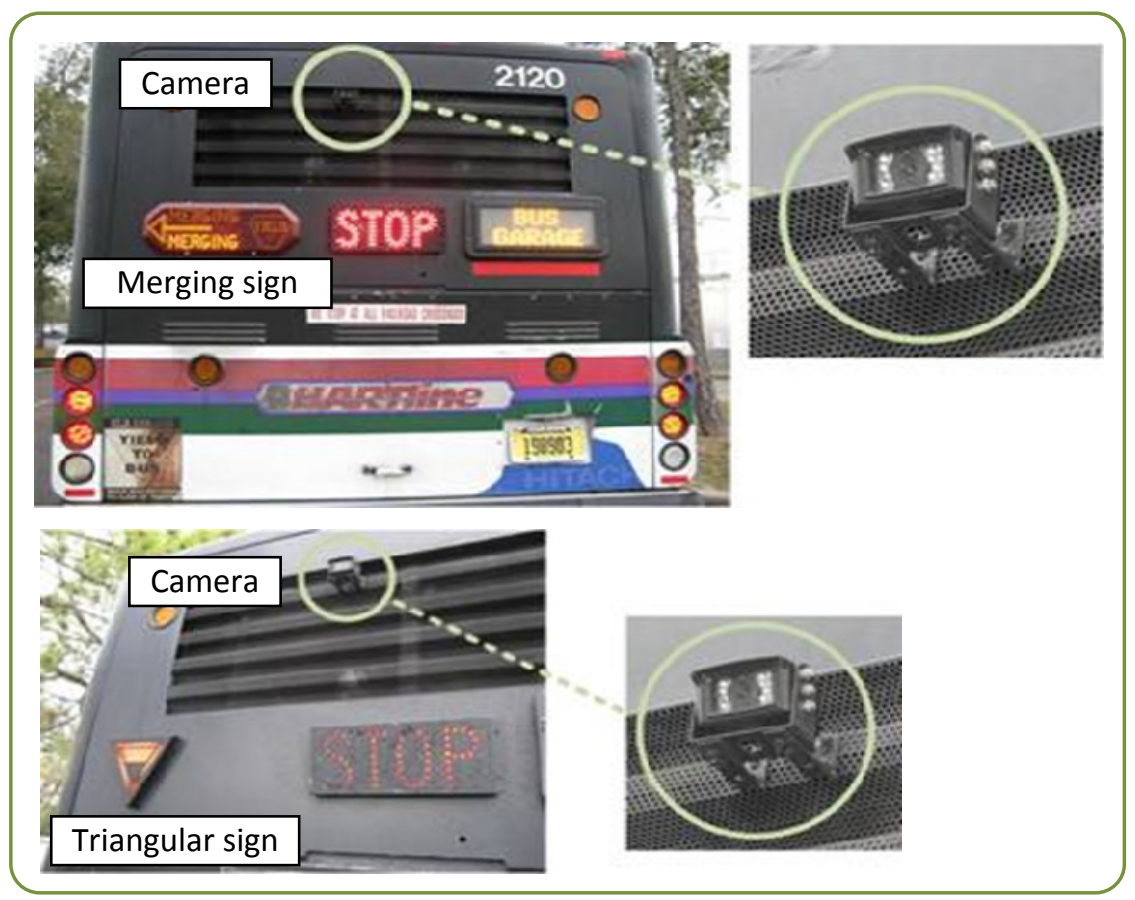

Figure 9: Sign installation and data collection setting for HART.

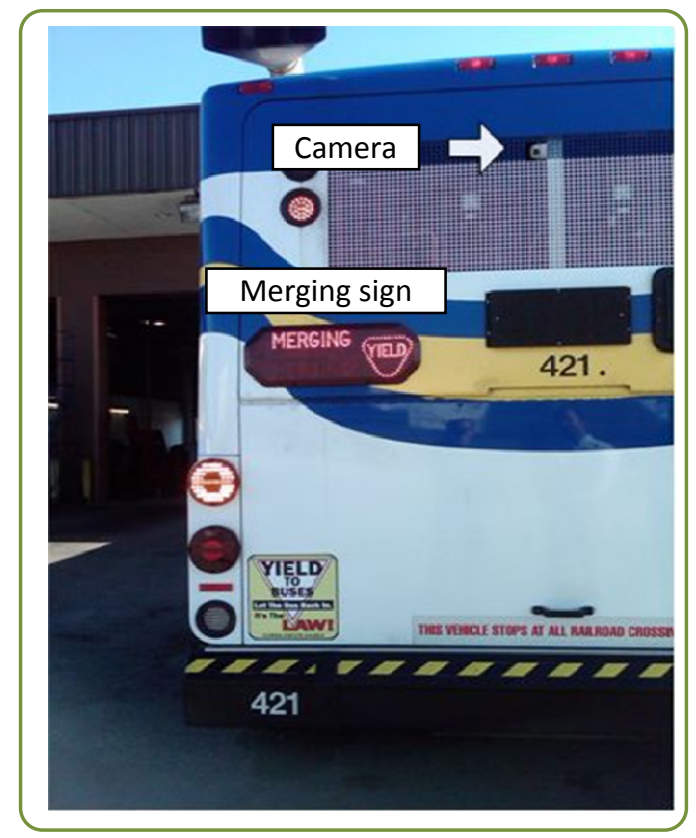

Figure 10: Sign installation and data collection setting for LeeTran. 


\subsection{Data Collection Sites}

The test corridors for data collection were selected such that the geometric features and traffic characteristics were appropriate to observe yield-to-bus behavior. In Tampa, the test corridor was an urban minor arterial, which was selected because of the presence of bus bays along the selected three-mile corridor. Corridor characteristics are presented in Figure 11 and traffic information is presented in Table 2.

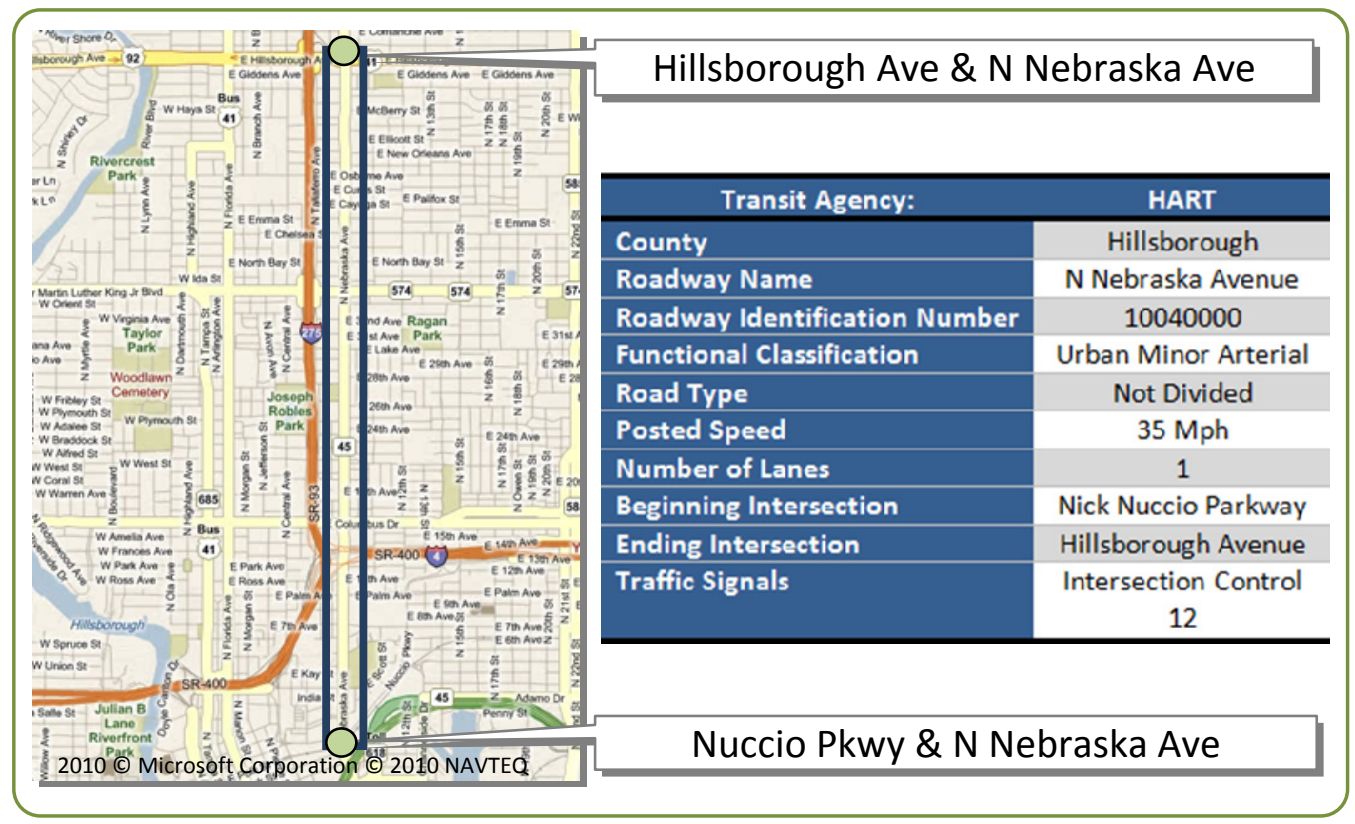

Figure 11: Characteristics of test corridor in Tampa. Table 2: Annual Average Daily Traffic (AADT)
by milepost on test corridor in Tampa.

\begin{tabular}{|ccc|}
\hline $\begin{array}{c}\text { Beginning } \\
\text { Milepost }\end{array}$ & $\begin{array}{c}\text { Ending } \\
\text { Milepost }\end{array}$ & AADT \\
\hline $\mathbf{0 . 2 1 6}$ & $\mathbf{0 . 7 1 0}$ & 6,500 \\
\hline $\mathbf{0 . 7 1 0}$ & $\mathbf{1 . 1 4 9}$ & 16,400 \\
\hline $\mathbf{1 . 1 4 9}$ & $\mathbf{2 . 1 5 5}$ & 16,500 \\
\hline $\mathbf{2 . 1 5 5}$ & $\mathbf{3 . 1 6 5}$ & 16,800 \\
\hline $\mathbf{0 . 2 1 6}$ & $\mathbf{0 . 7 1 0}$ & 7,800 \\
\hline $\mathbf{0 . 7 1 0}$ & $\mathbf{1 . 1 4 9}$ & 19,900 \\
\hline $\mathbf{1 . 1 4 9}$ & $\mathbf{2 . 1 5 5}$ & 19,600 \\
\hline $\mathbf{2 . 1 5 5}$ & $\mathbf{3 . 1 6 5}$ & 19,000 \\
\hline
\end{tabular}

The test corridor in Fort Myers consisted of approximately a three-mile section of US 41. The predominant geometric feature was bus stops at right turn lanes and one bus stop at a bus bay. Corridor characteristics are presented in Figure 12 and traffic information is presented in Table 3. 


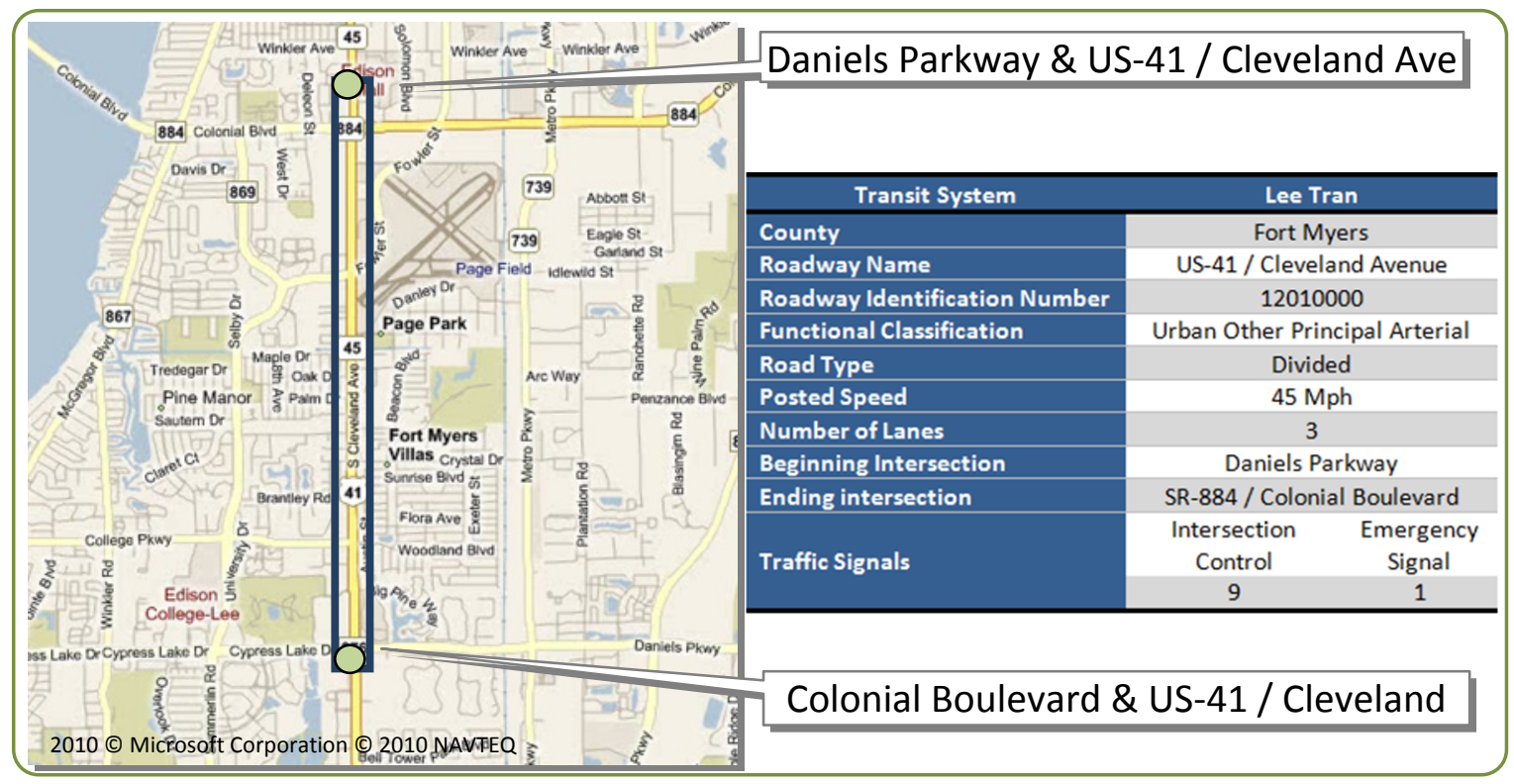

Figure 12: Characteristics of test corridor in Fort Myers.

Table 3: AADT by milepost on test corridor in Fort Myers.

\begin{tabular}{|c|c|c|}
\hline $\begin{array}{l}\text { Beginning } \\
\text { Milepost }\end{array}$ & $\begin{array}{l}\text { Ending } \\
\text { Milepost }\end{array}$ & AADT \\
\hline 17.040 & 17.746 & 67,000 \\
\hline 17.746 & 19.146 & 66,000 \\
\hline 19.146 & 19.550 & 74,000 \\
\hline 19.550 & 20.288 & 50,500 \\
\hline 20.288 & 20.530 & 55,500 \\
\hline 17.040 & 17.059 & 55,000 \\
\hline 17.059 & 17.765 & 70,500 \\
\hline 17.765 & 19.167 & 62,000 \\
\hline 19.167 & 19.574 & 69,000 \\
\hline 19.574 & 20.310 & 49,000 \\
\hline 20.310 & 20.530 & 60,500 \\
\hline
\end{tabular}

The test corridor in Daytona Beach consisted of a seven-mile segment of US 1 (Ridgewood Ave). In this corridor, the predominant geometric feature of bus stops was the presence of curbside parking that was used by buses to get out of the traffic stream to facilitate the boarding and alighting of passengers. These bus stops required a merging maneuver for the bus to resume travel in the traffic stream. The segment has a posted speed of 40-45 miles per hour. Additional details are provided in Figure 13. Traffic information by milepost is provided in Table 4. 


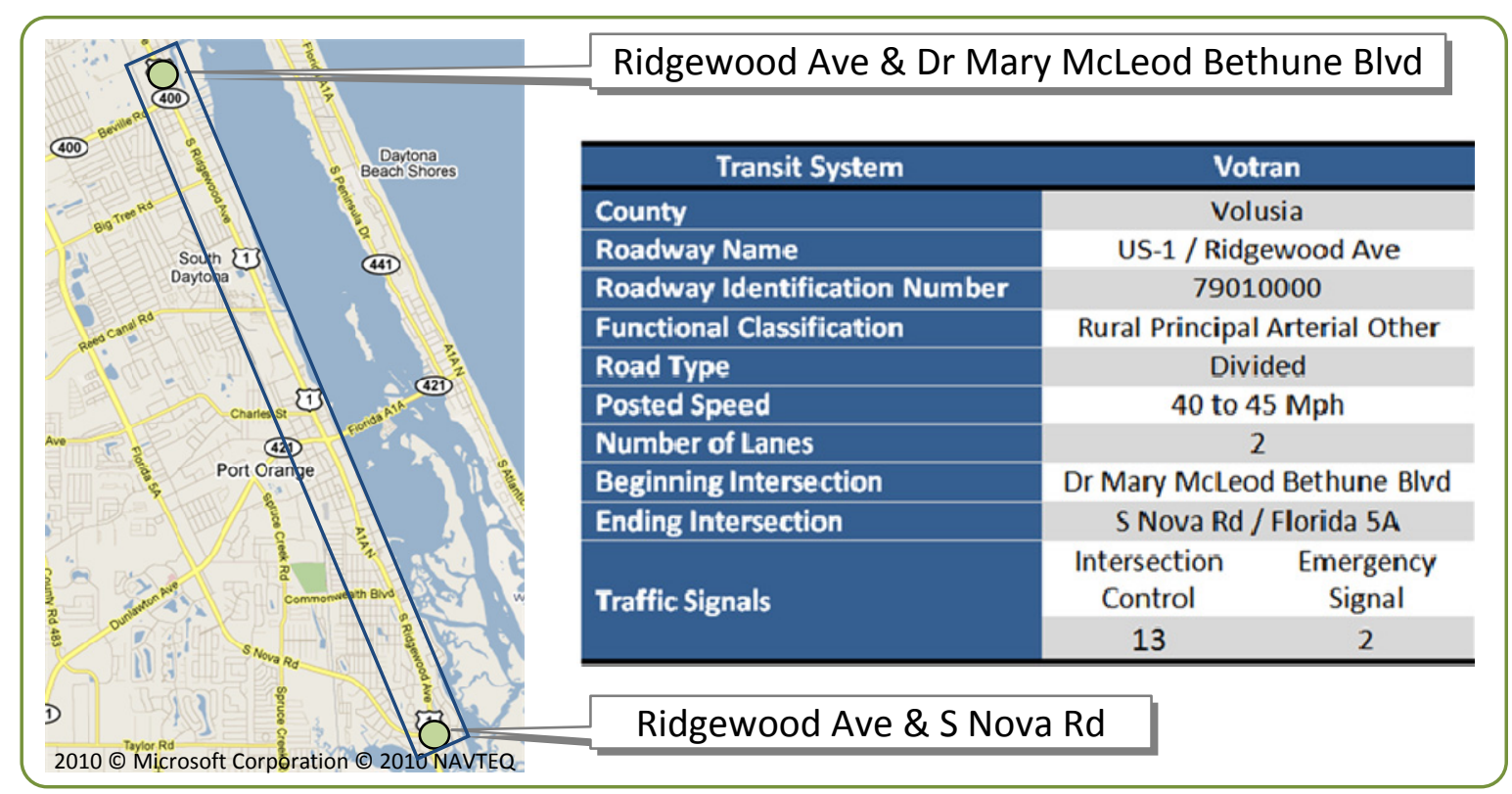

Figure 13: Characteristics of test corridor in Daytona Beach.

Table 4: AADT by milepost on test corridor in Daytona Beach.

\begin{tabular}{|ccc|}
\hline $\begin{array}{c}\text { Beginning } \\
\text { Milepost }\end{array}$ & $\begin{array}{c}\text { Ending } \\
\text { Milepost }\end{array}$ & AADT \\
\hline 32.696 & 32.593 & 32,000 \\
\hline 32.593 & 32.394 & 32,000 \\
\hline 32.394 & 31.669 & 32,500 \\
\hline 31.669 & 30.623 & 33,500 \\
\hline 30.623 & 30.357 & 33,000 \\
\hline 30.357 & 29.908 & 31,500 \\
\hline 29.908 & 29.402 & 33,000 \\
\hline 29.402 & 27.56 & 29,500 \\
\hline 27.56 & 26.867 & 23,500 \\
\hline 26.867 & 24.946 & 20,500 \\
\hline 24.946 & 24.954 & 23,500 \\
\hline
\end{tabular}

\subsection{Yield-to-Bus Behavior Examples}

This section presents several screenshots at the data collection sites. Figure 14 presents a screenshot from the rear-view camera of a vehicle yielding to a bus entering the travel lane from a bus bay. Figure 15 shows two examples of vehicles yielding to a bus leaving a stop on a right turn lane. Figure 16 presents two examples of motorists yielding to a bus coming from curbside parking. 


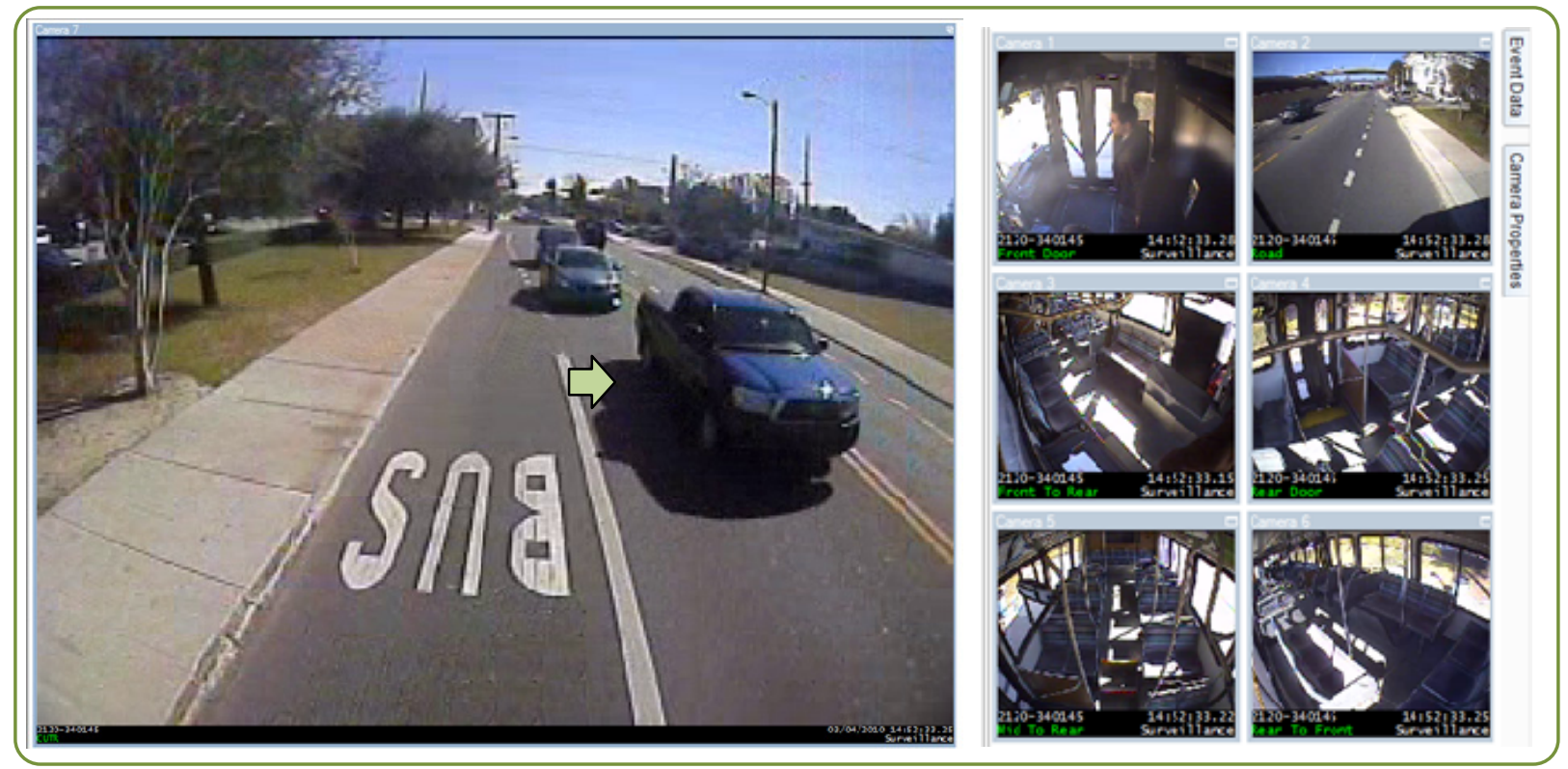

Figure 14: Screenshot of vehicle yielding to bus on test corridor in Tampa.

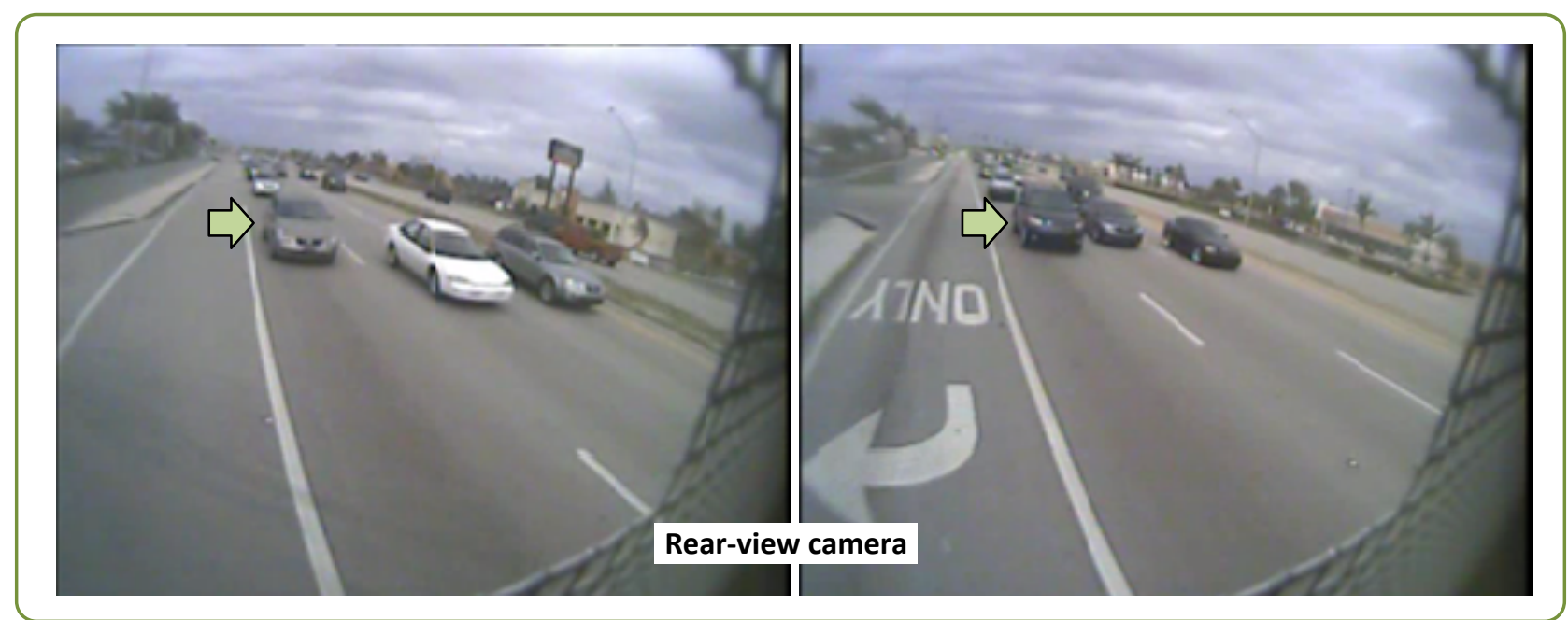

Figure 15: Screenshot of vehicle yielding to bus on test corridor in Fort Myers. 


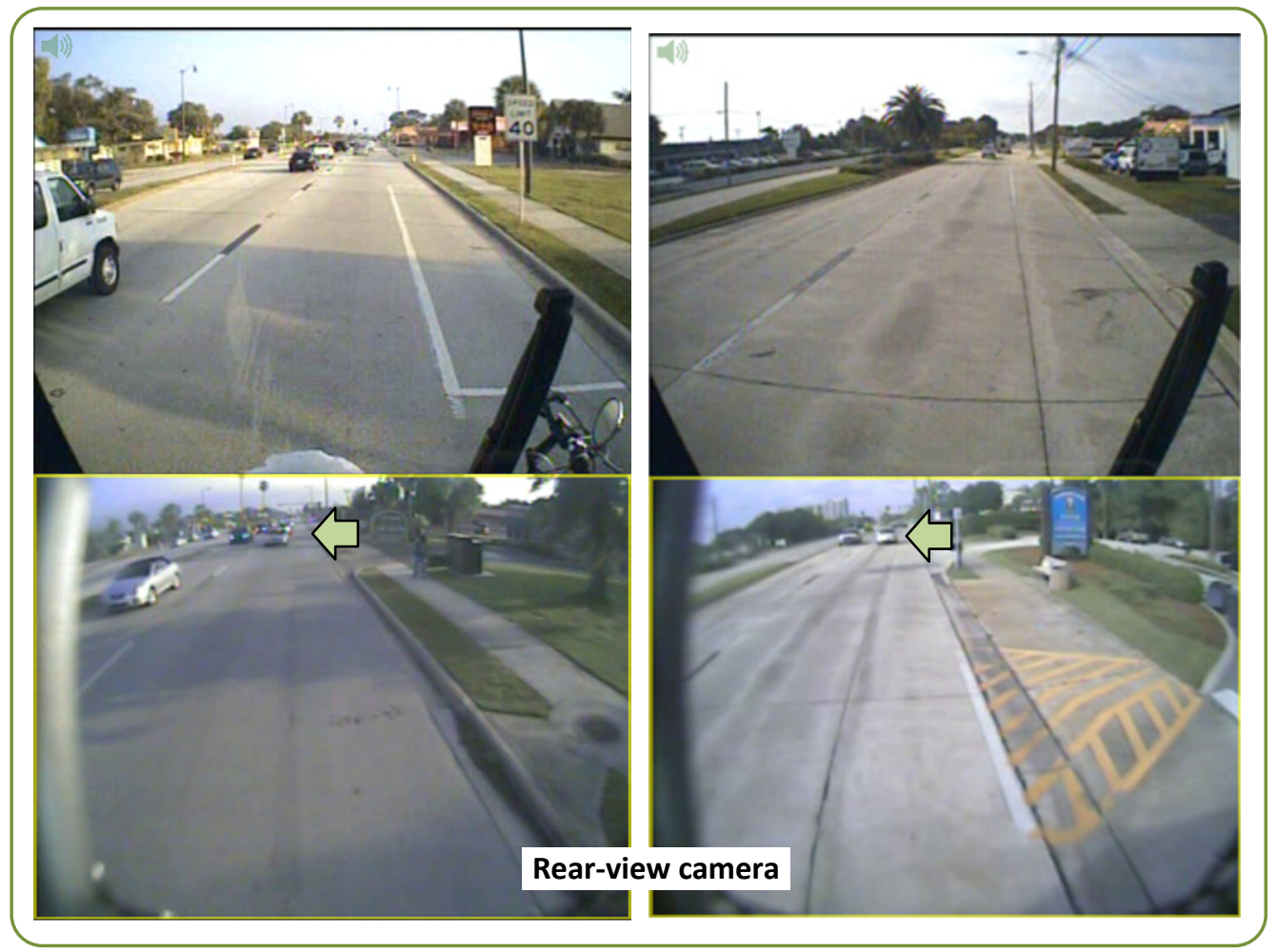

Figure 16: Screenshot of vehicle yielding to bus on test corridor in Daytona Beach. 


\section{RESULTS}

This section presents the results of the data collection performed in Tampa with HART, in Fort Myers with LeeTran, and in Daytona Beach with Votran. The collected data were aimed to obtain quantitative evidence for the assessment of the operational and safety effects of the use of YTB-LED lights on the back of buses.

\subsection{Observed Behavior at Bus Stops in Tampa}

Field observations in Tampa (HART) were made primarily at bus bays on the test corridor. Other locations also were observed and are presented as additional information. The analytical tests were performed using test corridor data only to ensure statistical validity. A total of 138 merging maneuvers were observed, 54 with traffic present. Two buses were equipped with one of the test YTB-LED signs each. At the time of the field observations, the bus with the triangular YTB-LED sign was out of service due to major maintenance work; thus, only data with the merging signs were obtained for the test corridor.

At each bus stop on the test corridor, the merging maneuver was analyzed and classified as yield, no-yield, or lane-change. The summary of the test runs at different bus stops in Tampa is presented in Figure 17. Only a few observations could be performed with the triangular yield sign and are presented for informational purposes. Figure 17 presents a general result for all the test runs performed with HART (including runs not on the test corridor).

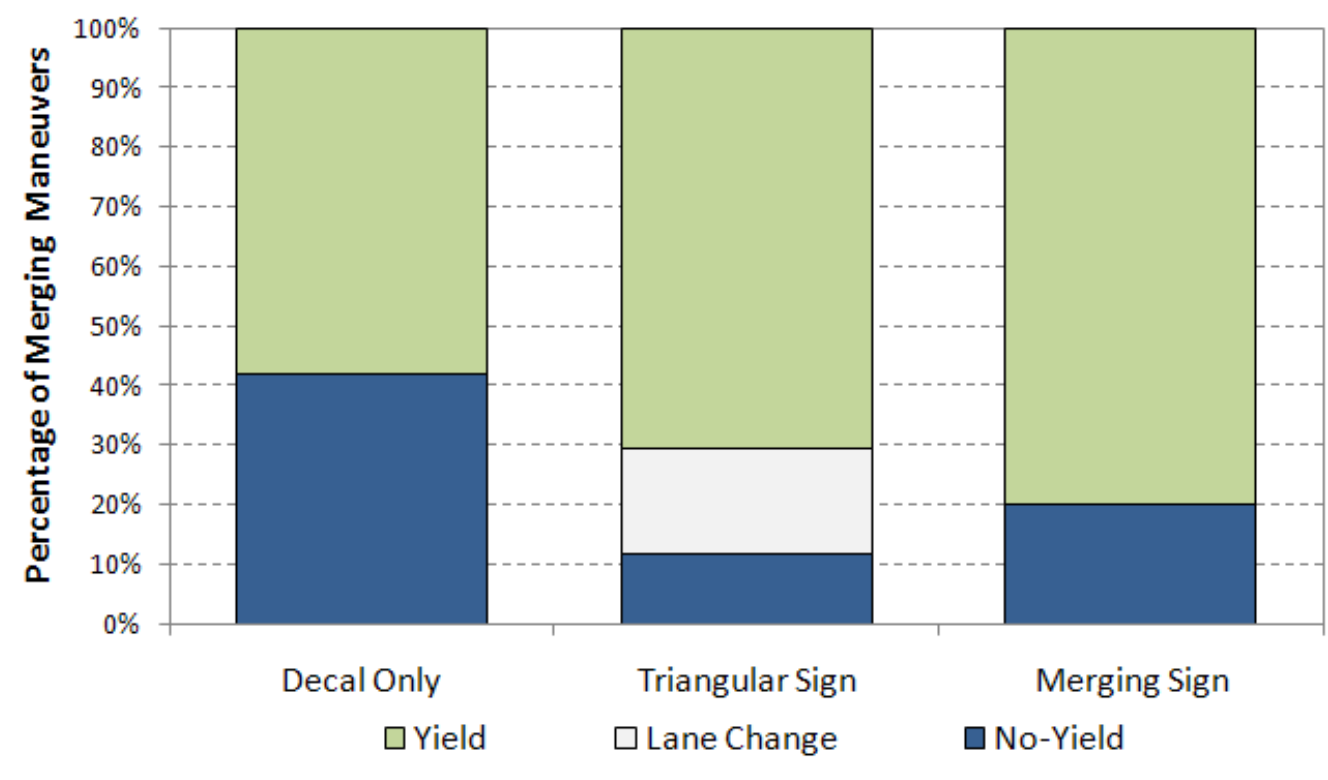

Sign Type

Figure 17: Summary of observed yield-to-bus behavior at test bus stops in Tampa.

In Figure 17, it can be observed that the proportion of maneuvers that ended in a non-yield behavior (darker portion of the bars) tended to be greater for the decal-only test runs. The triangular YTB-LED sign was used on only a few test runs; however, it showed a considerable increase in the yielding behavior of motorists. 
For analysis of significance, data from the test corridor were analyzed separately from the overall observations. This helped to isolate the effect of a particular YTB treatment. A mean test for proportions and a chi-square test were performed on the data. The test corridor data are summarized in Figure 18.

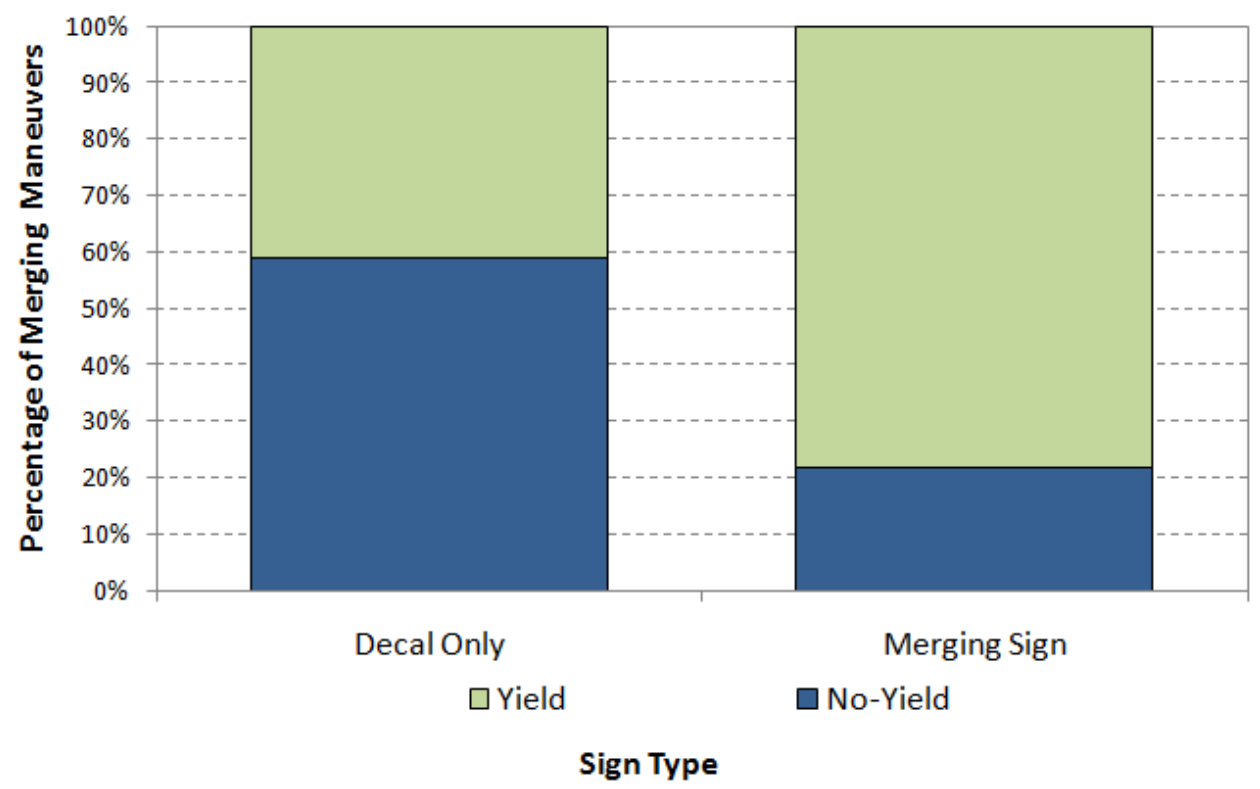

Figure 18: Observed yield-to-bus behavior on test corridor in Tampa.

For the test corridor, the proportion of merging maneuvers ending in a yield while using the decal was 41 percent and while using the merging sign was 78 percent. The analysis of the observations on the test corridor in Tampa is presented in Table 5.

Table 5: Analysis of yield-to-bus behavior on test corridor in Tampa.

\begin{tabular}{ll}
\hline Performance Measure & \multicolumn{1}{c}{ Proportion of merging maneuvers that ended in yield (P) } \\
\hline Hypothesis & $\begin{array}{l}\text { The use of an LED merging sign has no effect on the yielding behavior of } \\
\text { motorists compared to the current YTB Decal on the test corridor. }\end{array}$ \\
\hline P (Decal) & $41 \%$ \\
\hline P(LED-Merging) & $\begin{array}{l}78 \% \\
\text { Result }\end{array}$ \\
& $\begin{array}{l}\text { The use of an LED merging sign had a significant effect on yield-to-bus } \\
\text { behavior ( } p \text {-value=0.007). Moreover, P(Decal) is less than P(LED-Merging), } \\
\text { with a p-value of } 0.003 .\end{array}$ \\
\hline
\end{tabular}

The 95-percent upper confidence interval difference between $\mathrm{P}$ (Decal) and P(LED-Merging) indicated that the increase in the proportion of maneuvers ending in a yield will be at least 14 units or more (34\%) when using the merging sign as compared with the YTB decal on the test corridor.

Based on the test corridor data, there is statistical evidence to assume that the proportion of maneuvers ending in yield increases with the use of the merging sign ( $p$-value $=0.00355)$. 
Similarly, a chi-square test of the proportion resulted in significant differences between the tested YTB treatments with a p-value of 0.004 .

\subsubsection{Traffic conflicts}

Traffic conflicts were analyzed from the video-based data. Merging from a bus bay is a conflictprone maneuver, especially for buses. Since the bus is restricted by the bay, it cannot gain speed to merge back into traffic quickly. This will lead to primary conflicts such as Car and Merging Bus and Car and Accelerating Bus, as observed in Figure 19. Traffic conflict definitions can be consulted in Section 4.

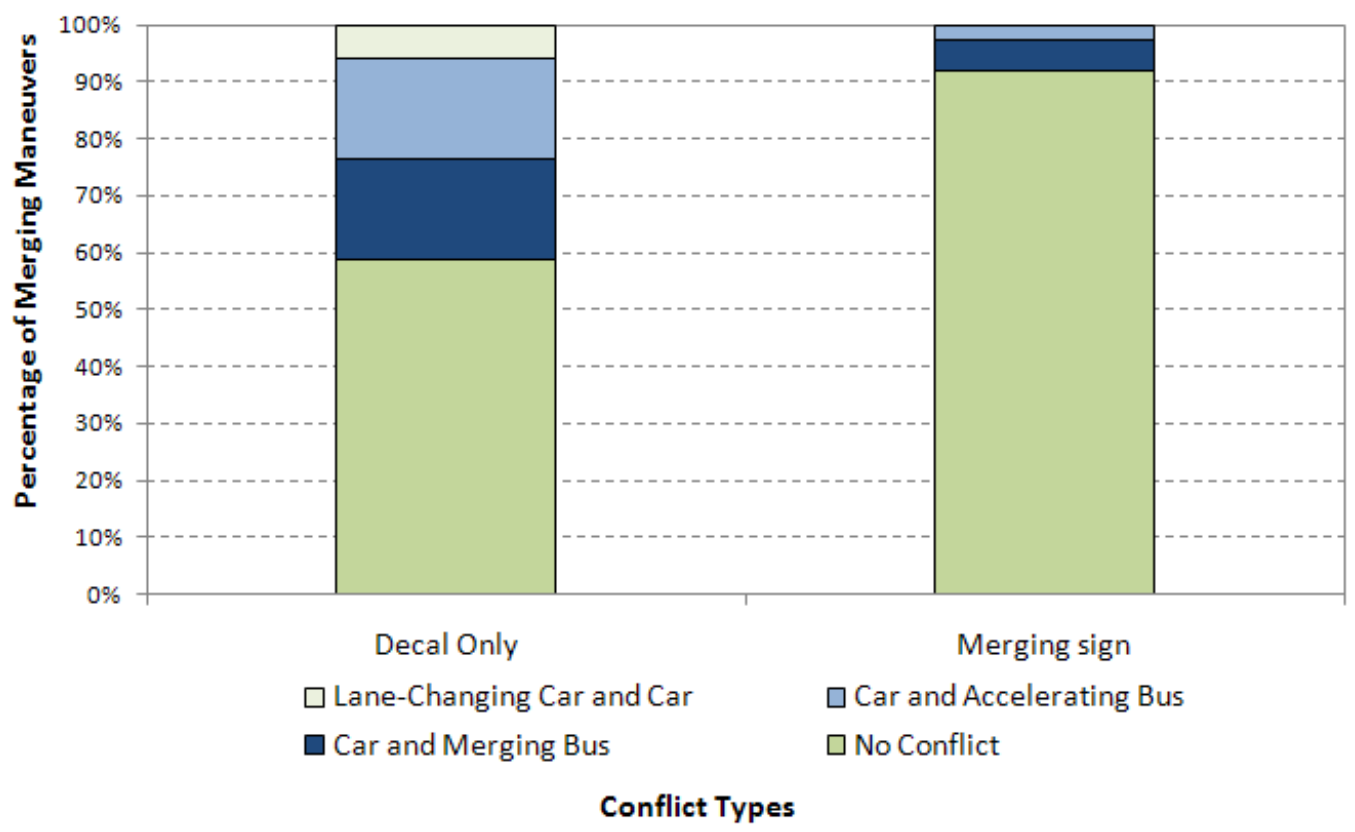

Figure 19: Observed conflicts on test corridor in Tampa.

Figure 19 presents the counts of observed conflicts for the test runs performed with HART in Tampa. Not many secondary conflicts were observed (Car-Car). This may be explained, in part, because the test corridor was a low-speed, urban, undivided road that had little room for sudden lane changes that lead to secondary Car-Car conflicts. The posted speed also makes the breaking distance generally shorter and helps to avoid rear-end-type conflicts.

Each maneuver was assigned the most clearly-defined conflict such that the proportion of maneuvers that ended in a conflict could be analyzed as a performance measure. The results of the analysis are presented in Table 6. 
Table 6: Analysis of traffic conflicts on test corridor in Tampa.

\begin{tabular}{ll}
\hline Performance Measure & \multicolumn{1}{c}{ Proportion of merging maneuvers involving traffic conflicts (C) } \\
\hline Hypothesis & $\begin{array}{l}\text { The use of an LED merging sign has no effect on the number of traffic } \\
\text { conflicts in merging maneuvers. }\end{array}$ \\
\hline C (Decal) & $\begin{array}{l}4 \% \\
\text { C(LED-Merging) }\end{array}$ \\
\hline & $\begin{array}{l}\text { The use of an LED merging sign had a significant effect on the number of } \\
\text { merging maneuvers involving traffic conflicts ( } p \text {-value }=0.003) . \text { Moreover, } \\
\text { Result }\end{array}$ \\
\hline
\end{tabular}

The mean reduction in the proportion of maneuvers involving conflicts was 33 units (80 percent). Further statistical tests indicated that the proportion of maneuvers involving traffic conflicts using the YTB decal is at least 12 units or more greater than that of the merging sign. This translates to a 29 percent decrease or more in the number of conflicts on the test corridor in Tampa.

\subsubsection{Re-entry time}

Re-entry time was calculated for the test corridor in Tampa. The results of the re-entry time are summarized graphically in the box plot in Figure 20. It can be observed that the use of the merging sign decreases the mean of the re-entry time on the test corridor. Another important effect that can be observed is that the variance potentially can be reduced. The analysis of reentry time for the test corridor in Tampa is presented in Table 7.

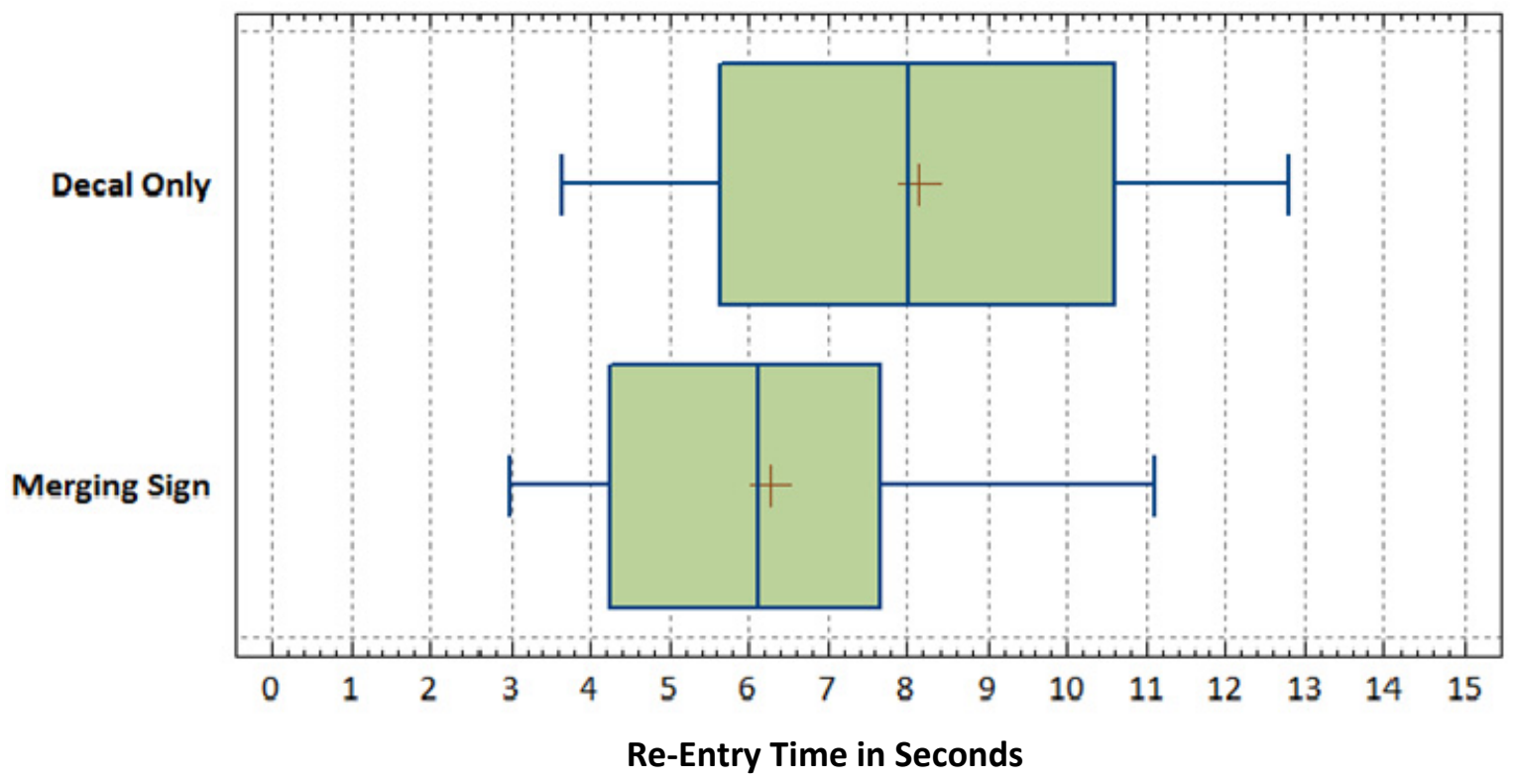

Figure 20: Boxplot for re-entry time on test corridor in Tampa. 
Table 7: Analysis of re-entry time on test corridor in Tampa.

Performance Measure

Hypothesis

R(Decal)

R(LED-Merging)

Result
Re-entry time in seconds ( $R$ )

The use of an LED merging sign has no effect on the re-entry time of buses.

8.15

6.28

The use of an LED merging sign had a significant effect on the re-entry time of buses ( $p$-value $=0.024)$. Moreover, $R($ Decal) is greater than R(LEDMerging), with a $p$-value of 0.012 .

The 95-percent confidence interval for the mean difference in re-entry times for the two YTB treatments ranges from 0.26 to 3.49 seconds. The expected mean reduction in re-entry time was 1.87 seconds (23 percent). Further statistical tests indicated that the use of the YTB-LED sign is expected to reduce the re-entry time by at least 1.077 seconds or more. Although the magnitude of the reduction may seem negligible, a 1.077 reduction compared to the original mean of 8.67 gives a reduction of 13 percent. In more congested urban corridors, greater reentry time efficiencies potentially can be obtained.

\subsection{Observed Behavior at Bus Stops in Fort Myers}

The field observations in Fort Myers (LeeTran) were made mainly on right turn lanes. One of LeeTran's existing buses equipped with a triangular yield sign was used for data collection. Both YTB-LED signs were successfully equipped and tested on a segment of US 41. A total of 235 merging maneuvers was observed, with 154 performed in the presence of surrounding traffic. The results of the field data collection are presented in the following sections.

\subsubsection{Yield-to-bus behavior}

A summarized view of the observed field data in Fort Myers is presented in Figure 21. It can be observed that the number of lane changes is very similar across the different yield-to-bus treatment scenarios. It also can be observed that the no-yield behavior is reduced with the use of YTB-LED signs.

By inspecting the proportion of merging maneuvers that ended in a no-yield action in Figure 21 (dark blue portion of the bar), it can be observed that they tend to decrease with the use of YTB-LED signs. It also can be observed that a safe lane change in the proximity of a bus entering traffic is a common behavior on the test corridor in Fort Myers. 


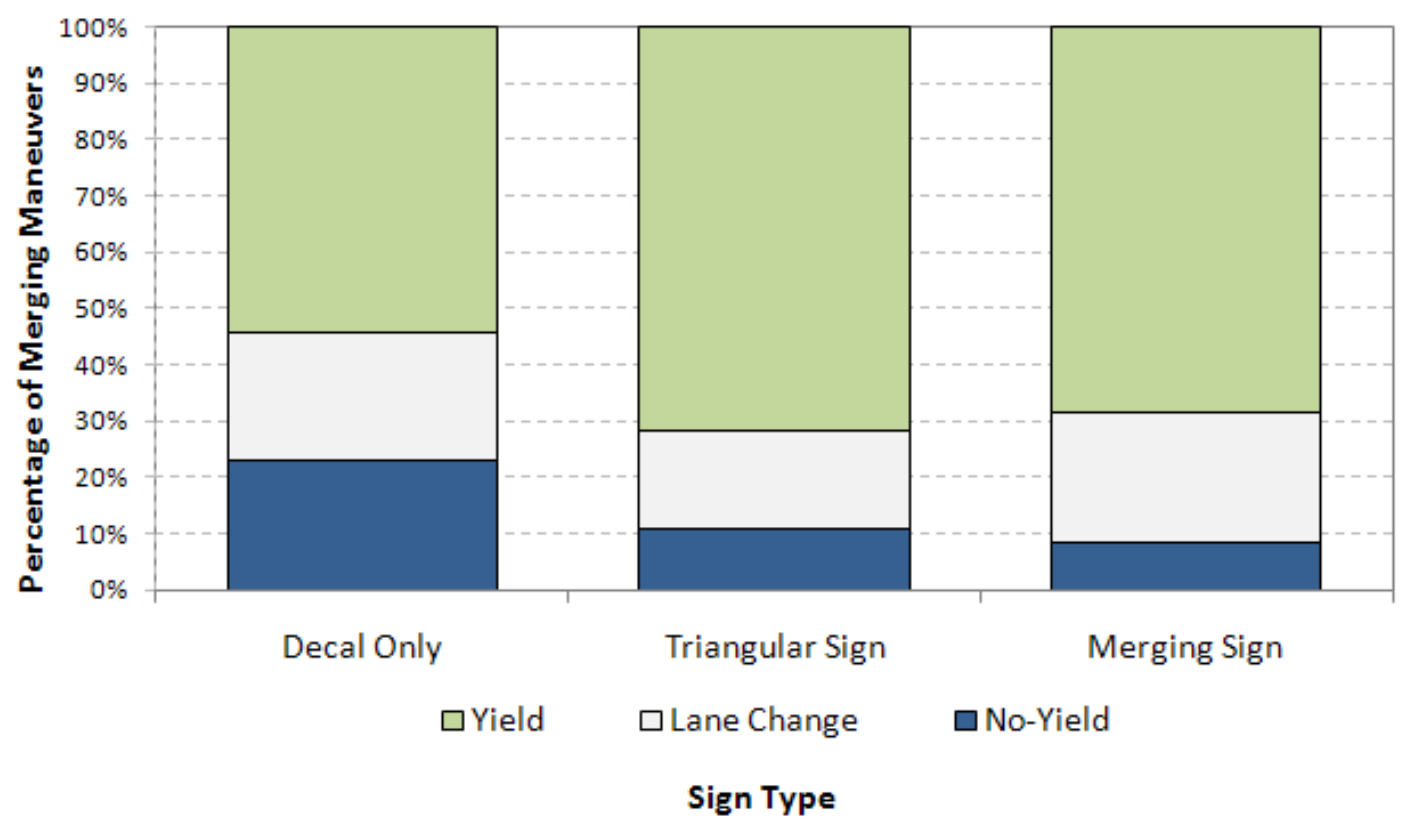

Figure 21: Summary of observed yield-to-bus behavior on test corridor in Fort Myers.

For data analysis of yield-to-bus behavior in Fort Myers, the lane change action was added to the yield action since both help the bus to merge back into traffic. First, a decal vs. LED yield-tobus treatment was performed. The results of this analysis are presented in Table 8.

Table 8: Analysis of yield-to-bus behavior on test corridor in Fort Myers.

\begin{tabular}{l|l}
\hline Performance Measure & \multicolumn{1}{c}{ Proportion of merging maneuvers that ended in yield (P) } \\
\hline Hypothesis & $\begin{array}{l}\text { The use of a YTB-LED sign has no effect on the yielding behavior of } \\
\text { motorists compared to the current YTB decal on the test corridor. }\end{array}$ \\
\hline P (Decal) & $\begin{array}{l}70 \% \\
\text { P(LED-Signs) }\end{array}$ \\
$\begin{array}{l}\text { Result } \\
\text { The use of an LED merging sign had a significant effect on the yield-to-bus } \\
\text { behavior ( } p \text {-value }=0.017) . \text { Moreover, } P(\text { Decal) is less than P(LED-Merging), } \\
\text { with a } p \text {-value of } 0.008 .\end{array}$ \\
\hline
\end{tabular}

The 95-percent upper confidence interval showed that the increase in the proportion of maneuvers ending in a yield will be at least 4.1 units or more when using the merging sign, as compared with the YTB decal on the test corridor. The mean increase in the yield-to-bus behavior was 17.8 units (20 percent increase).

To test whether the different YTB treatments had no effect on the yield-to-bus behavior, a contingency table analysis was performed on the data. The contingency table analysis at a 0.05 significance level resulted in a non-significant effect of the YTB-LED signs with respect to yieldto-bus behavior ( $p$-value=0.07). However, at a confidence level of 0.1 , the test is significant. The Marascuillo test for multiple-proportion comparisons (11) that was applied to the data provided 
that the contingency analysis was significant at a 0.1 significance level. The Marascuillo test was not sensitive to the changes in the data at the selected significance level, as can be observed in Table 9.

Table 9: Multiple-proportion comparison test for yield-to-bus behavior in Fort Myers.

\begin{tabular}{ccccccc}
\hline Treatment $\mathbf{i}$ & Treatment $\mathbf{j}$ & Proportion $\mathbf{i}$ & Proportion $\mathbf{j}$ & $\mathbf{P}_{\mathrm{i}}-\mathbf{P}_{\mathrm{j}}$ & $\begin{array}{c}\text { Test } \\
\text { Statistic }\end{array}$ & $\begin{array}{c}\text { Significant } \\
\text { Difference }\end{array}$ \\
\hline Decal only & Triangular sign & $77 \%$ & $89 \%$ & 12 & 18.61 & No \\
\hline Decal only & Merging sign & $77 \%$ & $92 \%$ & 14.5 & 17.22 & No \\
\hline Triangular sign & Merging sign & $89 \%$ & $92 \%$ & 2.5 & 14.22 & No \\
\hline
\end{tabular}

Another way to compare multiple proportions is through an Analysis of Means (ANOM) procedure (12). At a 0.1 significance level, the upper decision limit for the ANOM test is 94 percent and the lower decision limit is 78 percent. Any proportion value outside this range can be considered significantly different from the overall mean. The result of the application of the ANOM procedure is presented graphically in Figure 22. It can be observed that the proportions of maneuvers ending in yield or lane changes for the decal-only treatment fall out of the decision limits. Since the triangular signs and the merging signs are within the decision limits, it can be assumed that there are no significant differences between these two YTB treatments.

\section{Comparison of treatments using ANOM with 90-percent decision limits}

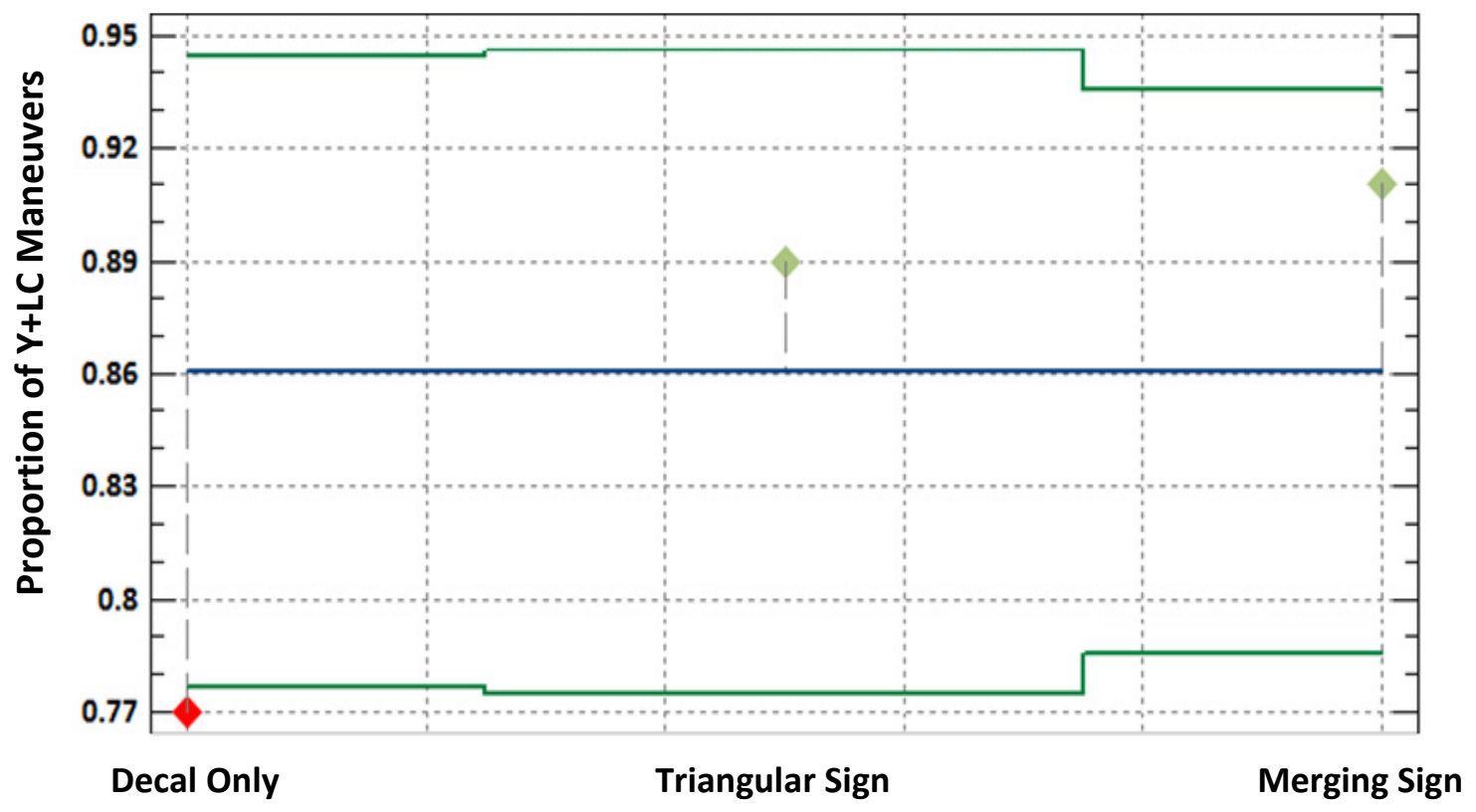

Figure 22: Comparison of YTB treatments in yield-to-bus behavior in Fort Myers. 


\subsubsection{Traffic conflicts}

Traffic conflict counts were obtained from the video-based data collection using several on-bus cameras. In spite of the frequent lane-changing behavior observed in the corridor, little or no related conflicts were observed during the data collection period. The conflict counts for the test corridor in Fort Myers are presented Figure 23.

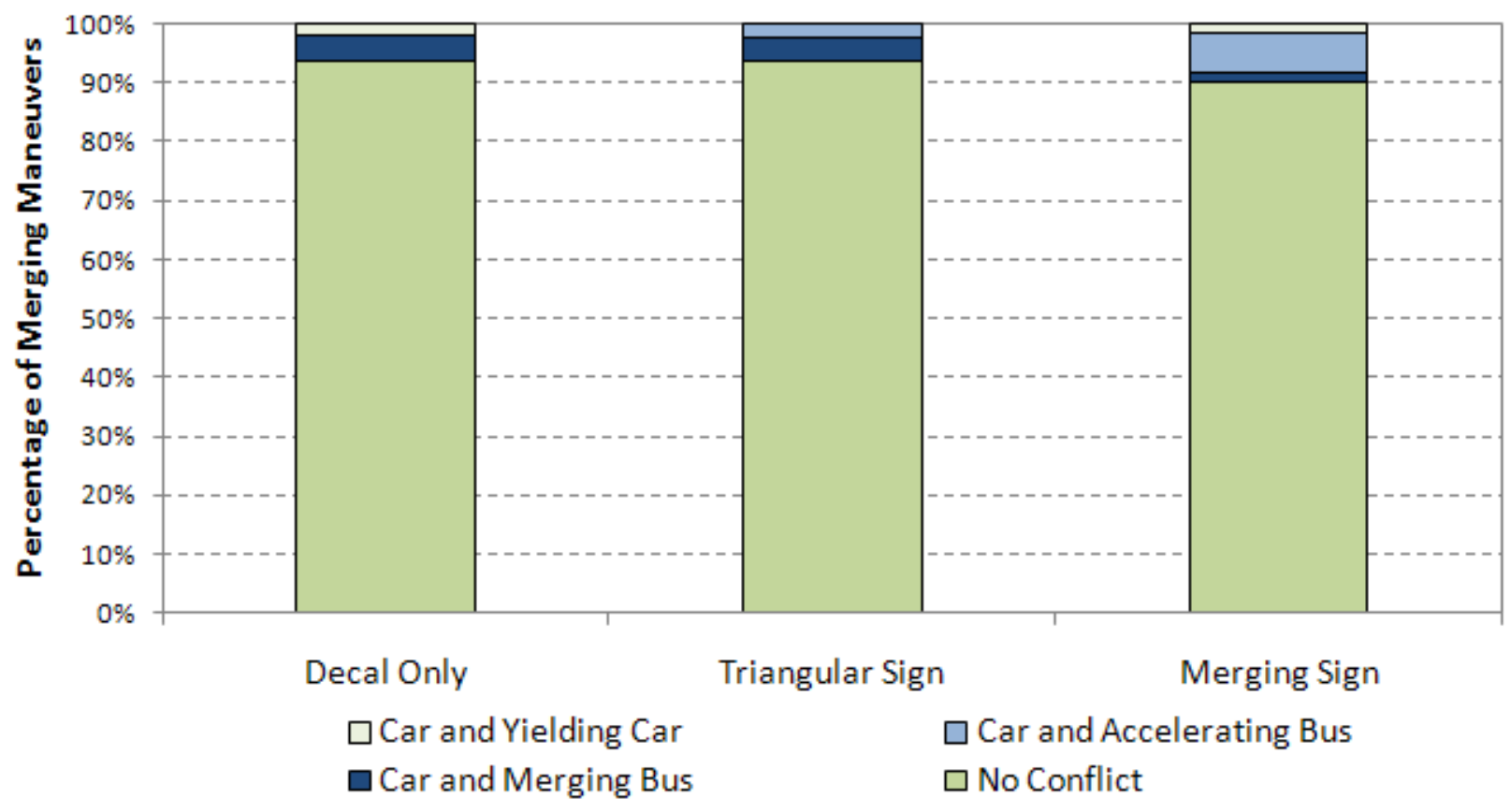

\section{Conflict Types}

Figure 23: Observed traffic conflicts on test corridor in Fort Myers.

Since the test corridor's posted speed limit is $45 \mathrm{mph}$, there are more chances for Car and Accelerating Bus conflicts and Car and Yielding Car conflicts. Car and Merging Bus conflicts are expected to decrease in right turn lanes as compared to bus bays due to the opportunity of the bus to gain more speed before merging back into traffic.

Car and Accelerating Bus conflicts occur when the bus is gaining speed after merging back into traffic and a motorist approaches the bus at a relatively high speed. These conflicts can be alleviated from both the motorist's and bus operator's perspectives. From the motorist's perspective, an education campaigns can help to improve the yield-to-bus behavior. From the bus operator's perspective, the use of the YTB-LED sign may give a false sense of confidence, leading to conflicting maneuvers. Periodic reminders on the correct use of YTB-LED signs can help to alleviate this issue.

Car and Yielding Car conflicts occur when a motorist yields the right-of-way to a bus and the following car may be unaware of the situation, causing a sudden stop. These conflicts can be alleviated by introducing the YTB-LED flashing signs to the public through an adequate 
awareness campaign. These conflicts also may be avoided by locating the yield sign on the upper half of the back of the bus where it is visible two vehicles behind. Improving the YTB behavior in a particular corridor implies using different strategies such as education, YTB treatments, and enforcement.

The results of the analysis of traffic conflicts on the test corridor in Fort Myers are presented in Table 10. The total number of conflicts was aggregated for both YTB-LED signs and compared to the decal-only treatment.

Table 10: Analysis of traffic conflicts on test corridor in Fort Myers.

\begin{tabular}{ll}
\hline Performance Measure & \multicolumn{1}{c}{ Proportion of merging maneuvers involving traffic conflicts (C) } \\
\hline Hypothesis & $\begin{array}{l}\text { The use of an LED merging sign has no effect on the number of traffic } \\
\text { conflicts in merging maneuvers. }\end{array}$ \\
\hline C (Decal) & $\begin{array}{l}8.4 \% \\
\text { C(LED) }\end{array}$ \\
& $\begin{array}{l}\text { There is no evidence to disprove the hypothesis; therefore, it can be } \\
\text { assumed that impact on traffic safety derived from the use of YTB-LED sign } \\
\text { on buses on the test corridor will be no different than using the decal-only } \\
\text { treatment (p-value=0.64). }\end{array}$ \\
\hline
\end{tabular}

An analysis of means (ANOM) also was performed on the data, leading to the same conclusion for the different treatments. Therefore, the use of YTB-LED flashing signs did not increase the number of conflicts as compared to the decal-only scenario. Based on average proportions, there is an indication that the LED-YTD potentially can improve safety (2.15 percentage points); based on statistical tests, this difference was not significant.

\subsubsection{Re-entry time}

Re-entry time also was measured on the test corridor in Fort Myers. The minimum observed reentry time was 6.1 seconds and the maximum was 46.35 seconds for all YTB treatments. A graphical summary of the re-entry time is presented in Figure 24. It can be observed that the re-entry times have very similar average values. The decal-only buses experienced more aboveaverage re-entry times as compared to the YTB-LED treatments. This indicates that YTB-LED signs can help the bus to signal to re-enter the travel lane under heavy traffic situations during peak periods (e.g., long traffic lines). An analysis of variance (ANOVA) was applied to the reentry time data and is presented in Table 11. 


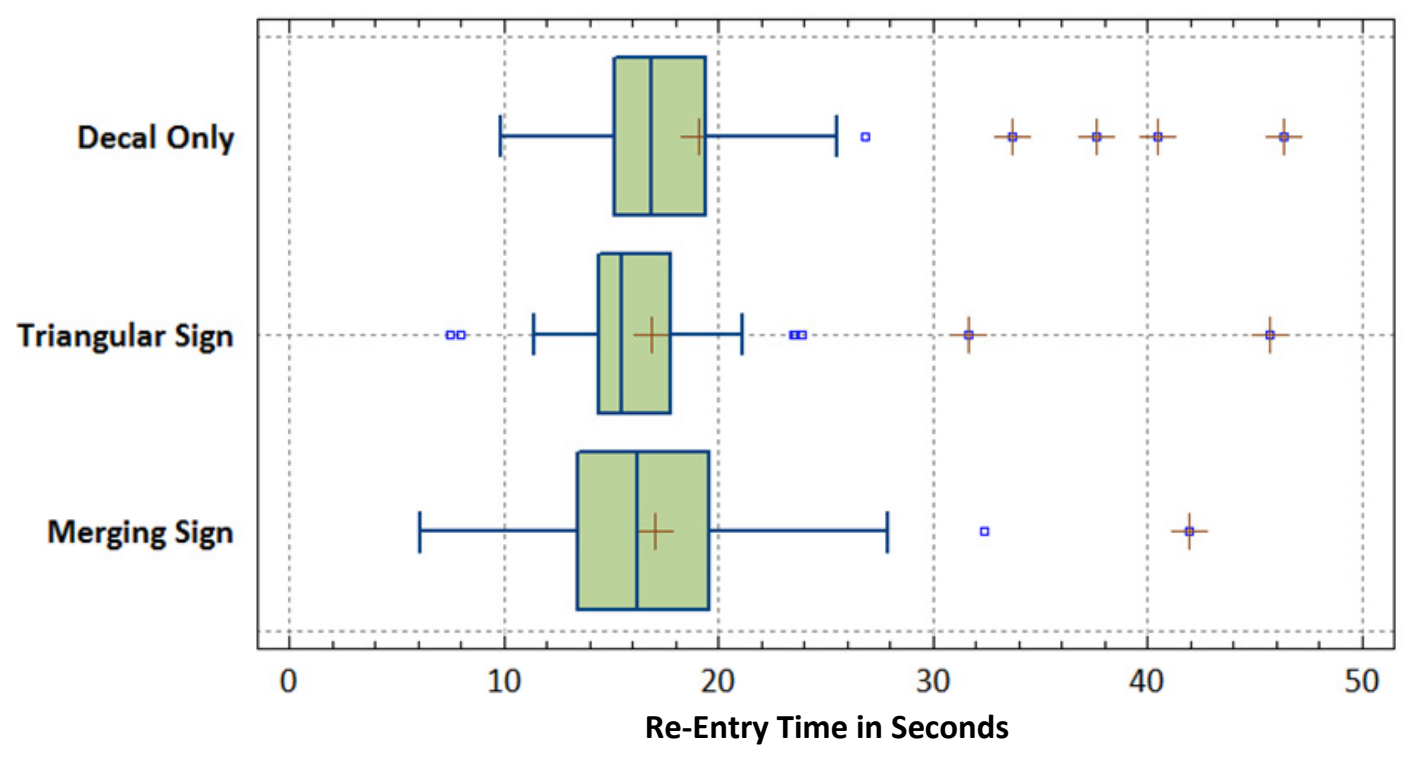

Figure 24: Boxplot for re-entry time on test corridor in Fort Myers.

Table 11: ANOVA table for re-entry on test corridor in Fort Myers.

\begin{tabular}{|cccccc}
\hline Source & SS & DF & MS & F-Ratio & P-value \\
\hline Between groups & 144 & 2 & 72.0267 & 1.79 & 0.1702 \\
\hline Within groups & 6069 & 151 & 40.19 & & \\
\hline Total & 6213 & 153 & & & \\
\hline
\end{tabular}

Based on the results of the ANOVA, the use of YTB-LEDs do not cause a statistically significant change in the re-entry time for buses merging back into traffic from a right turn lane. The reentry time average values are presented in Table 12.

Table 12: Analysis of re-entry time on test corridor in Fort Myers.

Performance Measure

Hypothesis

R(Decal only)

R(Triangular sign)

R(Merging sig)

Result

\section{Re-entry time in seconds ( $R$ )}

The use of an LED merging sign has no effect on the re-entry time of buses.

19.05

16.89

17.03

The re-entry time with YTB-LED signs is comparable to the decal-only YTB treatment for the test corridor ( $p$-value=0.1702). 


\subsection{Observed Behavior at Bus Stops in Daytona Beach}

The field data collection was performed on a 7.7-mile section of US 1 in Daytona Beach. Both YTB-LED signs were tested against the baseline alternative decal-only. All the observations were taken on the same corridor segment to ensure statistical validity of the data. The results of the data collection for Votran are presented in the following sections.

\subsubsection{Yield-to-bus behavior}

Yield-to-bus behavior was analyzed at each bus stop requiring merging maneuvers on the test corridor. The test corridor in Daytona Beach presented a number of stops located at curbside parking spaces. Buses use the curbside parking space to pull out of traffic to allow safe boarding/alighting of patrons. The results of the observed yield-to-bus behavior are presented in Figure 25.

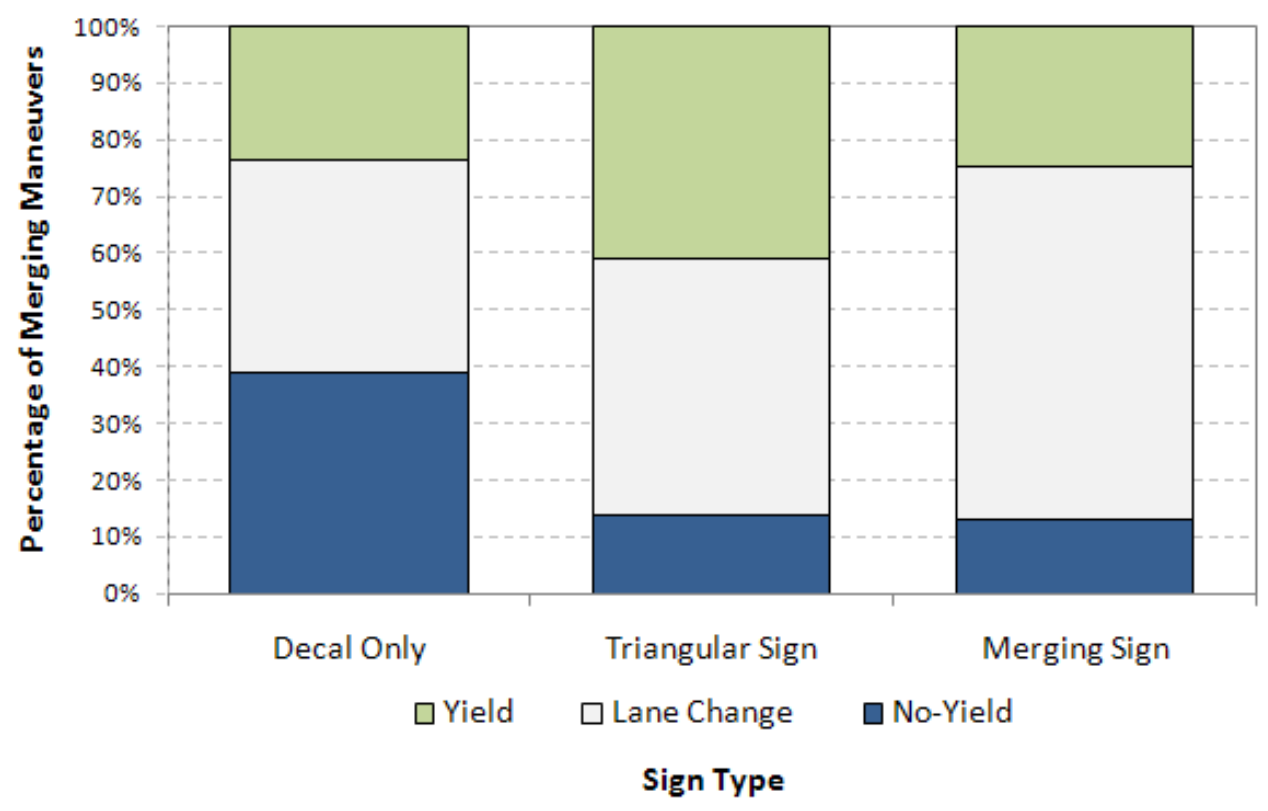

Figure 25: Summary of observed yield-to-bus behavior on test corridor in Daytona Beach.

It can be observed in Figure 25 that a significant proportion of the observed merging maneuvers ended in safe lane changes. When the traffic is low to moderate, it is likely that lane changes can be performed safely by motorists approaching a bus coming from an out-of-traffic bus stop. In addition, the use of a YTB-LED may increase the visibility of the bus merging back into traffic and, thus, help motorists to either yield or safely change lanes well in advance. This can be observed by the reduction in the fraction of no-yield maneuvers when using any of the YTB-LED signs and the corresponding increase in lane changes. The use of the triangular yield sign showed a reduction in the no-yield followed by an increase in the fraction of maneuvers ending in yield when compared to the decal-only scenario. When using the merging sign, the fraction of no-yield maneuvers was reduced, but the fraction of maneuvers ending in yield was similar to the decal-only scenario, indicating that there was an increase in lane changes. This may be explained, in part, by the size of the merging sign; motorists may have had more 
opportunities to see the sign in advance and decided to change lanes earlier when compared to the triangular sign. A statistical test of the results obtained for yield-to-bus behavior in Daytona Beach is presented in Table 13.

Table 13: Analysis of yield-to-bus behavior on the test corridor in Daytona Beach.

\begin{tabular}{|l|l|}
\hline Performance Measure & \multicolumn{1}{c|}{ Proportion of merging maneuvers that ended in yield $(P)$} \\
\hline Hypothesis & $\begin{array}{l}\text { The use of an LED merging sign has no effect on the yielding behavior of } \\
\text { motorists compared to the current YTB decal on the test corridor. }\end{array}$ \\
\hline P (Decal) & $57.35 \%$ \\
\hline P(LED) & $85.61 \%$ \\
\hline Result & $\begin{array}{l}\text { The use of an LED merging sign had a significant effect on yield-to-bus } \\
\text { behavior ( } p \text {-value=0.000007). }\end{array}$ \\
\hline
\end{tabular}

The expected increase in the proportion of maneuvers ending in yield was 28 units (49 percent). Additional statistical tests indicated that the difference in proportions is at least 17 units (29 percent) or more. Therefore, the use of YTB-LED signs has a significant impact in the yield-to-bus behavior on the test corridor in Daytona Beach.

A contingency table analysis was performed on the data for the individual treatments. The proportion of maneuvers ending in yield was $\mathbf{5 7 . 3 5}$ for the decal-only, 86.56 for the triangular sign, and 84.72 percent for the merging sign. The test was significant at the 0.05 confidence level ( $p$-value=0.00004).

A multiple-proportion comparison test was performed on the yield-to-bus behavior data (Marascuillo test). The results of the test are presented in Table 14. It can be observed that there are significant differences between the decal-only treatment and both YTD-LED signs. However, the yield-to-bus behavior is equivalent between the YTB-LED signs. The significance level of the test was 0.05 .

Table 14: Multiple-proportion comparison test for yield-to-bus behavior in Daytona Beach.

\begin{tabular}{ccccccc}
\hline Treatment $\mathbf{i}$ & Treatment $\mathbf{j}$ & Proportion $\mathbf{i}$ & Proportion $\mathbf{j}$ & $\mathbf{P}_{\mathrm{i}}-\mathbf{P}_{\mathbf{j}}$ & $\begin{array}{c}\text { Test } \\
\text { Statistic }\end{array}$ & $\begin{array}{c}\text { Significant } \\
\text { Difference }\end{array}$ \\
\hline Decal only & Triangular sign & $57.35 \%$ & $86.56 \%$ & 29.21 & 17.87 & Yes \\
\hline Decal only & Merging sign & $57.35 \%$ & $84.72 \%$ & 27.36 & 17.97 & Yes \\
\hline Triangular sign & Merging sign & $86.56 \%$ & $84.72 \%$ & 1.8 & 14.54 & No \\
\hline
\end{tabular}

The results can be further explored by an ANOM plot. In the ANOM plot, an overall mean is calculated and the values of the proportions that are significantly different from that mean will fall outside the decision limits. Figure 26 presents the ANOM plot for the yield-to-bus behavior. It can be observed that the decal-only treatment is significantly different from the overall mean because it falls outside (downwards) the decision limits. The triangular sign and the merging 
sign also are significantly different from the overall mean but they fall on the opposite side of the decal-only treatment. The YTB-LED signs are both significantly different from the decal-only treatment but similar between each other.

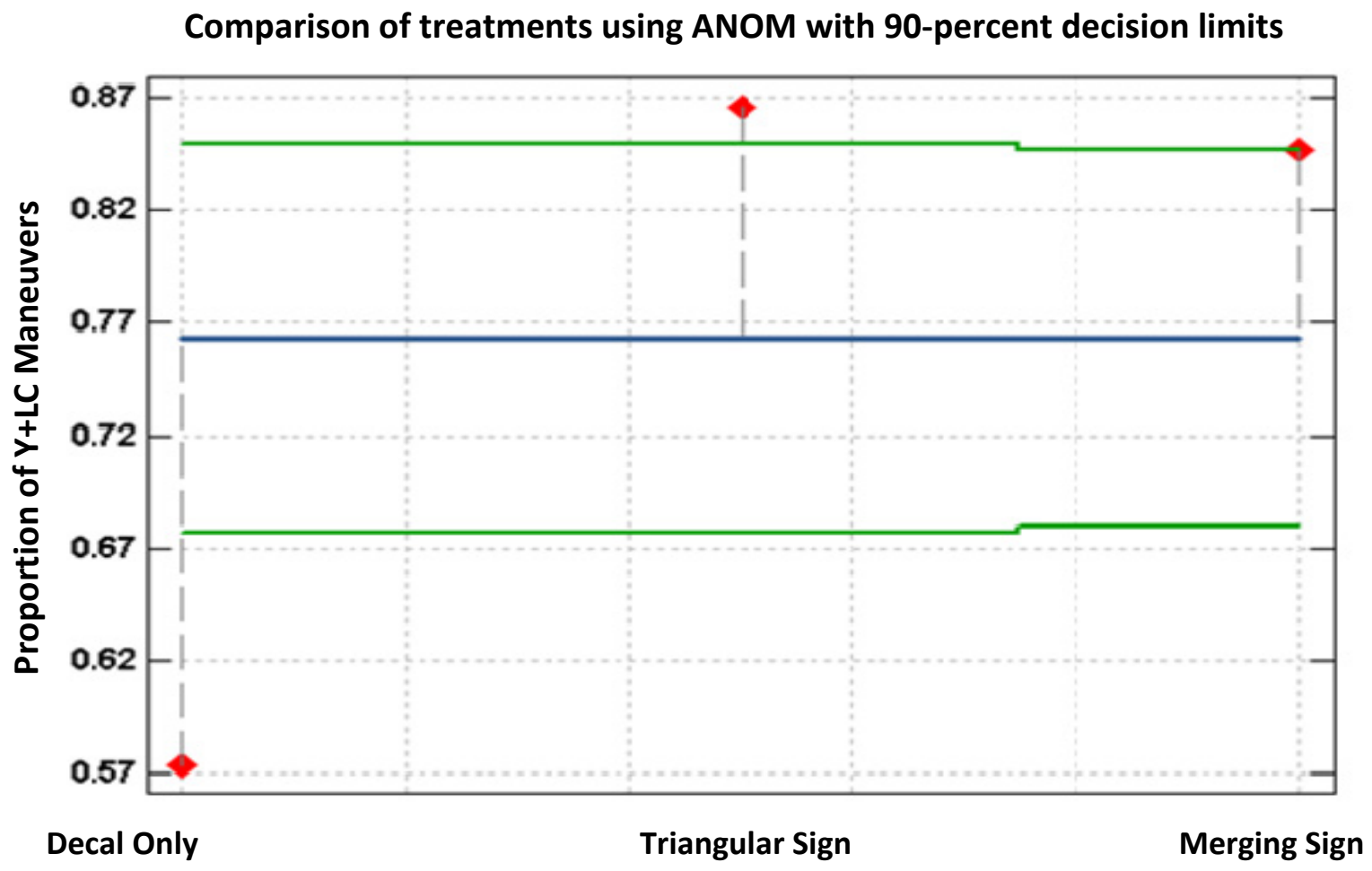

Figure 26: Comparison of YTB treatments in yield-to-bus behavior in Daytona Beach.

\subsubsection{Traffic conflicts}

Traffic conflicts were observed for the collected video data from the Daytona Beach test corridor. Car and Merging Bus was the most frequently observed conflict during the test period. The results of the observed conflicts are presented in Figure 27.

It can be observed that the conflicts are reduced with the use of YTB-LED flashing signs. The most frequently observed conflict was Car and Merging Bus. These conflicts are observed mainly when the bus starts to move to merge back into traffic and there are motorists traveling in the adjacent lane that are not yielding to the bus. This type of conflict also was common for bus bays for the test corridor in Tampa. This can be explained by the type of bus stop and the number of lanes. On the Daytona Beach test corridor, buses must merge back into traffic with reduced room to accelerate. Since there are only two traffic lanes, a considerable number of vehicles may be traveling in the lanes adjacent to the bus stop. With the use of YTB-LED signs, the intention of the bus of to merge back into traffic is communicated to the motorists behind the bus so they can change lanes or yield and thus reduce the chances of conflict. A statistical 
test of the effect of the use of YTB-LED signs on the number of traffic conflicts is presented in Table 15.

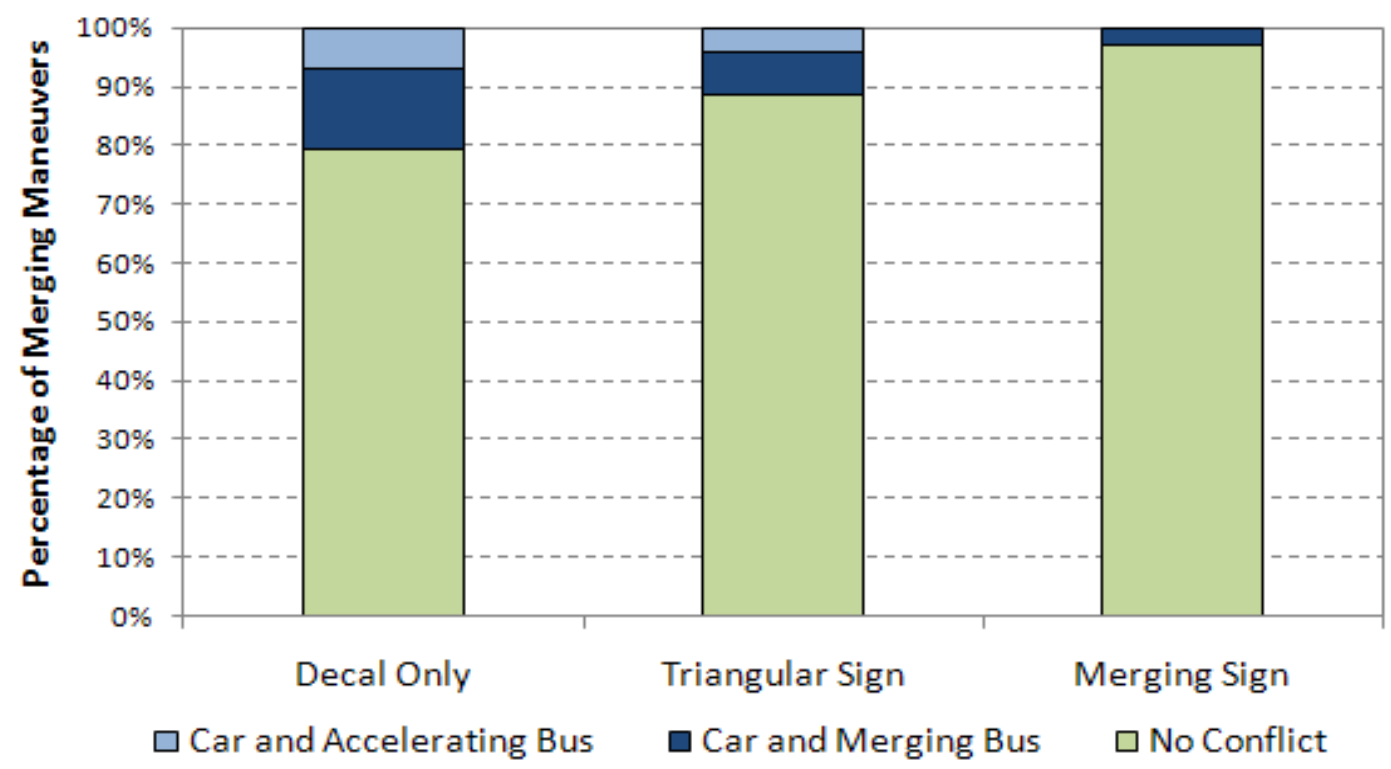

Sign Type

Figure 27: Observed conflicts on test corridor in Daytona Beach.

Table 15: Analysis of traffic conflicts on test corridor in Daytona Beach.

Performance Measure

Hypothesis

C (Decal)

C(LED)

Result

\section{Proportion of merging maneuvers involving traffic conflicts (C)}

The use of an LED merging sign has no effect on the number of traffic conflicts in merging maneuvers.

$20.8 \%$

$7.04 \%$

The test was statistically significant, with a p-value of 0.00299

Table 15 presents a statistical test for the proportion of merging maneuvers involving traffic conflicts. The test indicated that the use of YTB-LED signs has a significant effect in reducing the number of traffic conflicts, with a p-value of 0.002 . The proportion of merging maneuvers involving conflicts was reduced by 13.76 units (66 percent) with respect to the decal only treatment. Further statistical analyses indicated that the reduction on the proportion of maneuvers involving conflicts could be 5.1 units or more (22 percent).

\subsubsection{Re-entry time}

Re-entry time was calculated for the test corridor in Daytona Beach. It was noted that this performance measure depends on different attributes such as bus operator driving behavior, geometry of the bus stop, and traffic. The re-entry time was slightly reduced with the use of YTB-LED signs. A graphical summary of the re-entry time for the test corridor in Daytona Beach is presented in Figure 28. 


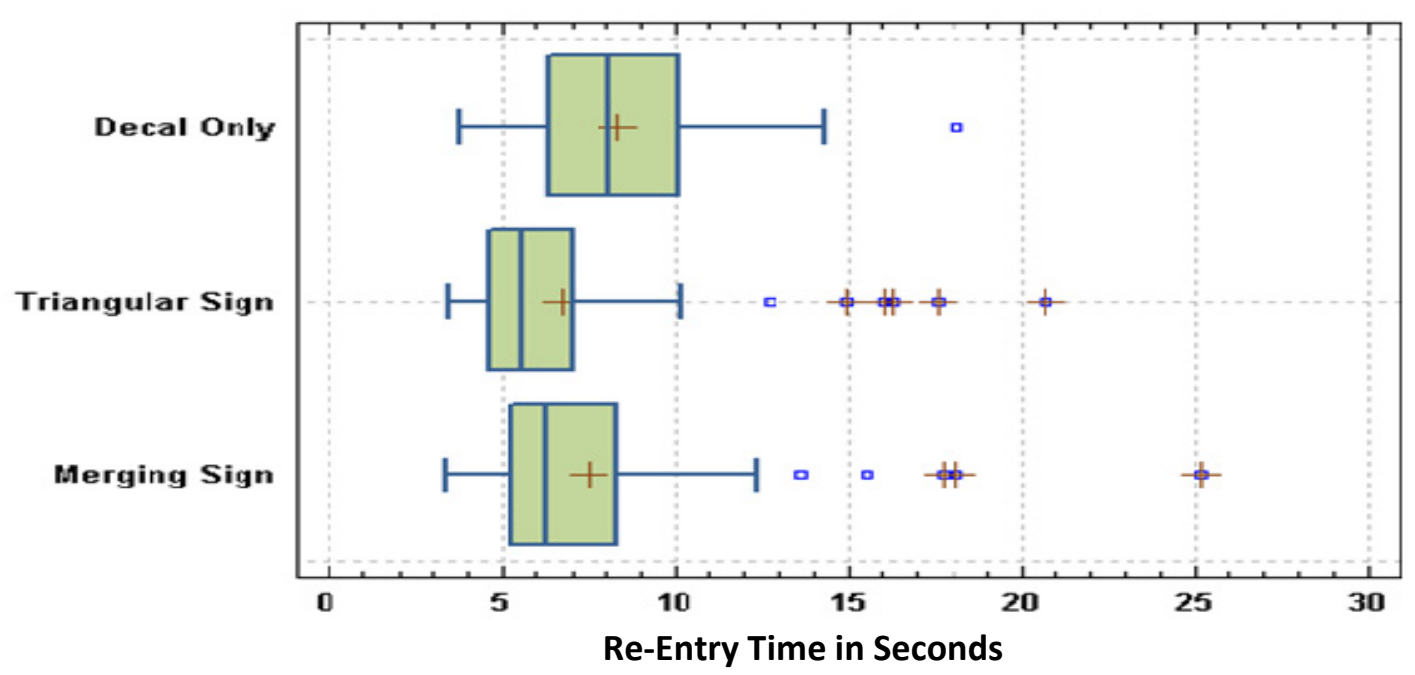

Figure 28: Boxplot for re-entry time on test corridor in Daytona Beach.

Figure 28 presents a boxplot of the re-entry time. It is observed that the mean re-entry time is slightly improved with the use of YTB-LED signs. It also is observed that the spread of the reentry time tends to be reduced with the use of YTB-LED signs. An ANOVA test was performed on the data; the results are presented in Tables 16 and 17. The ANOVA test results were significant at a significance level of 0.05 . The $p$-value of the test was 0.0161 . This implies that there is statistical evidence that the effect of the YTB-LED sign is significant on the re-entry time for buses on the test corridor in Daytona Beach. The mean reductions in re-entry time ranged from 0.9 to 1.62 seconds. These improvements are equivalent to 10 and 19 percent for the merging and the triangular YTB-LED signs respectively.

Table 16: ANOVA table for re-entry on test corridor in Daytona Beach.

\begin{tabular}{|cccccc}
\hline Source & SS & DF & MS & F-Ratio & P-value \\
\hline Between groups & 92.866 & 2 & 46.43 & 4.21 & 0.0161 \\
\hline Within groups & 2326.47 & 211 & 11.02 & & \\
\hline Total & 2419.33 & 213 & & & \\
\hline
\end{tabular}

Table 17: Analysis of re-entry time on test corridor in Daytona Beach.

Performance Measure

Hypothesis

R(Decal only)

$\mathbf{R}$ (Triangular sign)

R(Merging sig)

Result

\section{Re-entry time in seconds ( $R$ )}

The use of an LED merging sign has no effect on the re-entry time of buses.

8.31

6.69

7.45

The re-entry time with YTB-LED signs is significantly different to the reentry time with the decal-only YTB treatment on the test corridor ( $p$ value $=0.0161$ ). 


\section{INTERVIEWS WITH OTHER TRANSIT AGENCIES}

Based on TCRP report 49 (3), transit agencies in California and Oregon had well-established, solid YTB programs by 2003. Santa Clara Valley Transportation Authority (VTA, San Jose, California) and Tri-County Metropolitan Transportation District of Oregon (TriMet, Portland) were interviewed via conference calls to obtain additional details regarding their YTB programs and educational campaigns.

VTA began the implementation of the California YTB law in 2001. The implementation of the law was complemented by the installation of electronic YTB-LED signs. The funds for VTA came from the State of California as part of a special YTB pilot program. VTA launched an aggressive public awareness campaign of the YTB law, which included radio and television advertising.

TriMet has been active consistently regarding YTB initiatives. The Oregon YTB law was introduced in 1997; the installation of yield LED signs began in late 1998. A moderate public education campaign was carried out during the implementation phase of the program; less intensive campaigns have been performed periodically since then as reminders for the general public.

The interviews were complemented by a review of TCRP Synthesis 49, as suggested by both transit agencies, since no major changes have been introduced since the beginning of their YTB programs.

\subsection{Interview Summaries}

This section presents a summary of the main topics discussed during the interviews with the transit agencies. Since much of the information collected for TCRP Synthesis 49 has not changed, some references to that document are presented. At the end of each interview, the transit agencies were asked about the lessons learned from their YTB program experience.

\subsection{Santa Clara Valley Transportation Authority (VTA)}

\subsubsection{YTB public education campaign}

As part of the California YTB law, it was required that participating transit agencies develop and implement a public education program. VTA partnered with the Santa Cruz Metropolitan Transit District (SCMTD) to launch an aggressive YTB public education and awareness campaign, which included radio and television public service ads, television news interviews, news releases in newspapers, posters, handouts, flyers, and signs on buses. The costs associated with the YTB public education and awareness campaign for VTA are presented in Table 18. The public education ad on the back panel of the buses in VTA is shown in Figure 29. 
Table 18: Promotional and educational costs for VTA.

\begin{tabular}{llc|}
\hline \multicolumn{1}{c}{ Component } & \multicolumn{1}{c}{ Activity } & Cost (\$) \\
\hline Radio advertising & $\begin{array}{l}\text { Local and regional stations-estimated total audience of } \\
\text { 6+ million adults age 18 and older. }\end{array}$ & $\$ 100,867$ \\
\hline Print advertising & $\begin{array}{l}\text { State, regional, and local publications with estimated } \\
\text { exposure of almost 12 million. }\end{array}$ & $\$ 70,584$ \\
\hline Transit advertising & $\begin{array}{l}\text { All VTA revenue-generating vehicles-bus and rail- } \\
\text { bus boards, rail cards, posters, etc. }\end{array}$ & $\$ 21,981$ \\
\hline Incentive items & Flashing buttons, highlighters, etc. & $\$ 21,241$ \\
\hline Professional services & Copywriting, translations, etc. & $\$ 11,495$ \\
\hline Yield to Bus flyers & & $\$ 11,249$ \\
\hline Yield to Bus posters & & $\$ 3,795$ \\
\hline News coverage & Local and regional radio, TV, and newspapers & $\$ 0$ \\
\hline VTA website & YTB information posted on Web site & $\$ 0$ \\
\hline Total Cost & & $\$ 240,212$ \\
\hline
\end{tabular}

Source: TCRP Synthesis 49 (3).

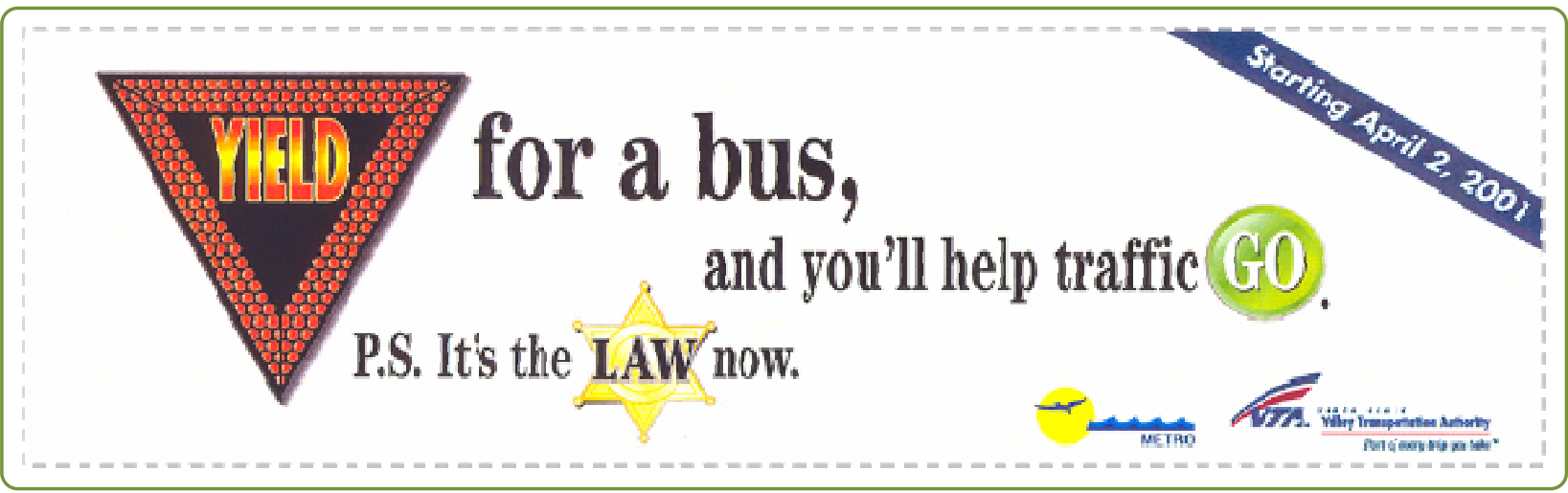

Source: TCRP Synthesis 49 (3).

Figure 29: Public education ad on back panel of VTA buses.

\subsubsection{Bus operator training}

Bus operators were trained on the proper use of the yield LED sign. Also, VTA operators were given laminated cards with the YTB law and instructions on how to use the yield LED sign. In addition, VTA disseminated information on the YTB program through staff meetings, posters on bulletin boards, and articles in the employee newspaper.

\subsubsection{Yield LED sign operation and maintenance}

The sign type used by VTA was similar to the sign used by TriMet in color and shape. VTA's signs were located on the left side of the rear panel of the bus above the engine access. The 
mounting height was greater than that of the signs in TriMet, providing increased visibility (see Figure 30). Samples of the public education campaign for TriMet are shown in Figure 31.

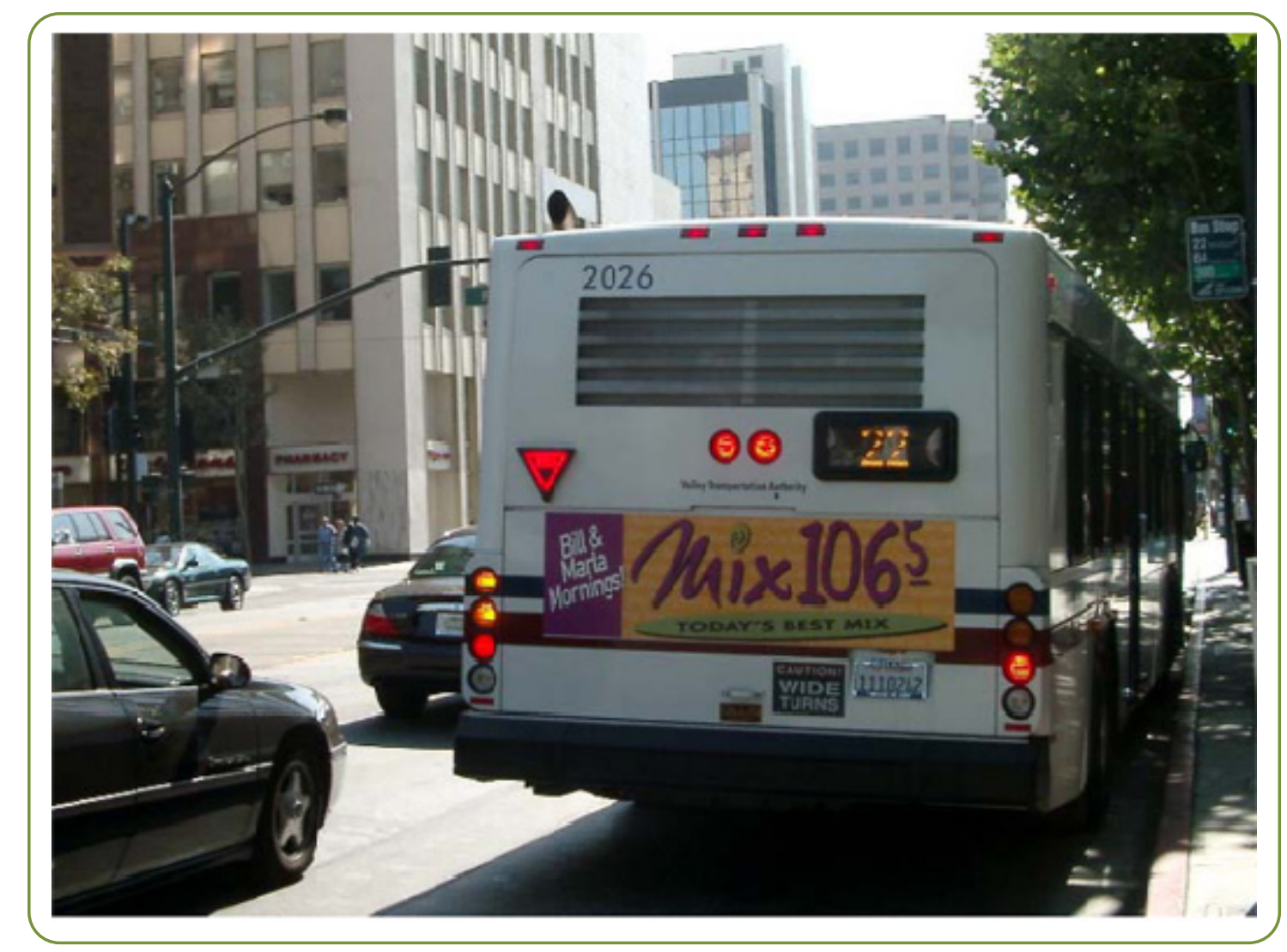

Source: TCRP Synthesis 49 (3).

Figure 30: Yield LED sign on VTA buses.

When merging back into traffic, the operator first pushes the activation switch to arm the yield LED sign, which is timed to remain armed for 10 to 15 seconds. The armed yield LED sign will be turned on only when the operator activates the left turn signal, and then both will flash at the same rate. The yield LED sign will remain on until the operator releases the left turn signal. If a yield LED sign has timed out (more than 15 seconds), the left turn signal must be released and the activation switch must be pushed again. The operation of the yield LED sign is restricted to the activation of the left turn signal. Currently, all VTA vehicles have yield LED signs.

\subsubsection{Lessons learned and recommendations}

The following are lessons learned and recommended practices for a successful YTB program based on the experiences of VTA:

- Because of the lack of performance measures and data collection, there were no means to demonstrate the benefit of the program. This resulted in the discontinuation of the YTB program after a few years of operation. 
- The lack of communication between police and YTB program leaders caused enforcement issues. For the YTB law to be enforced, police officers need to understand the rules or specifications to determine when a driver needs to yield the right-of-way to a bus merging back into traffic.

\subsection{Tri-County Metropolitan Transportation District of Oregon (TriMet)}

\subsubsection{YTB public education campaign}

During the implementation of its YTB program, TriMet carried out a public education and awareness campaign that included news releases to the media, Web pages with news releases, and information on the rear advertisement panels of buses. Also, the Oregon Department of Transportation (ODOT) devoted a Web page to the YTB law with frequently asked questions and additional informational material (3). The most-used marketing strategy by TriMet has been advertising panels on the rear of the bus (see Figure 31). Approximately once every two years, a public outreach campaign is conducted, consisting of selecting approximately 10 percent of the bus fleet and placing YTB ads on the rear panel. The ads are displayed between two and six months, depending on the demand for commercial advertisement. This requires appropriate fund allocation and special agreements with marketing companies in managing the advertising on the buses.

\subsubsection{Bus operator training}

In addition to mandatory training, bus operators are informed periodically through flyers and bulletins about the YTB program to remind them of their responsibilities under the YTB program. TriMet has emphasized to its bus operators that right-of-way is something that is given, not taken; therefore, it is the responsibility of the operator to properly judge any overtaking vehicles and merge back into traffic safely. If complaints are received, then the operator in question is contacted and reinstructed on the proper use of the yield LED sign.

\subsubsection{Yield LED sign operation and maintenance}

The use of the yield LED sign is strictly linked to the activation of the left turn signal. The operator has to activate the left turn signal and keep it on before activating the yield LED sign. Then, the operator pushes the yield LED sign control located on the left dash panel. The yield LED sign will be turned off when the left turn signal switch or pedal is released.

TriMet's yield LED sign is activated by pushing a button after the left turn signal has been turned on. The original button had maintenance problems and was susceptible to moisture. A new button was tested and is being installed when old ones need to be replaced. The new button is sealed to moisture (e.g., coffee spills).

There are ongoing maintenance costs. Eventually, LEDs go out and need replacing. This is checked through routine maintenance inspections. The sign as a whole is not replaced, only the individual LEDs when they stop working. 


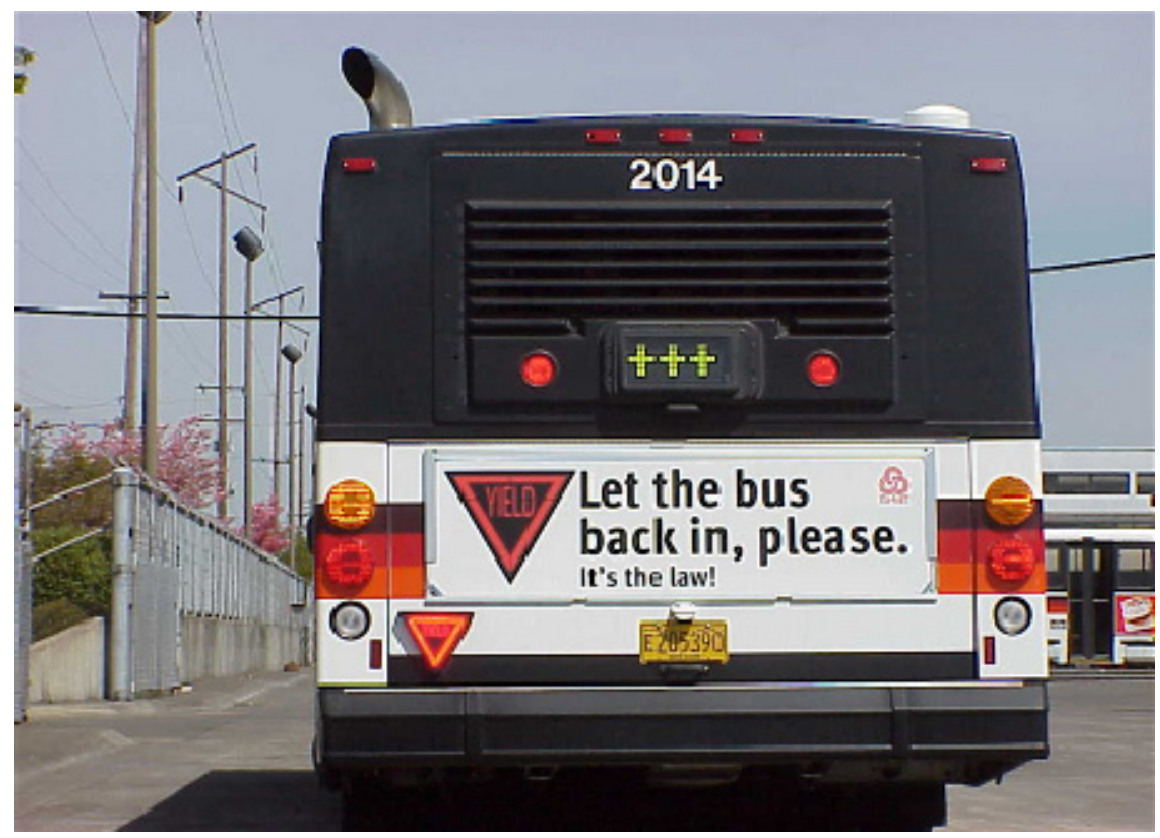

a. Yield LED sign and public education ad, 2001

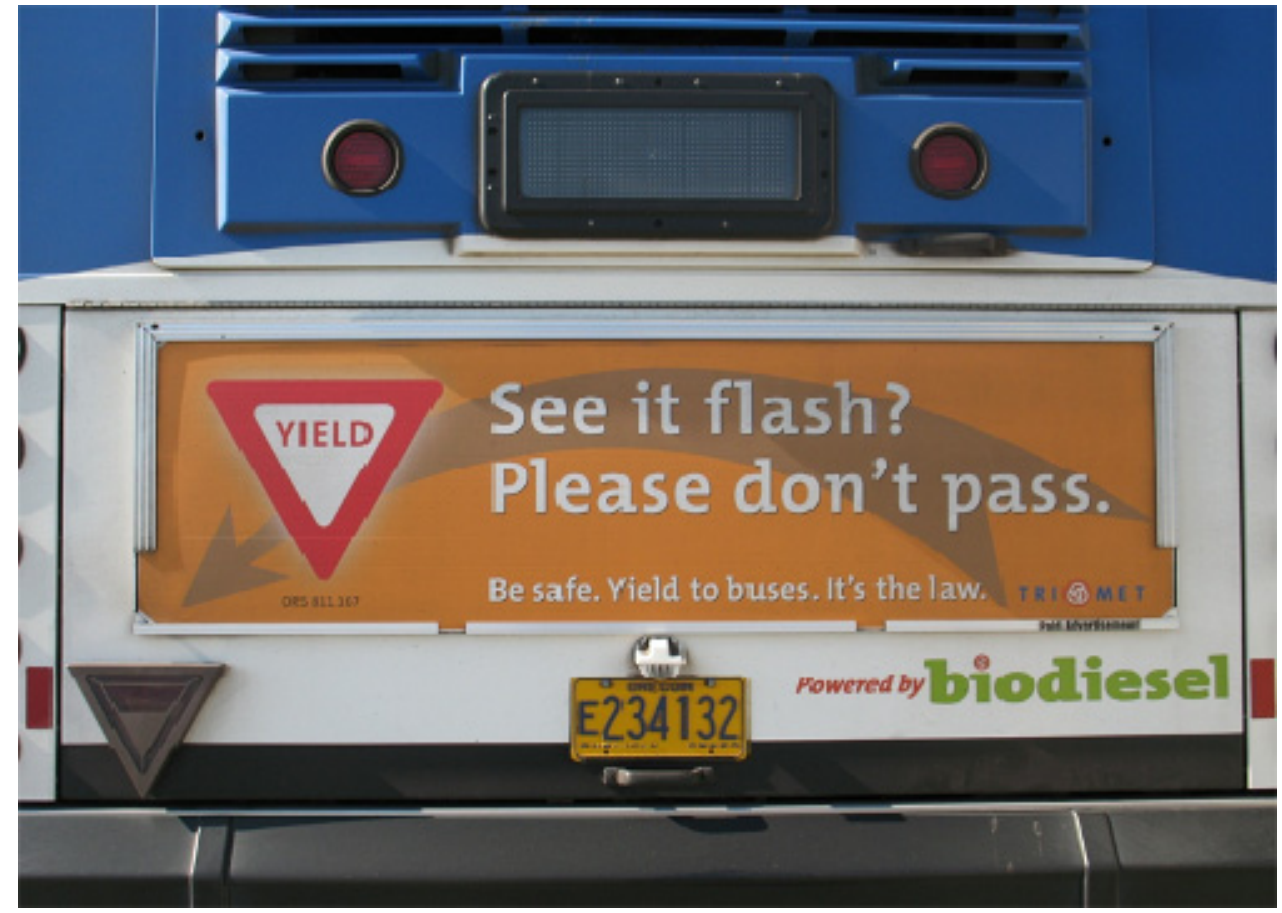

b. Most recent public education ad

Figure 31: Samples of public education campaign in TriMet. 


\subsubsection{Lessons learned and recommendations}

The following are the lessons learned and recommended practices for a successful YTB program based on the experiences of TriMet:

- An active, well-coordinated public information campaign is needed upon the enactment of a YTB law.

- Periodic reminders to the public and bus operators are needed.

- TriMet's signal is mounted too low. Flashing signs like the yield LED sign need to be high enough such that the first approaching car does not block line of sight of any following motorists. Trucks and large SUV s will block the line of sight, but the average car should not.

- "Queue jump" lights should be considered for buses at major intersections as an alternative. TriMet has a number of these throughout the Portland area. The bus has a separate lane with a queue jump light, which allows the bus to go ahead of other traffic.

- TriMet also has Opticom priority through on-board radio/dispatch equipment on each bus. At Opticom-enabled intersections, the system automatically signals the traffic light controller and a shortened red or extended green light is forced, but only if the bus is running late.

- There are enforcement issues with the YTB law since this type of violation is a low priority for police.

- There have been no complaints about the YTB law. However, immediately after enactment of the law, occasional complaints were received about the driving of individual bus operators. Currently, TriMet receives these types of complaints far less often than it did at the beginning.

- TriMet is not aware of any traffic accident directly related to the use of the yield LED sign or motorists being rear-ended because of yielding to a stopped bus merging back into traffic. 


\section{CONCLUSIONS}

This study focused on the assessment of the safety and operational benefits of the use of YTBLED signs on the back of the buses through the following objectives:

- Determine if the use of YTB-LED signs has an effect on the yield-to-bus behavior of motorists behind the bus.

- Assess the potential effects on traffic safety of the use of YTB-LED signs.

- Establish the operational benefits of the YTB-LED signs.

- Provide recommendations for implementation of YTB-LED signs and a public awareness campaign for YTB programs.

Three transit agencies in Florida were recruited to evaluate the effects of YTB-LED signs. Hillsborough Area Regional Transit (HART) in Tampa, Volusia County Transit (Votran) in Daytona Beach, and Lee County Transit (LeeTran) in Fort Myers participated in the study by installing the required YTB-LED and data collection equipment. Based on the video-based data collection on the test buses of the participating agencies, the following conclusions were drawn.

\section{Safety}

1. Yield-to-bus issues are present not only in bus bays but also at several locations that require transit buses to pull out of the traffic mainline. All these locations can benefit from the implementation of YTB-LED signs.

2. There is statistical evidence that the use of YTB-LED signs will have a positive effect on the yield-to-bus behavior of motorists behind the bus. In all three test corridors in this study, the proportion of maneuvers involving yielding to the bus increased with the implementation of YTB-LED signs. The signs will help the bus to better signal when merging back into traffic.

3. On the test corridor in Tampa, where buses were observed merging from bus bays, it was found that with the implementation of YTB-LED signs, the proportion of merging maneuvers involving a yield increased in 34 percent compared to the use of the decalonly treatment. On the test corridor in Fort Myers, where buses were observed merging from right turn lanes, the implementation of the YTB-LED sign improved yielding behavior by 20 percent. On the test corridor in Daytona Beach, where buses were observed merging from parallel parking spaces, the use of YTB-LED signs improved the yielding behavior by 50 percent.

4. Bus bays are more likely to experience direct conflicts than bus stops at right turn lanes. This is mainly because in a bus bay the bus cannot gain enough speed to facilitate the merging maneuver. Longer bus bays potentially could alleviate this issue. 
5. On the test corridor in Tampa, the total number of maneuvers involving conflicts was reduced by 80 percent through the implementation of YTB-LED signs. On the Daytona Beach corridor, the number of conflicts was reduced by 66 percent. On the Fort Myers corridor the number of conflicts across the different YTB treatments (YTB-LED signs and Decal) was similar.

6. The use of YTB-LED signs has great potential for reducing the number of conflicts for buses merging back into traffic from pullout bays on urban minor arterials. For major roads, the use of YTB-LED signs may improve yield-to-bus behavior without compromising safety.

7. The YTB-LED sign can potentially help to improve the yield-to-bus behavior of motorists without introducing new traffic conflicts.

\section{Operations}

1. The use of YTB-LED signs on the back of the buses helps to reduce the re-entry time of buses in bus bays on minor urban arterials. Based on field observations, this reduction ranged from 10 to 23 percent.

2. YTB-LED signs can help the bus merge back into traffic in long traffic lines during peak hours.

3. In general, the minimum observed values for re-entry time were observed in buses using YTB-LED signs. In contrast, the maximum observed values for re-entry time were observed in buses with decals only on major arterial roads.

4. YTB-LED signs have a significant impact on re-entry time for cases of 2-lane and 4-lane corridors. This is mainly due to reduced space to maneuver on such corridors for both transit buses and motorists. On 6-lane corridors, the re-entry time was not significantly affected.

Santa Clara Valley Transportation Authority (VTA, San Jose, California) and Tri-County Metropolitan Transportation District of Oregon (TriMet, Portland) were interviewed to obtain details regarding their YTB programs and educational campaigns. The following insights and lessons learned were obtained.

\section{Public Education}

1. Periodic reminders to the public and bus operators are needed to carry out a successful yield-to-bus program.

2. Placing educational ads on the back of buses is one of the most effective ways to keep the general public informed about traffic safety practices related to transit buses. 
3. Traffic safety and engineering studies are important to justify the benefits of a YTB program. This will also help to ensure the continuity of the program.

4. Promotion of effective communications between YTB program leaders and enforcement officials is necessary. In this way, police can help the YTB efforts and improve road safety for transit buses. 


\section{RECOMMENDATIONS}

Based on the video-based data collection on the test corridors and the interviews with VTA and TriMet, the following recommendations are suggested.

1. Implement YTB-LED signs on transit buses to help the buses merge back into traffic safely. The final sign design of the bus should be unified such that motorists become familiar with a single sign type. Both the triangular sign and the merging sign have the potential to improve yield-to-bus behavior. The triangular sign design has been adopted by several agencies throughout the United States and displays an actual traffic control device. The merging sign offers more visibility and displays an arrow and a small yield sign. Other designs for YTB-LED signs also may work similarly as long as they are properly introduced to the public.

2. Off-traffic bus stops (e.g., right turn lanes, curbside parking) with yield-to-bus problems can be designated as pullout bays to promote compliance and enhance safety. For instance, a right turn lane can be restriped such that a part of it is designated as a bus pullout bay and, therefore, motorists should yield the right-of-way to a bus leaving the designated area.

3. If implemented, YTB-LED signs should be installed as aftermarket equipment. The signs should be wired to operate only when the left turn signal is active. However, the left turn signal can be activated independently.

4. If the YTB-LED signs are activated manually, it is recommended to provide a handle that is different from other controls, not only in color but also in texture and size. In this way, the bus operator can find the yield activation switch easily among the existing controls in the operator's control board.

5. Yield sign activation could be automated by linking its operation to the left turn signal activation and positional information of the bus via Global Positioning Systems (GPS) or Radio Frequency Identification (RFID) beacons at certain bus stops. A bus stop can be coded as a merge/no merge type such that every time the bus departs from locations tagged as merge, the yield sign can be activated automatically with the left turn. The sign can be deactivated when the left turn signal is deactivated.

6. The use of YTB-LED signs is only one of many treatments that can be used to improve yield-to-bus behavior; additional treatments include roadside signs and pavement markings as pointed out in Phase I of this project.

7. Yield-to-bus programs should encompass several initiatives involving motorists, buses/operators, law enforcement officers, and local governments. 
- For motorists, YTB initiatives may include public education through billboards, ads on the back of the buses, and YTB-LED information signs on the back of the buses.

- For buses/operators, YTB initiatives may include training on the proper use of bus bays and YTB-LED signs. Also, technological improvements such as sensors or rearview cameras can help bus operators avoid car-accelerating bus conflicts. Research into sensor-assisted merging maneuvers for transit buses is an area where potential safety improvements can be achieved.

- Law enforcement agent training and awareness of the YTB law are important to ensure the success of YTB programs.

- Local governments can request specific features for construction of new bus bays such as more space for acceleration.

8. YTB-LED signs should be properly introduced to the public though a public awareness campaign. This campaign may include the following initiatives:

- Ads on the back of buses

- Print advertising

- News coverage

- Yield-to-bus flyers

- Yield-to-bus posters

- Incentive items

More aggressive campaign initiatives may include radio ads and billboards on critical transit corridors.

9. Critical transit corridors with increased YTB-related accidents should be identified. Intensify enforcement of YTB law on these corridors during the YTB campaign.

10. Evaluations of YTB programs are necessary to ensure their continuity. Detailed evaluations can be performed by conducting engineering studies. Regular evaluations can be performed by transit agencies by carrying out the following procedures:

- Identify segments of transit corridors with merging problems for off-traffic stops.

- Collect data on accidents related to buses in the selected transit corridor segments.

- Classify the data, tagging left-rear accidents as possible YTB accidents.

- The number of possible YTB accidents could be a measure of effectiveness for a YTB program. 


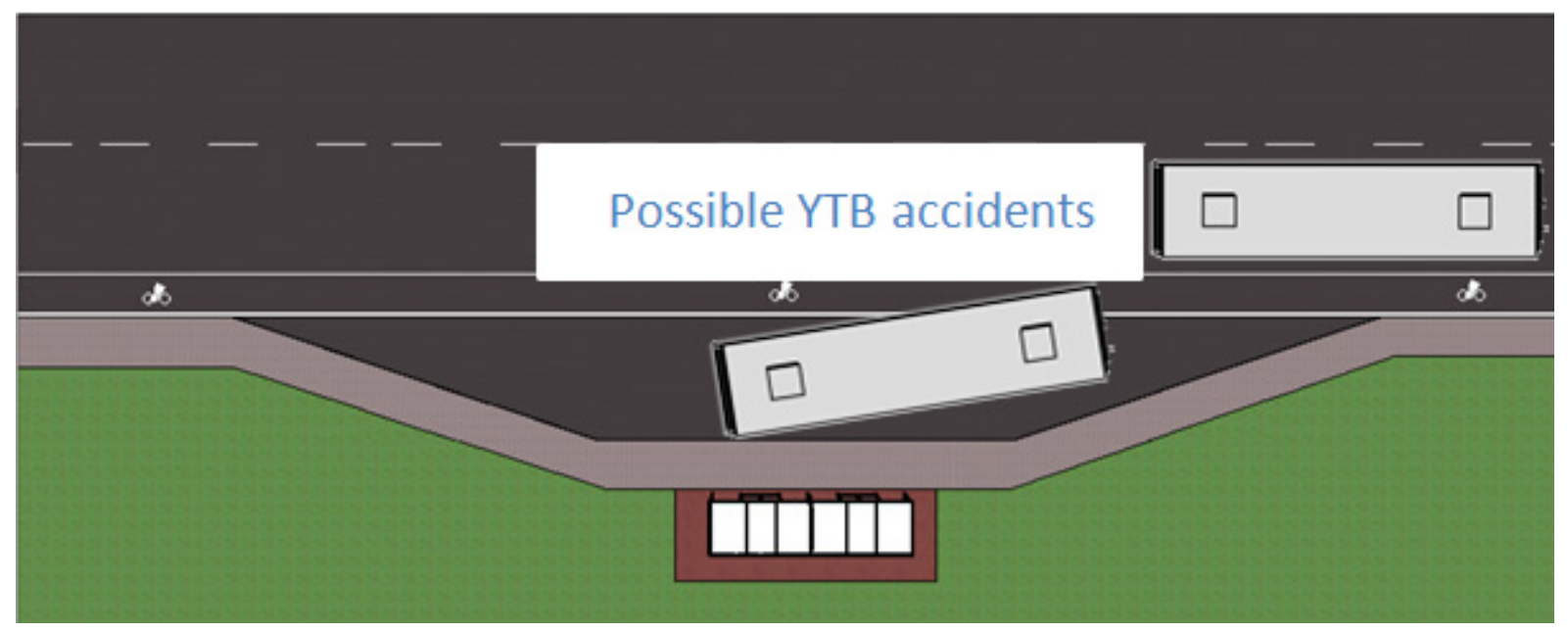

Figure 32: Possible YTB accident classification zone.

- If the technology is available, transit agencies can record event times at bus stops in the corridor such as the amount of time the left turn signal was on for each bus stop. Since the left turn signal is turned off when the bus is back into traffic, this can be used to estimate the re-entry time per bus stop.

- If the technology is not available, then calculate travel time between two critical time points on the corridor as a measure of operational benefits of the YTB program. Operational measures should be collected for peak time periods. Large sample sizes are recommended if the segment between time points contains a traffic light.

11. Additional recommendations for potential funding sources for local agencies to implement YTB-LED signs are provided in Appendix B. Potential funding programs may include bus equipment and facilities programs, rural and small urban areas programs, and large urban cities programs. 


\section{REFERENCES}

[1]. Luke Transportation Engineering Consultants. "Florida State Highway System Transit Safety Study." Florida Department of Transportation, Tallahassee, 2004.

[2]. Zhou, H., and S. Bromfield. "Moving the Bus Back into Traffic Safely-Signage and Configuration, Phase I." Report BD 549-34, Florida Department of Transportation, 2007.

[3]. King, R. "TCRP Synthesis 49: Yield-to-Bus State of Practice." Transportation Research Board of the National Academies, Washington, D.C., 2003.

[4]. Fitzpatrick, K., K. Hall, S. Farnsworth, and M. Finley. "TCRP Report 65, Evaluation of Bus Bulbs." Transportation Research Board of the National Academies, Washington, D.C., 2001.

[5]. Fitzpatrick, K., K. Hall, S. Farnsworth, and M. Finley. "TCRP Web Document 19 (Project A10A), An Evaluation of Bus Bulbs on Transit, Traffic, and Pedestrian Operations." Transportation Research Board of the National Academies, Washington, D.C., 2000.

[6]. Fitzpatrick, K., K. Hall, D. Perdinson, L. Nowlin, and R. Koppa. "TCRP Report 19, Guidelines for the Location and Design of Bus Stops." Transportation Research Board of the National Academies, Washington, D.C., 1996.

[7]. Federal Transit Administration. Stops, Spacing Location and Design. http://www.fta.dot.gov/research_4361.html\#TCRP. Accessed March 2010.

[8]. Highway Capacity Manual. Transportation Research Board of the National Academies, Washington, D.C., 2000.

[9]. Parker, M., and C. Zegeer. "Traffic Conflict Technique for Safety and OperationsObserver's Manual." FHWA-IP-88-27, Federal Highway Administration, U.S. Department of Transportation, 1989.

[10]. National Highway Traffic Safety Administration (NHTSA) Interpretations files, March 2008. Interpretation letter for the product Transpec Merge Alert, http://isearch.nhtsa.gov/files/07-005005as.htm. Accessed March 2010.

[11]. United States Department of Commerce, NIST/SEMATECH e-Handbook of Statistical Methods, Section 7.4.7.4, "Comparing Multiple Proportions: The Marascuillo Procedure." http://www.itl.nist.gov/div898/handbook/. Created June 2003; last updated June 2010; accessed July 2010.

[12]. Nelson P. "Testing for Interactions Using the Analysis of Means." Technometrics, Vol. 30, 1988, pp. 53-61. 


\section{APPENDIX A}

\section{Sample of Observed Conflicts in the Field}

\section{Conflict Type: Car and Merging Bus}
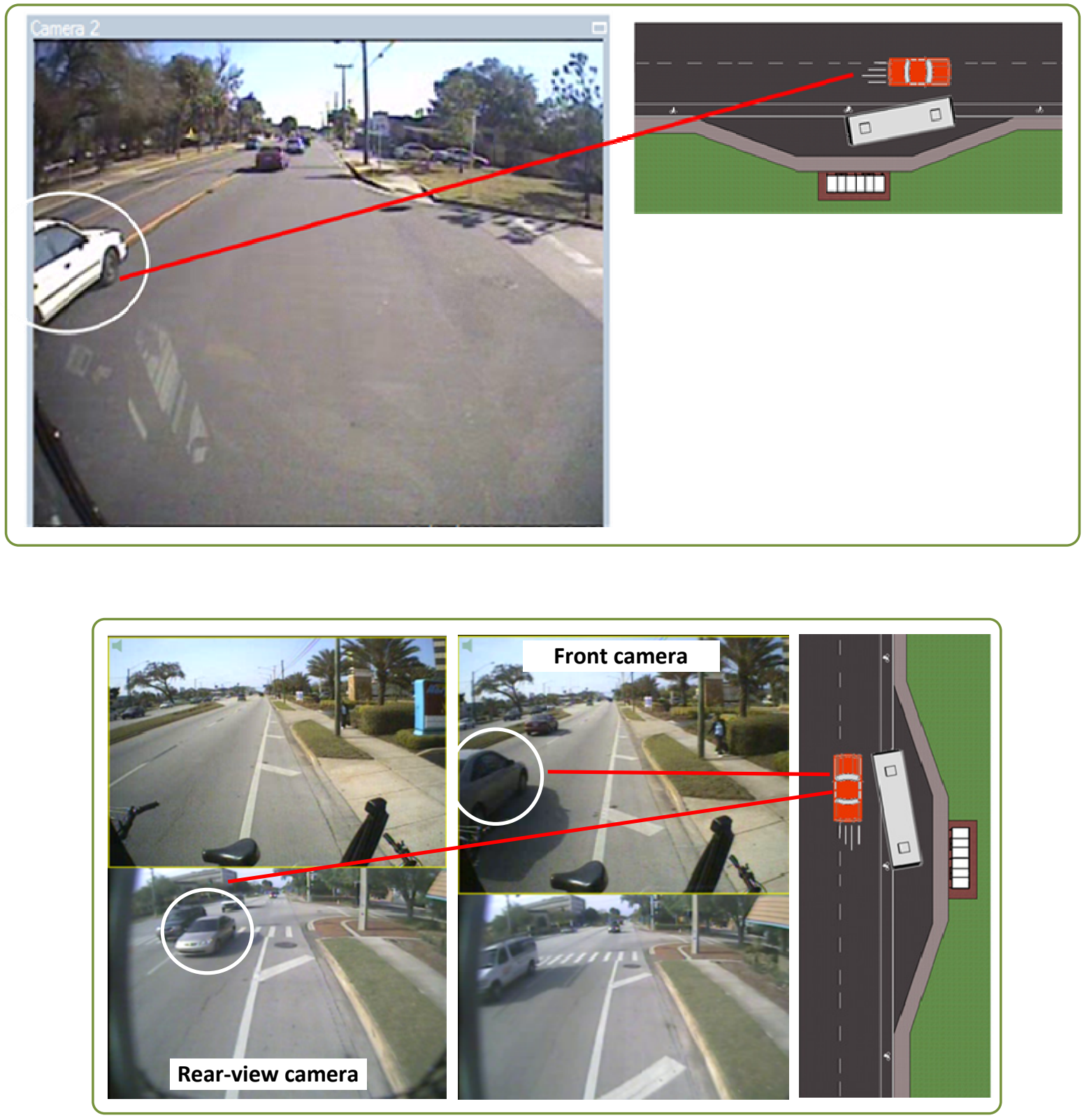
Conflict Type: Car and Accelerating Bus

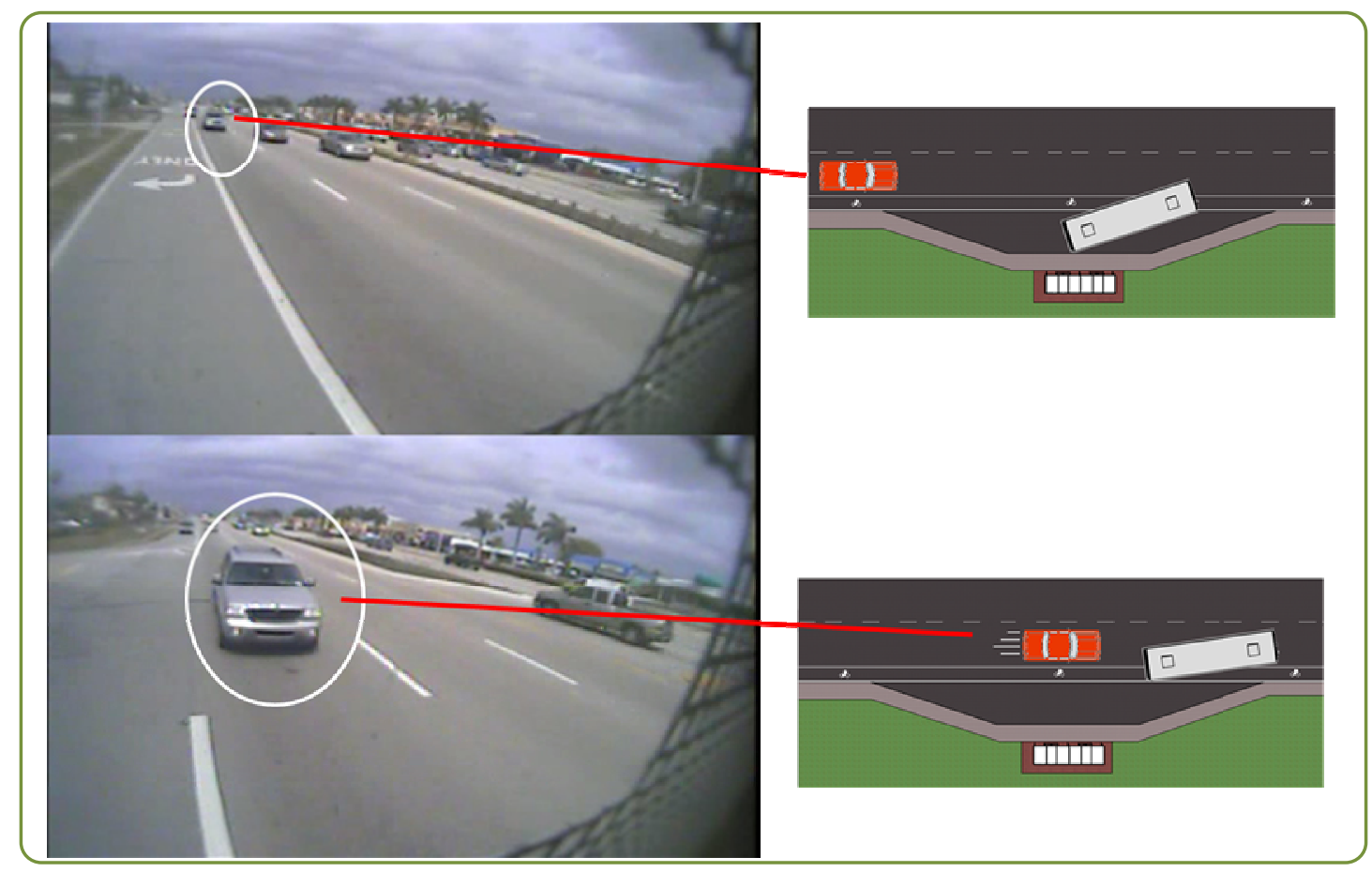

Conflict Type: Lane-Changing Car and Car

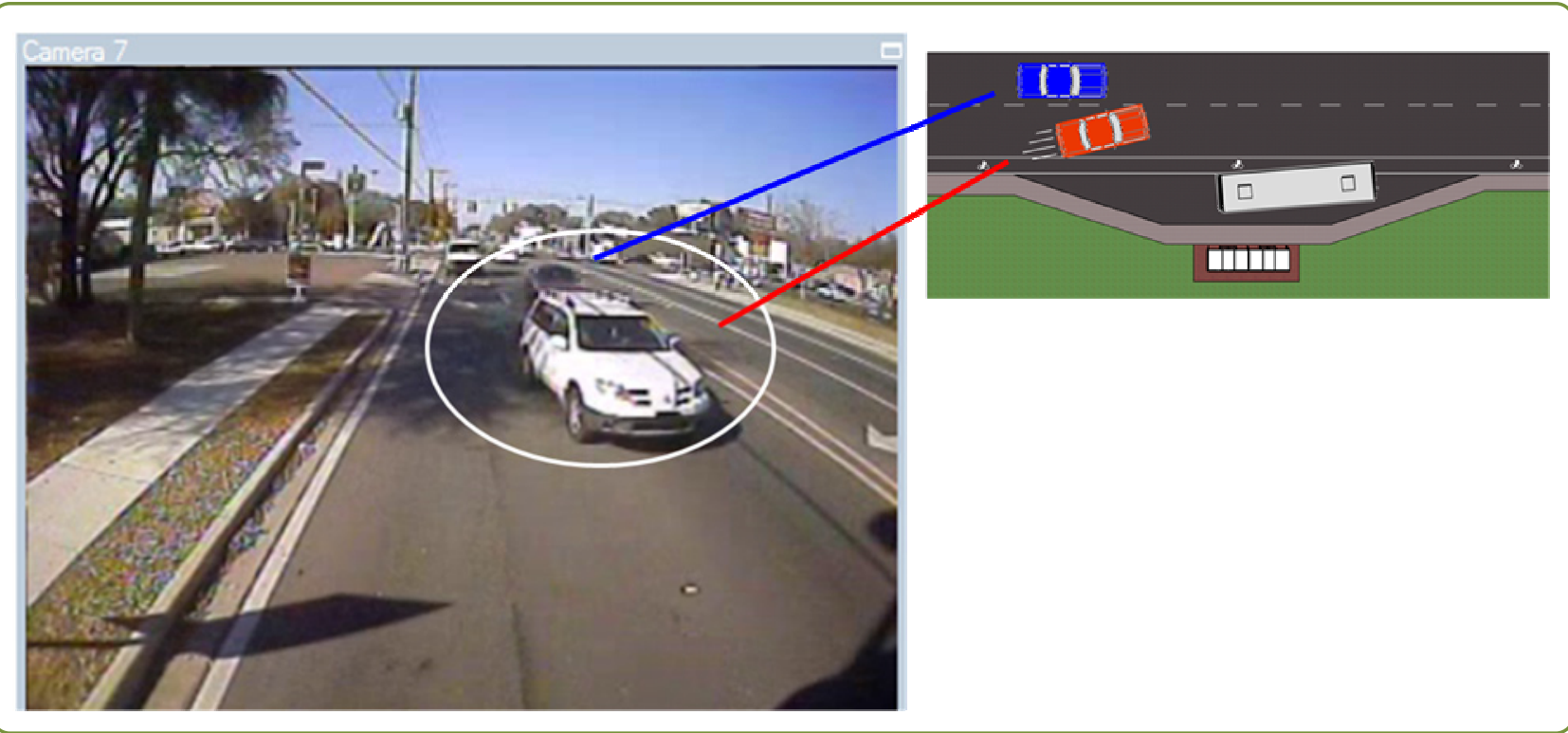


Conflict Type: Car and Yielding Car

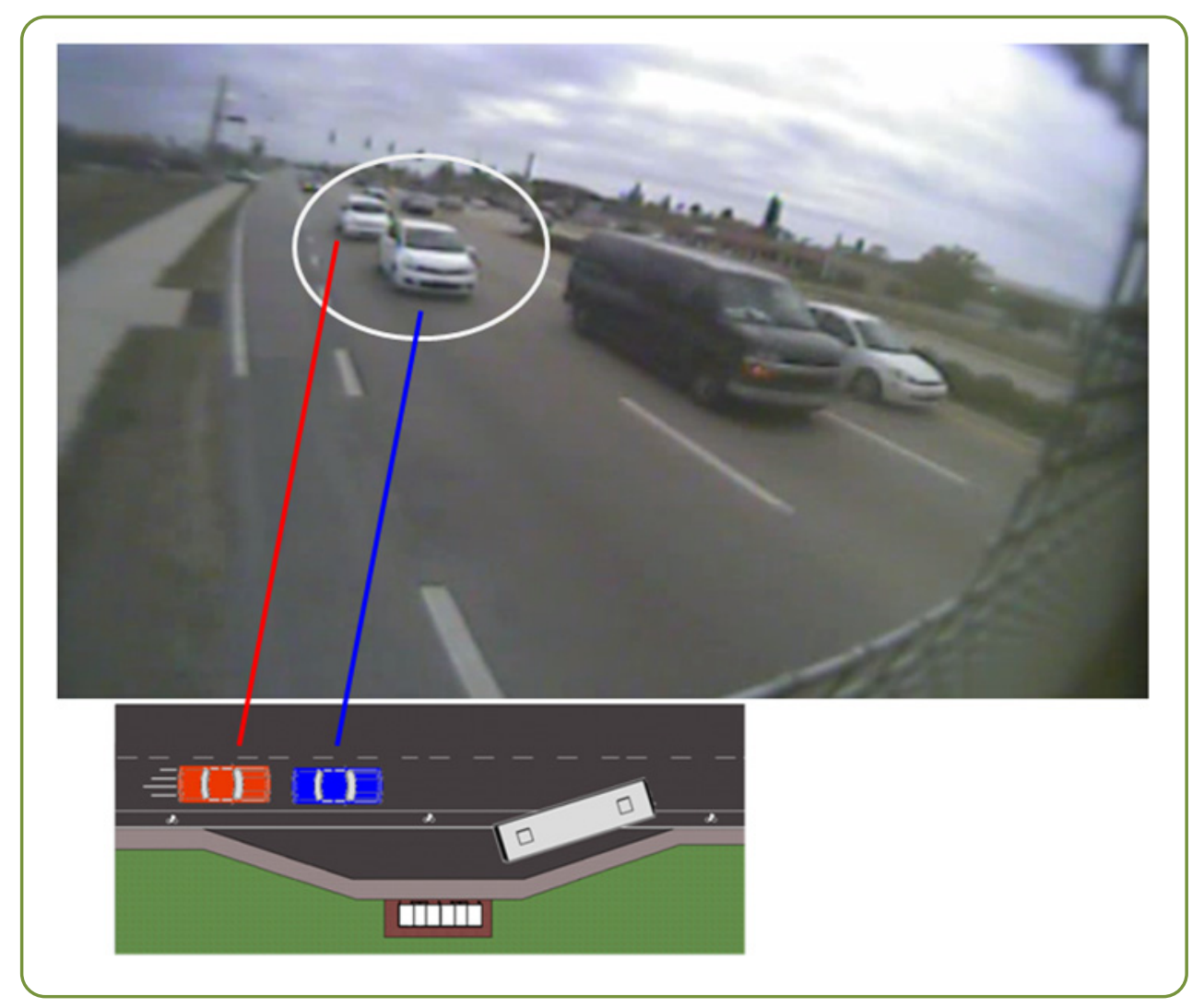




\section{Potential Funding Sources for Local Agencies to Implement YTB-LED Signs}

The objective of this section is to provide transit agencies with a series of funding alternatives for the implementation or retrofitting of existing vehicles with YTB-LED signs. Also explored are options available for transit agencies to fund maintenance or replacement of existing YTB-LED signs that have reached the end of their useful life.

\section{Federal Granting Opportunities}

FTA sponsors a series of grant programs for the planning, operation, and maintenance of public transit systems in the United States. The following are potential granting opportunities for the implementation or retrofitting of the YTB-LED signs. ${ }^{1}$

\section{Bus and Bus-Related Equipment and Facilities Program}

This program provides capital assistance for new and replacement buses, related equipment, and facilities. Funds are intended primarily to support one-time or periodic capital needs left unmet by federal formula funding or by local or state funding sources. Eligible capital projects include bus rebuilds, bus preventive maintenance, acquisition of replacement vehicles, and accessory and miscellaneous equipment. Accordingly, this program can be used to fund maintenance or replacement of YTB-LED signs that are out of their service life. Eligible recipients are public bodies and agencies.

\section{Rural and Small Urban Areas Program}

Public transit agencies in rural and small urban areas of less than 50,000 in population are qualified for this program. Eligible projects include maintenance, development, improvement, and use of public transportation systems in rural and small urban areas. Funds may be used for capital, operating, and administrative assistance to state agencies, local public bodies, and operators of public transportation services, etc. This program can be used to fund maintenance or replacement of YTB-LED signs.

\section{Large Urban Cities Program}

Eligible projects include capital investments in bus and bus-related activities such as replacement of buses, rebuilding of buses, and crime prevention and security equipment, etc. Urbanized areas with a population of 50,000 or more are qualified for this program. Funding is made available to designated recipients that are public bodies with the legal authority to receive and dispense federal funds.

\footnotetext{
${ }^{1}$ Federal Transit Administration, http://www.fta.dot.gov/funding/grants_financing_263.html.
} 


\section{State Granting Opportunities}

The following programs sponsored by FDOT could provide funding for the implementation or retrofitting of the YTB-LED signs: ${ }^{2}$

\section{Public Transit Service Development Program}

This program provides initial funding for special projects. Projects involving the application of new technologies or methods for improving operations, maintenance, and marketing in public transit systems are eligible for service development program funding.

\section{Public Transit Block Grant Program}

This program may be used for eligible capital and operating costs of providing public transit service.

\section{Recommended Grant Opportunities}

It is recommended that local agencies apply for the Bus and Bus-Related Equipment and Facilities Program sponsored by FTA. Agencies within Florida should explore the availability of Service Development Grants and consider using funds from the Block Grant program.

\section{Application Procedure}

1. Pre-application Stage - Before grant application submission, project planning requirements should be complete and properly documented. Project activities to be funded should be included in a federally-approved Statewide Transportation Improvement Program (STIP) for capital and/or operating projects.

2. Application Stage - Applications for FTA grant program funds must be submitted electronically through the Transportation Electronic Award Management (TEAM) system.

3. Application Submission - Once FTA deems the activities eligible and determines that all pre-application requirements have been satisfied, a grant number is assigned. At this point, the grant is ready to be pinned (approved) and submitted via TEAM by the designated recipient/grantee.

4. Grant Approval - Once FTA staff determine through a final review of the application that program requirements have been met, funds requested in the grant are awarded and obligated.

\footnotetext{
${ }^{2}$ Resource guide for transit and transit-related programs. Available at http://www.floridartap.org/pdfs/ TransitResourceGuide.pdf.
} 
5. Grant Execution - After FTA has approved and awarded the grant, the applicant executes the award before funds can be drawn down from the grant. Grants that include preaward activity require the submission of a Financial Status Report before grant execution.

\section{Required Information}

Applications for FTA grant program funds must be submitted electronically through the TEAM system. Information that should be entered into TEAM when preparing an application includes:

1. Recipient information - Applicants enter or update all required information about their organization in the appropriate fields in TEAM.

2. Project Information - The project start/end dates, program date, Executive Order 12372 review date, metropolitan planning organization (MPO) concurrence date (if applicable), and grant project costs shall be identified.

- Project Description - This information must be in sufficient detail for FTA to obtain a general understanding of the nature and purpose of the planned activities. At a minimum, the project description should identify sub-recipients funded through the grant application and the projects being implemented by each sub-recipient. Project activities should be sufficiently described to assist the reviewer in determining eligibility under the program.

- Program Date and Page of STIP - All projects for capital and operating funds in the grant application must be included in the current STIP. The application should note the page(s) in the most recently approved STIP on which the project(s) contained in the application are listed.

3. Budget - All sources of funds should be identified and confirmed. The project budget should reflect the precise activities for which the grant funds will be used, and the budget should be prepared in accordance with requirements for specific funding programs.

4. Project Milestones - Estimated completion dates for all milestones should be provided.

5. Environmental Findings - The application should include a proposed classification of each activity line item (ALI) in accordance with FHWA/FTA Environmental Impact and Related Procedures.

6. Fleet Status - Fleet status data are required for some of the grant applications. 